Alma Mater Studiorum - Università di Bologna DEPARTMENT OF ECONOMICS

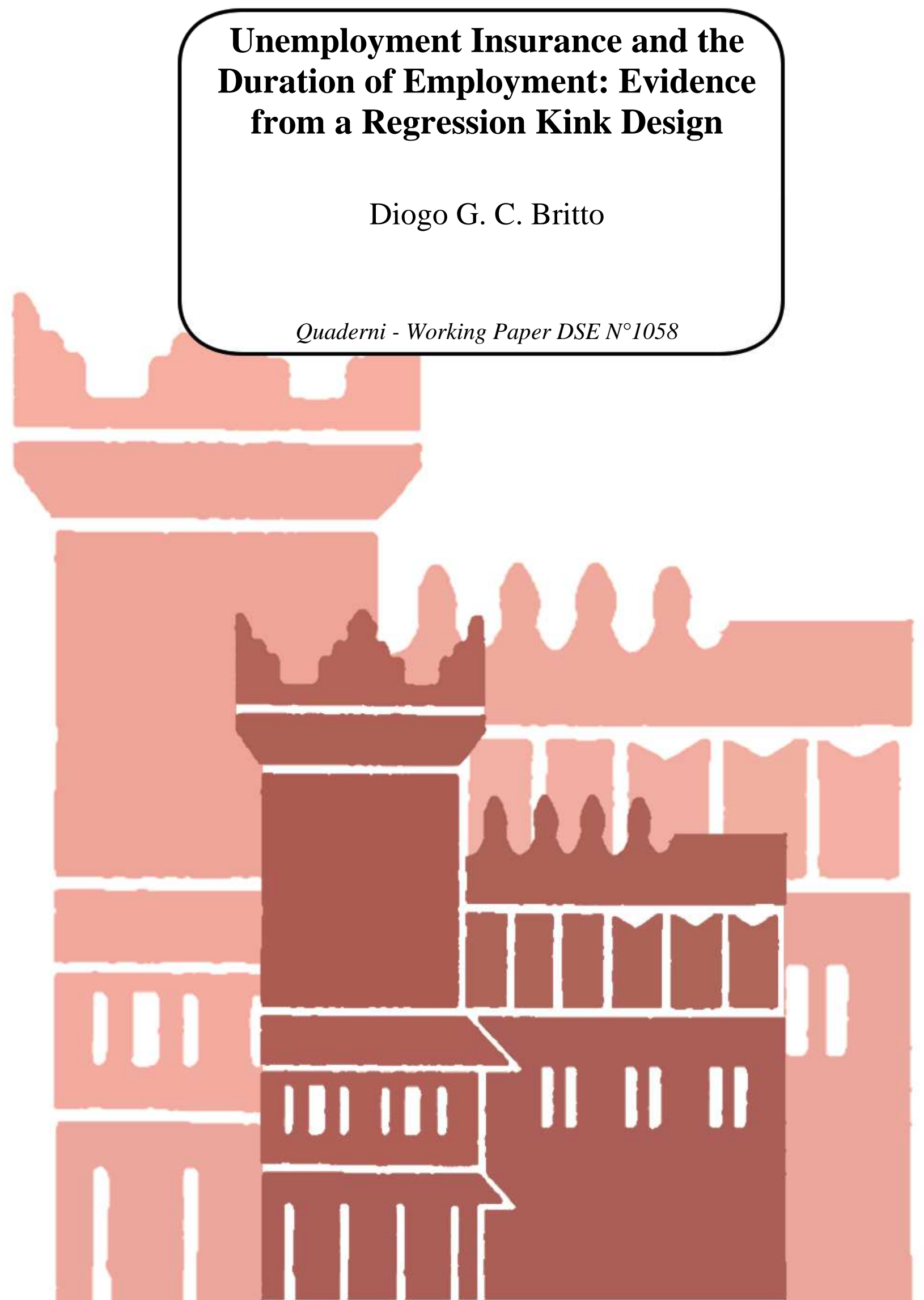




\title{
Unemployment Insurance and the Duration of Employment: Evidence from a Regression Kink Design
}

\author{
Diogo G. C. Britto*
}

December 2015

\begin{abstract}
Can the potential availability of unemployment insurance (UI) affect the behavior of employed workers and the duration of their employment spells? I apply a regression kink design (RKD) to address this question using linked employer-employee data from the Brazilian labor market. Exploiting the UI schedule, I find 1\% higher potential benefit level increases job duration by around $0.3 \%$. Such result is driven by the fact that higher UI decreases the probability of job quits, which are not covered by UI in Brazil. These estimates are robust to permutation tests and a number of falsification tests. I develop a simple model to assess the economic relevance of this finding. It shows that the positive effect on employment duration implies that the optimal benefit level is higher than otherwise. More importantly, the model delivers a simple welfare formula based on sufficient statistics which can be easily linked to the data. A simple calibration exercise shows that this elasticity impacts welfare with a similar magnitude to the well-known elasticity of unemployment duration to benefit level.
\end{abstract}

JEL classification: I38, J65.

Keywords: Unemployment Insurance, Employment Duration, Regression Kink Design, Sufficient Statistics Welfare Analysis.

${ }^{*}$ Contact author: diogo.gerhardcastro5@unibo.it ; I am particularly grateful to Giulio Zanella for extremely useful discussions. I thank Matteo Cervellati, Margherita Fort, Daniel Hamermesh, Peter Kuhn, Fabio Roitman, Maya RossinSlater, Heather Royer and seminar participants at the University of Bologna, Hamburg, EUR Rotterdam, EEA Manheim, UC Santa Barbara for helpful discussion. I also thank Card, Lee, Pei and Weber for sharing their adapted rdrobust code. All errors remain mine. 


\section{Introduction}

There is a large body of both theoretical and empirical literature studying a number of issues related to unemployment insurance (UI). Perhaps its most well-established result is that more generous benefits increase the duration of unemployment spells. Instead, the question of whether (and how) unemployment insurance affects the dynamic of employment spells has been much less studied. This paper presents evidence on the existence of a causal link between the level of unemployment benefits and the duration of employment spells. I propose a novel identification strategy to investigate how job duration reacts to variations in the potential level of unemployment benefits to which workers are entitled in the case of a dismissal. Surprisingly, I find that higher potential benefit level causes an increase in the duration of employment spells.

Despite the absence of empirical evidence in the literature, there are a number of straightforward reasons to suspect that the availability of UI may affect the duration of employment. First, higher unemployment benefit increases the value of unemployment for employed workers. Therefore, it decreases the incentives for these workers to put effort in keeping their jobs, potentially decreasing the duration of employment. Second, in the majority of UI systems, only workers laid-off against their will are eligible to unemployment benefits. Therefore, it should decrease the incentives for workers to quit because it means giving up unemployment benefits, especially if the reason for quitting is not starting a new job. Differently from the first, this mechanism would cause an increase in job duration. Third, most UI systems have in place minimum eligibility requirements (MER). These usually require workers to be employed for a minimum length of time in order to acquire eligibility for UI. Such feature creates incentives for workers to hold their jobs until the minimum eligibility period, and thus should increase the duration of the employment spells. Moreover, in many systems potential duration of benefits is an increasing function of tenure prior to the dismissal. Similarly to MER, this provides an incentive for workers to hold their jobs for longer periods.

All these are simple theoretical predictions which can be made without the need to rely on any extreme assumption whatsoever. The real question however is whether one or more of these mechanisms are able to create any economically meaningful effect on the duration of employment spells. Notice that, depending on which channel described above dominates, such effect could be positive or negative. To answer to this question avoiding the interference of confounding factors, I exploit the assignment rule of benefit level in the Brazilian UI system by implementing a regression kink design (RKD). This strategy leverages on the kinked relationship between benefit level and pre-displacement earnings established by the UI schedule to assess the causal effect of benefit level on the duration of employment spells. To perform the analysis, I take advantage of eight years of linked employer-employee data from the whole Brazilian formal labor market. Even though the RKD is extremely data demanding, the very sizable dataset containing more than 50 millions observations per year allows me to have enough precision on 
these estimates. I find that a $1 \%$ increase in potential benefit level causes employment spells to last on average $0.3 \%$ longer. This result is local to low skilled workers and is driven by a strong negative effect on quitting behavior. To the best of my knowledge, this is the first paper to address the question of how UI affects average job duration with a credible quasi-experimental setup. These findings show that unemployment insurance can create powerful incentives affecting the dynamics of employment spells.

Even though such finding may be interesting per se, alone it falls short of addressing the relevant policy question. The obvious remaining issue is whether this result is of any relevance for welfare. Does the fact that UI lengthens the time which workers spend employed have any implication for the optimal level of unemployment benefits? To address this question, I provide a simple, yet general search model in partial equilibrium where the duration of employment spells is endogenous to the incentives created by unemployment insurance. The model reveals how UI effects on employment duration affect the optimal benefit level. It shows that when this effect is positive, as found in the data, the optimal benefit level is higher than otherwise because it leads workers to contribute for longer to the system, since they are now employed for longer. This allows the policy maker to sustain a given benefit level by imposing a lower distortionary tax on employed workers. Therefore, the qualitative implication of this paper's key empirical finding is clear: the positive effect of UI on job duration leads to a higher optimal benefit level.

One last concern is whether this effect is quantitatively relevant. To address this question, I take advantage of a simple welfare formula based on sufficient statistics derived from the model. It generalizes the reduced-form welfare formula provided by Chetty (2008) in a way that it can deal with UI distortions on employment duration, and can be easily linked to the data. A simple calibration exercise shows that the effect of UI on job duration weights on welfare with the same order of magnitude as the well-known effect on unemployment duration. Therefore, this result suggests that the effect of benefit level on the duration of employment spells can be, in quantitative terms, similarly relevant for policy as the moral hazard effect on search effort.

It is worth noting that there exists a small and mostly old literature which studies the effects of UI on few different aspects of unemployment inflow. Few old contributions argue that when UI is not fully experience rated, it represents a subside for firms to temporarily lay-off workers (Feldstein, 1976, 1978; Topel, 1983, 1984). Another strand of studies using Canadian and Spanish data find that employment hazard rates spike exactly when employed workers qualify for unemployment benefits, which usually happens when workers reach a given job tenure (Christofides and McKenna, 1995, 1996; Green and Sargent, 1998; Baker and Rea Jr, 1998; Rebollo-Sanz, 2012). Using US survey data, Solon (1984) empirically studies the effect of entitling job quitters to UI and cannot identify any robust response on quitting rates. Instead, Light and Omori (2004) exploit cross-state and cross-year variations in UI benefit in the US and find that an increase in UI benefits decreases job quits by a statistically significant but small amount. They argue that UI decreases quits because it provides less incentives for workers to 
perform on-the-job search in response to a expected lay-off.

The closest related contribution to this is Winter-Ebmer (2003) who studies how unemployment entry responds to a large increase in the potential duration of benefits for old workers in specific regions in Austria. He finds that unemployment inflow increases by $4-11 \%$ and argues that the effect seems to be driven by firms which aim to get rid from high-tenured and expensive old workers. A key difference to this paper is that such estimates are local to old workers (50-65 years old) and consist in the response to an unusually large extension of potential benefit duration (from 52 to 209 weeks). More importantly, it does not assess whether these changes in inflow affect average job duration. Interestingly, Lalive et al. (2011) assess the effects of a different policy change in Austria and find that an extension in UI potential duration led to higher unemployment rate mostly because of a rise in unemployment inflow rather than outflow.

Taken together, this literature indicates that UI affects the dynamics of employment spells, at least to some extent. One key question which is not directly answered in none of these studies is whether UI can affect the average time which workers spend employed in an economically significant way. This constitutes the first main contribution provided by this paper: using Brazilian data, it presents credible quasi-experimental evidence that UI benefit level actually increases the duration of employment spells. These estimates are local for low-skilled workers and imply in an elasticity as large as 0.3. This contribution is complemented with the finding that such responses are driven by a strong negative effect on quitting probabilities, while lay-off hazard seems not to be significantly affected. Besides from satisfying all the standard tests from RD designs, these results are robust to permutation tests (Ganong and Jäger (2014)), and RK estimates in double and triple differences. ${ }^{1}$

A second and more important shortcoming of this small literature is that it provides little guidance on the normative question concerning the implications of these results for optimal UI policy. This paper's second main contribution is providing a welfare formula for benefit level based on sufficient statistics which explicitly indicates how employment duration responses affect welfare. Interestingly, the formula shows that a positive elasticity of job duration to benefit level actually implies that the optimal benefit level is higher than otherwise. The intuition is that if higher benefit level causes longer employment spells, it also induces workers to contribute for longer periods to finance the system. This implies that the policy maker needs to raise by less the distortionary tax imposed on employed workers to sustain a benefit increase.

The third key contribution from this work is putting together these empirical results with the theory to show that the welfare effect of this response on the duration of employment spells is economically

\footnotetext{
${ }^{1}$ The RKD in double differences was originally proposed by Landais (2014)
} 
meaningful. From the theoretical prospective, it weights on welfare with the same weight as the wellknown elasticity of unemployment duration to UI benefits. On the empirical spectrum, the estimated effect on job duration (0.3) falls within the range of estimates on the elasticity of unemployment duration to benefit level found by previous studies (0.1-0.9). Since both responses equally weight on welfare, their relevance for the optimal benefit level is likely to be similar. It is also interesting to highlight that, since the terms present in the welfare formula are sufficient statistics, these conclusions are not based on any specific model calibration: they hold for any given set of model primitives.

As regards the generality of the empirical findings, it is worth noting that, similarly to Brazil, many developed countries have in place UI schedules yielding a kinked relationship between benefit level and earnings prior to dismissal. It means that the empirical strategy here proposed could serve as an useful tool for assessing whether this paper's estimates based on Brazil generalize to different contexts.

In the next section, I present the model from which the reduced-form welfare formula is derived and highlight its key differences to Chetty (2008). In section 3, I describe the institutional background and present the identification strategy. In section 4 , I show the results and provide evidence on the validity of the regression kink design. In section 5, I discuss the results and how they link to welfare.

\section{Theory}

The goal of this partial equilibrium model of labor supply is to derive a reduced form welfare formula which can deal with distortions of benefit level on the duration of employment spells. It generalizes the setup proposed by Chetty (2008) by allowing UI to affect employment duration. It features incomplete markets where workers are not able to privately insure against unemployment and have a limited ability to borrow against the future. These elements provide the rational for government intervention with unemployment insurance policy. If, otherwise, credit and insurance markets were complete, workers would be able to perfectly insure against unemployment and would face no liquidity constrains. In such world, there would be no reason for the government to intervene.

\subsection{Model Setup}

The model runs in discrete time and agents live for $\mathrm{T}$ periods $\{0,1, \ldots, \mathrm{T}-1\}$. For a matter of simplicity, I further assume that the agent's discounting rate and interest rates are equal to zero, as in Chetty (2008). In this economy, all agents start the model employed with a wage equal to $w$ and have to pay a $\operatorname{tax} \tau$ which finances the UI system. At the beginning of each period, workers have to decide whether to quit or not their job setting the decision variable $x_{t} \in\{0,1\}$. In case they quit $\left(x_{t}=1\right)$, they remain out of the labor force until the end of the model and are not entitled to UI benefits. The value of quitting is randomly determined in each period according to some probability distribution. In 
case workers decide to keep their jobs $\left(x_{t}=0\right)$, they face a lay-off risk which negatively depends on the level of effort $e_{t}$ that they put in keeping their job. The idea is that workers can make costly decisions which may help them holding their jobs. For instance, workers can decide how punctual they are or how willing they are to do extra hours. It can also be understood under the framework of a standard shirking model: firms use the threatening of firing to motivate workers to exert effort. The more effort the worker puts into his job, the lower the probability of being fired. It is worth noting, however, that this model is silent with respect to the fact that variations in effort may affect firm productivity. Work effort $e_{t}$ is costly for the workers and its cost is given by the function $c\left(e_{t}\right)$, which is assumed to be continuous and convex $\left(c^{\prime}\left(e_{t}\right)>0\right.$ and $\left.c^{\prime \prime}\left(e_{t}\right)>0\right)$. Furthermore, without loss of generality, $e_{t}$ is normalized in such a way that it directly represents the probability of a lay-off. The problem of the worker who keeps his job is given by:

$$
\begin{array}{r}
V_{t}\left(A_{t}\right)=\max _{A_{t+1} \geq L} v\left(A_{t}-A_{t+1}+w_{t}-\tau\right)+J_{t+1}^{V}\left(A_{t+1}\right) \\
J_{t}^{V}\left(A_{t}\right)=\max _{e_{t}, x_{t}}\left(1-x_{t}\right)\left[e_{t} V_{t}\left(A_{t}\right)+\left(1-e_{t}\right) U_{t}\left(A_{t}\right)\right]+x_{t} Q_{t}-c\left(e_{t}\right) \\
Q_{t}\left(A_{t}\right)=\max _{A_{t+1} \geq L} v\left(A_{t}-A_{t+1}+q_{t}\right)+Q_{t+1}^{V}\left(A_{t+1}\right)
\end{array}
$$

$V_{t}$ defines the value of the job the worker has at the beginning of the model over time. $A_{t}$ defines the worker's asset level at period $t$. Such a level is constrained by a lower bound $L$, which defines the maximum amount the worker is able to borrow against the future. $v($.$) defines the utility from$ consumption of the employed worker. If the worker decides to quit his job, he moves into the quit state which is an absorbing state of value $Q_{t}$. In case the worker does not quit, he keeps his job with probability $e_{t}$, which yields the value $V_{t}$. With probability $\left(1-e_{t}\right)$ he loses his job and becomes unemployed immediately at period $t$, which yields value $U_{t}{ }^{2}$

In the case where the worker is laid-off, he receives unemployment benefits equal to $b_{t}<w_{t}$, provided that he has worked for at least $k$ periods; otherwise, $b_{t}=0$. This characterizes a minimum eligibility requirement (MER) for UI, which is a typical feature in many countries. ${ }^{3}$ Nevertheless, since $k$ is a parameter which can take any value, the model is also able to suit the case of systems which do not have MER. At this point, the unemployed worker chooses his level of search effort $s_{t}$ in order to find a new job. As for work effort, $s_{t}$ is normalized to equal the probability that the worker finds a new job at period $t$. The cost of search effort is defined by $\psi\left(s_{t}\right)$ which is assumed to be continuous and convex $\left(\psi^{\prime}\left(s_{t}\right)>0\right.$ and $\left.\psi^{\prime \prime}\left(s_{t}\right)>0\right)$. Thus, with probability $s_{t}$ the unemployed worker finds a new job which

\footnotetext{
${ }^{2} \mathrm{~A}$ more intuitive and conventional assumption would be that a lay-off at period $\mathrm{t}$ leads to unemployment at period $\mathrm{t}+1$. However, here I shall assume that unemployment comes immediately for a matter of tractability of the model.

${ }^{3}$ More precisely, to the best of my knowledge, I am not aware of any UI system which does not require a minimum number of working months for workers to be granted with UI benefits.
} 
immediately starts at period $t$ and yields value $E_{t}$. With probability $\left(1-s_{t}\right)$ he fails to find a job at period $t$ and remains unemployed, which yields him the value $U_{t}$. His problem is given by:

$$
\begin{gathered}
U_{t}\left(A_{t}\right)=\max _{A_{t+1} \geq L} u\left(A_{t}-A_{t+1}+b_{t}\right)+J_{t+1}^{U}\left(A_{t+1}\right) \\
J_{t}^{U}\left(A_{t}\right)=\max _{s_{t}} s_{t} E_{t}\left(A_{t}\right)+\left(1-s_{t}\right) U_{t}\left(A_{t}\right)-\psi\left(s_{t}\right)
\end{gathered}
$$

$E_{t}$ is defined as the value of employment subsequent to unemployment. Following the same spirit of Chetty (2008), I assume this to be an absorbing state. It means that once an unemployed worker finds a new job, he remains employed indefinitely. Furthermore, once reemployed, workers no longer have to contribute for UI since they no longer face any unemployment risk, their jobs now last forever.

$$
E_{t}\left(A_{t}\right)=\max _{A_{t+1} \geq L} v\left(A_{t}-A_{t+1}+w_{t}\right)+E_{t+1}\left(A_{t+1}\right)
$$

The underlying idea of this setup is that the UI system can be properly represented by a initial period where employed workers contribute to the system, and a subsequent period where workers who have lost their jobs are benefited from the insurance. This also seems to be the appropriate order of facts because any UI system requires workers first to work and, only then, they can become eligible for UI. In other words, new entrants in the labor market are not entitled to benefits when they first start looking for a job. Therefore, in this model, for a matter of simplicity, the third state is neutral with respect to the UI system exactly because the initial employment and subsequent unemployment period are enough to capture the relevant features of the system. Making a link with the "real world", once workers are reemployed after enjoying UI benefits, it works as if they were starting their first employment again, for all that matters for UI.

In sum, the model defines an economy with incomplete credit and insurance markets. All workers are employed at $t=0$ with a net wage of $w_{t}-\tau$ and face a lay-off risk which negatively depends on their choice level of work effort, period after period. Workers are also allowed to quit their jobs and remain out of the labor force. If a worker is laid-off, he has to choose a level of search effort in order to find a new job. While unemployed, he is entitled to UI benefits $b_{t}$, which last for a maximum of $B$ periods, provided that he has worked for more than $k$ periods (MER), otherwise he receives zero benefits. Once the worker leaves unemployment, he falls into an absorbing state where his new job lasts indefinitely and he has no longer to contribute for the UI system. 


\subsection{The Reduced-Form Welfare Formula}

I leave the solution of the worker's problem in each state of the model to the appendix (B.1 and B.2), and move to the social planner's problem to derive the welfare formula. The social planner aims to maximize expected utility by choosing the level of unemployment benefits and a tax level $\tau$ on employed workers in order to finance the system. In principle, the profile of benefit level and duration could vary over time, however for a matter of simplicity I focus on "constant benefit, finite duration", as in Chetty (2008). ${ }^{4}$ Therefore, I here assume $b_{t}$ to be constant over time and that benefits last for a maximum of B periods.

The general social planner's problem is given below:

$$
\begin{aligned}
& \max _{b, \tau} J_{0}^{V}(b, \tau)=\left(1-x_{0}\right)\left[e_{0} V_{0}(b, \tau)+\left(1-e_{0}\right) U_{0}(b, \tau)\right]+x_{0} Q_{0}-c\left(e_{0}\right) \\
& \text { s.t. } \quad f^{U I} D_{B} b=D_{E} \tau
\end{aligned}
$$

The goal of the social planner is to maximize $J_{0}^{V}$ which defines the representative worker's expected utility, who is assumed to start the model employed. Since the choice of effort at period 0 can lead to a lay-off at the same period as discussed before, expected utility is the weighted sum of the expected utility of workers who are not laid-off at the initial period, $V_{0}$, and of those who enter unemployment already at period $0, U_{0}$, adjusted by the probability that the worker does not quit; plus the expected utility of quitting adjusted by the probability of quitting, minus the cost of effort.

The constraint assures that the government budget is balanced. $D_{E}$ describes the expected duration of the agent's employment at the beginning of the model. Only this duration matters for the government budget's revenue because, as stated before, upon reemployment workers remain employed forever and no longer contribute to the system. $D_{B}$ defines the agent's expected unemployment duration under UI benefits and $f^{U I}$ is the fraction of workers receiving unemployment benefits. Such fraction is composed by those workers who are laid-off after meeting UI minimum eligibility requirements. $D_{B}$ differs from the simple unemployment duration because when the unemployment spell exceeds the maximum duration of benefits ( $B$ periods), workers no longer receive benefits. Thus, once the unemployment spell exceeds the maximum duration of benefits, its duration no longer matters for the government budget. Therefore, the left-hand-side of the budget constraint in (9) denotes the expected cost of the policy, while the righthand-side represents the expected amount received in taxes, which are levied on employed workers.

At this point, it is possible to evaluate how a marginal change in the level of benefits impacts on welfare. In the same spirit of Chetty (2008), I assume that the consumption path during employment

\footnotetext{
${ }^{4}$ Chetty (2008) also remarks that most UI policies indeed provide constant benefits with finite duration. This is also the case for Brazil, which is analyzed in the empirical section.
} 
is constant since unemployment is unlikely to cause large losses on life cycle earnings. Furthermore, I assume both the worker's need for liquidity and the probability of finding a job to be independent to the period of displacement. ${ }^{5}$ The idea is that these should not vary according to the period in which individuals become unemployed. Together with the results from the agent's optimal choice of work and search effort, it is possible to derive the final welfare formula (see Appendix B.4 for details):

$$
\frac{d W}{d b}=f^{U I} \frac{D_{B}}{D_{E}}\left\{\frac{1}{1-s_{0}}(\rho+1)-\left(1+\epsilon_{f^{U I}, b}+\epsilon_{D_{B}, b}-\epsilon_{D_{E}, b}\right)\right\}
$$

where $f^{U I}=\sum_{i=k}^{T-1}\left[\Pi_{j=0}^{i-1}\left(1-x_{j}\right) e_{j}\right]\left(1-x_{i}\right)\left(1-e_{i}\right)$ is the share of laid-off workers eligible for UI due to MER and $\rho=-\frac{\frac{\partial s_{0}}{\partial A_{0}} \mid B}{\frac{\partial s_{0}}{\partial W_{0}} \mid B}$ is the liquidity-to-moral hazard ratio.

This formula shows the net welfare effect from increasing UI benefits by $\$ 1$ in comparison to the welfare from raising wages by $\$ 1$. Welfare effects are a trade-off between the benefits from the liquidity provided to unemployed workers and the costs from higher taxes imposed on employed workers. The benefit from providing liquidity to the unemployed is captured by the liquidity-to-moral hazard ratio $\rho$. It is also weighted by the fraction of unemployed workers actually eligible for UI, since those not meeting MER and job quitters are not entitled to benefits. On the cost side $\epsilon_{D_{B}, b}$ captures the behavioral response from higher benefits on the UI covered duration of unemployment; and $\epsilon_{D_{E}, b}$ captures the behavioral response from higher benefits on the duration of employment. Furthermore, there is also the behavioral response on the fraction of workers meeting MER, $\epsilon_{f^{U I}, b}$. These last two terms capture exactly the distortionary effect of UI on employment and is the key difference from this result to the original formula provided by Chetty (2008). They affect welfare because they change the length of time during which individuals contribute for the system. If UI causes employment spells to be longer, the policy marker needs to impose less distortionary taxes on employed workers in order to finance the system. This implies in a positive addition to the welfare effects of an increase in UI. If instead UI leads to shorter employment spells, the government has to impose higher taxes on employed workers. This causes an additional welfare burden from increases in benefit level. Whether the elasticity of employment duration to benefit level is positive or negative is an empirical question.

The formula shows that $\epsilon_{D_{E}, b}$ affects welfare exactly with the same magnitude of $\epsilon_{D_{B}, b}$. In the empirical section, I estimate $\epsilon_{D_{E}, b}$ to equal a value around 0.3 , which is clearly in the range of $\epsilon_{D_{B}, b}$ found by other studies, roughly going from 0.1 to 0.9 .

\footnotetext{
${ }^{5}$ Indeed this is an implicit assumption in Chetty (2008) since the representative worker starts the model unemployed
} 


\section{Institutional Background and Identification Strategy}

To recover the effect of benefit level on the duration of employment spells without the interference of confounding factors, I implement a regression kink design to explore kinks on the policy rule which conditions benefit level on previous earnings in Brazil. Throughout this section, I introduce the main characteristics of the UI system in Brazil and the benefit level schedule; explain the identification strategy - the regression kink design; and present the data.

\subsection{UI Schedule in Brazil}

The Brazilian unemployment insurance system is a federal program established in 1986. It offers temporary income for formal sector workers who are dismissed against their will and meet minimum eligibility requirements. These are: (i) have been employed in all the last 6 months prior to the lay-off; (ii) have no other source of income ; (iii) have not been granted with UI benefits for the last 16 months, counting from the date of the last lay-off which enacted benefits. It is important to notice that benefits are granted only for workers dismissed without a just cause. This is the most common type of dismissal in Brazil, since employers by law are free to dismiss workers without a just cause in the sense that they need no authorization from any tribunal or government agency to do so. Furthermore, even though dismissing with a just cause is less cost for employers, the conditions for this type of dismissal are very tight and it is very hard to collect enough proof to back up cause. ${ }^{6}$ Also notice that workers quitting their jobs are not entitled to benefits.

Benefit level is defined by a rule based on the 3-months average of previous earnings prior to the dismissal. Below I present on figure 1 the schedule with numbers from 2010 for illustrative purpose. The schedules for other years follow the very same shape but kinks are located at different points.

Monthly benefits are a function of a reference wage (r.w.) which is given by the average monthly earnings in the last three months prior to the dismissal. Benefit level equals $80 \%$ of the reference wage if it is lower than $\mathrm{R} \$ 841.88$, on the 2010 schedule. However, benefits can never be lower than minimum wage, $\mathrm{R} \$ 510$ for the year of 2010. This generates the first kink in the assignment rule which can be seen by the red line at the left side of figure 1 (at $\mathrm{R} \$ 637.50$ ). When the reference wage is higher than $\mathrm{R} \$ 841.88$ but not larger than $\mathrm{R} \$ 1403.28$, benefits are given by $[($ r.w. -841.88$) * 0.5+841.88 * 0.8]$. It defines the second kink present in the assignment rule, at $\mathrm{R} \$ 841.88$, which is indicated by the second red line in figure 1. For reference wages larger than $\mathrm{R} \$ 1403.28$, benefits are always equal to $\mathrm{R} \$ 954.20$. This cap defines the last kink in the assignment rule, which is indicated by the red line at the right side of figure 1.

\footnotetext{
${ }^{6}$ In general, workers can only be fired on cause only if they: (a) are continuously absent from work (usually more than 30 days) ; (b) commit serious misconduct ; (c) go to work under the effect of alcohol; or (d) commit a large number of small infractions.
} 
Figure 1: Benefit Level Assignment Rule - Year 2010

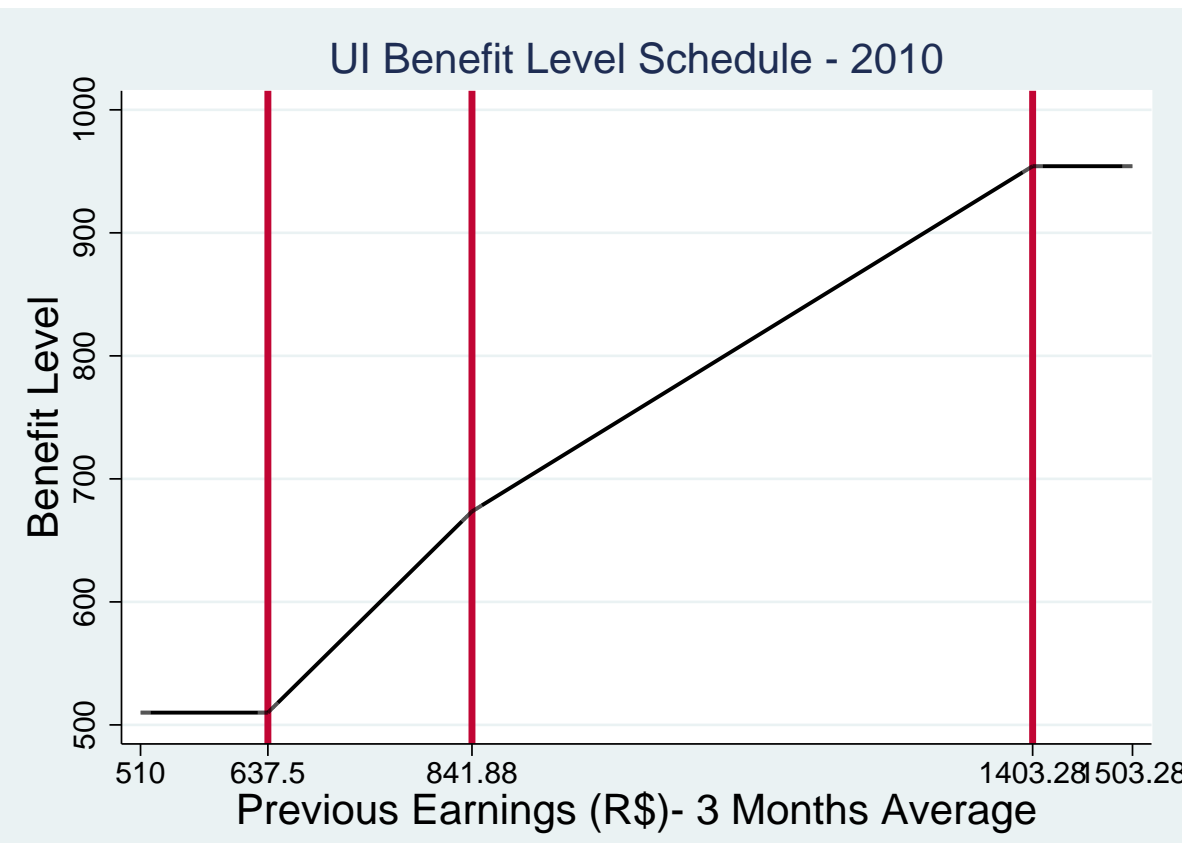

These three kinks are the source of exogeneity which is exploited to identify the effect of benefit level on employment duration. The size of the slope change around the three kinks are $0.8,-0.3$, and -0.5 , respectively. Every year the minimum monthly wage and all three kink points change. They are all raised by the inflation rate in the previous year plus the average real growth rate of the economy in the two previous years. This causes the minimum wage and the kinks to move to the right in real terms at the same pace, in all years. On average these have increased by roughly $8 \%$ per year in the period from 2005-2012. The time variation of the kink points is also exploited for identification as a robustness test. The details of this strategy is discussed in the results section.

As regards the maximum duration of benefits, it is a function of the number of months worked in the last 36 months prior to the lay-off. Table 1 presents the UI schedule of potential duration:

Table 1: Potential Duration Assignment Rule

\begin{tabular}{cc}
\hline Months worked in the last 36 months & Months of Benefit \\
\hline from 6 to 11 & 3 \\
from 12 to 23 & 4 \\
More or equal 24 & 5 \\
\hline
\end{tabular}




\subsection{The Regression Kink Design}

The idea of the regression kink design (RKD) is to exploit kinks in the relationship between an assignment variable and a treatment variable. These are the reference wage, based on previous earnings, and the level of unemployment benefits in this application, respectively. Such kinks are present in the relationship explained above and illustrated by figure 1. The intuition of the strategy is that if the treatment variable has a causal effect on a given outcome variable, there should also be a kink in the relationship between the outcome variable and the assignment variable. Therefore, in our context, if we expect that there is a causal relationship between UI benefit level and employment duration, there should also be a kink relationship between employment duration and the reference wage (the assignment variable) at the same kink points marked in red in figure 1.

The idea of this design is similar to a regression discontinuity design (RDD), except that in this case there is not a discontinuity in the level of the assignment rule, but in its slope (or first derivative). The intuition of why it is able to identify the treatment causal effect is exactly that in the vicinity of the kink, subjects have the same pre-treatment characteristics on the margin but are however assigned to different levels of treatment on the margin.

In figure 2 it is possible to see a graphic example of the RKD. The graph on the left illustrates the kink relationship between the treatment and the assignment variable when it equals 50. It illustrates a hypothetical case in which individuals to the right of the kink receive a linearly increasing level of treatment. The graph on the right side shows the three possible results which can be found by analyzing the relationship between a given outcome variable and the assignment variable. If the treatment yields no effect on the outcome, one should find no kink in the relationship around the kink point, as shown by the black line. In case the treatment has a positive effect on the outcome, one should expect to find a positive change of slope around the kink point, as shown by the blue line. In the case where the treatment has a negative effect on the outcome, there should be a negative change in slope around the kink point, as shown by the red line.

The key assumption for the RKD is formalized by Card et al. (2015) and requires that the density of the assignment variable is smooth conditional on observable characteristics around the kink point present in the policy assignment rule. As in the RDD, one crucial advantage for the credibility of this design is that its key assumption is testable in at least two ways. First, it is possible to test whether the empirical density function of the assignment variable is actually smooth around the kink point. I therefore provide evidence on whether the density of average previous wage is smooth around all the three kink points. Second, the key assumption described above implies that the conditional expectation function of any pre-determined characteristic is also smooth around the kink point. Therefore, I provide evidence on the smoothness of the conditional expectation function of pre-determined variables, such as previous tenure and years of schooling, around all the three kink points. Furthermore, I create a further 
Figure 2: RKD Graphic Example
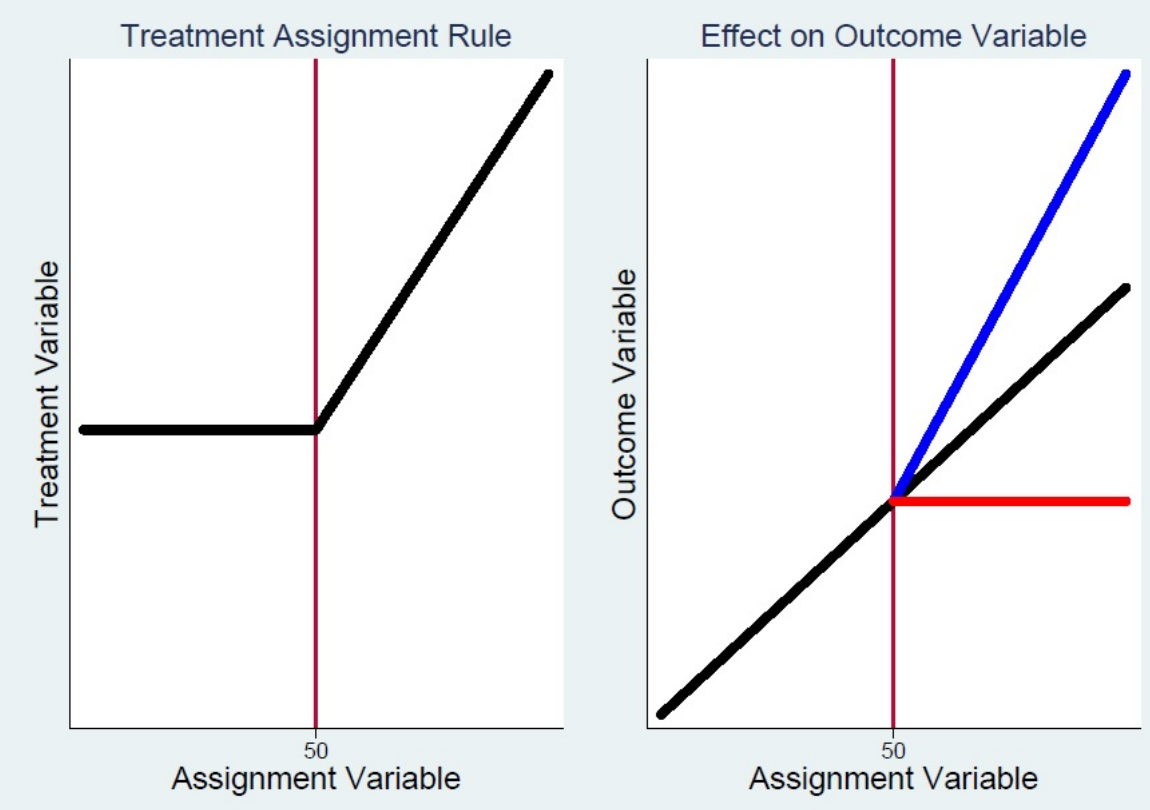

variable to test the validity of the design. I generate the best linear prediction based on a full set of pre-determined covariates around each kink to test whether it evolves smoothly around each kink. The idea is that if the design is valid, this linear prediction based on pre-determined covariates should not yield any kink around these points.

In order to test and identify the presence of kinks in the data, I apply a local regression in the following parametric form:

$$
Y_{i}=c_{0}+\left[\sum_{p=1}^{P} \gamma_{p}(w-k)^{p}+\beta_{p}(w-k)^{p} . D\right] \text { where }|w-k| \leq h
$$

where $w$ is the reference wage, based on previous earnings, in the year (the assignment variable) centered around the kink point $k, P$ is the polynomial order of the regression, $h$ is the bandwidth used, and $D$ is a dummy variable taking value 1 for $(w-k) \geq 0$. The estimate of interest is the slope change in the outcome variable at the kink point, which is identified by $\beta_{1}$. As regards the bandwidth and polynomial order choice, I decided to conduct Monte Carlo simulations with a variety of proposed bandwidth selectors with linear and quadratic polynomials to evaluate how each of these perform, as suggested by Card et al (2015). This procedure is discussed in details in the results section.

In the results section, I focus on the analysis around the first kink as it yields more statistical power because of two reasons. First, the variation in the slope of the treatment is the greatest (0.8 against 
-0.3 and 0.5 ) and there are more observations around this threshold (around 0.5 and 4 times more than the second and third kink). Therefore, due to lack of statistical power I only show results on the main variable for the second and third in the appendix, and suppress further results. Overall, they indicate that it is not possible to robustly identify moderate effects around these two points.

\subsection{Data}

The data I use in this paper comes from the Relao Anual de Informaes Sociais - RAIS. It is an administrative dataset covering all the employment relationships in the Brazilian formal Labor Market. I have access to this data from the year of 2005 to 2012. It contains detailed information on the characteristics of each labor contract such as start and end date, type of labor contract, type of termination, firm size at two different aggregation levels (branch and holding), municipality and industry; as well as information on workers, such as schooling, gender and average yearly earnings by each contract. Furthermore, it is possible to track workers and firms over time through an identification number.

\section{The Effect of Benefit Level on Employment Duration}

To assess the effect of benefit level on employment duration, I create three samples around each of the three kinks in the UI schedule pooling data from all years around each threshold. I consider all workers from the private sector which were employed at the first day in which the yearly schedule is introduced. Then, since the schedule is again updated in the subsequent year, the duration of employment is constructed as the spell between the first day in which a yearly UI schedule is in place and the last day of the year. For instance, for the 2010 schedule, I consider all workers employed in the first day in which the schedule is valid, January $1^{\text {st }}$ (2010) in this case, and count for how long they were employed in the year, i.e., until December $31^{\text {st }}$. In case a worker keeps his job until the last day of the year, I consider the last day of work as December $31^{\text {st }}$. Notice however that from 2005 to 2009, the yearly schedule was respectively introduced at the first day of May, April, April, March and February, therefore it would be possible to consider the duration until a date further than the December $31^{\text {st }}$ of the previous year in this period. However, I decide always to use the December $31^{\text {st }}$ as the last day of employment in the year because of the structure of dataset, which is based on yearly mandatory information provided by the firms to the government authorities. This procedure avoids computing the duration of spells using data from two different years, which eliminates the risk of any possible endogeneity arising from the selection of firms which report the data for only one of the years. As mentioned before, I display only results around the first kink due to lack of statistical power around the other kinks.

A drawback from the dataset is that it provides only the worker's average monthly earnings for each year, while the assignment variable for the UI schedule is based on the average monthly earnings only in the three months previous to dismissal. Due to that limitation, I use the average monthly earnings 
in the year as assignment variable for the RKD and need to expect that wages do not change too fast within a given year. In case wage evolution over the year is too steep, it is likely that the RKD design would be compromised as the kink would likely be smoothed and it would be hard to identify any kink in the data. Thus, such possibility could only work in favor of the null hypothesis of no effect.

\subsection{Density Smoothness}

To evaluate whether the necessary conditions for the RKD hold, the density function of reference wages must evolve smoothly around the kink. To test for this assumption, I extend the spirit of the McCrary (2008) density discontinuity test for RDD to check for the presence of a slope change in the density of the assignment variable. I create bins over the assignment variable and count for the number of observations in each bin. Then, I run a regression as in equation (11) on the number of observations allowing for a slope change at the kink in order to test for the smoothness condition. I set the polynomial order of this regression to minimize the Akaike criterion. Figure 3 displays the density of average monthly earnings and the manipulation test result for the first kink. ${ }^{7}$ From visual inspection, the density function seems to move quite smoothly around the kink and there seems not to be any evidence of slope changes. This impression is supported by the first-derivative test reported in the graph which does not allow one to reject the null hypothesis of no kink.

\subsection{Graphical Evidence}

A first and key piece of graphical evidence on how employment duration is affected by benefit level comes from observing how this variable evolves with earnings within a (UI schedule) year. Figures 4-5 display this evidence for 2005 and 2012. In both figures, this profile seems to evolve smoothly at all points except for the first kink. Job duration seems to be relatively flat between the minimum wage and the first kink, and starts increasing with earnings exactly at the first kink. Since potential UI benefit level increases on the margin at this point, this graphical evidence suggests that benefit level is causing employment duration to increase. It is also worth to highlight that the first kink changed in real terms by $45 \%$ between 2005 and 2012, suggesting that this is not a coincidence driven by a specific year.

In order to get some intuition on the potential drivers of this evidence on job duration, it is useful to analyze how the profile of quitting and firing probabilities, and the probability that a worker reaches MER evolve over earnings. The evidence on quits presented in figures 6-7 is striking: in both years, the probability of job quits displays a clear negative slope change around kink 1 . It strongly suggests that UI benefit level is causing job quits to decrease. As regards the probability of lay-off and the probability that a worker remains in the job until MER (6 months), the evidence displayed in appendix figures A1-A4 is much less clear. Firing probabilities seem to evolve relatively smooth at all points. The share

\footnotetext{
${ }^{7}$ Same results for kink 2 and 3 are reported in the appendix figures B1 and B2.
} 
of workers reaching MER seem to display a mild positive slope change around kink 1 in 2005 while the pattern is less clear in 2012.

At this point, I pool the data for all years around the first kink and display it on figure 8. There emerges the same pattern observed for 2005 and 2012: employment duration is apparently flat before the first kink and starts to increase just after it. To investigate whether any of these results might be driven by kinks in pre-determined workers' characteristics, I build a linear prediction of job duration based on an extremely rich set of pre-determined covariates: age at hiring date, job tenure at the date of the yearly schedule introduction, decile of firm size and previous firm size at two different aggregation levels, and dummies for whether the worker was recalled for this job and whether the workers was still facing the waiting period for UI due to prior benefit claim (16 months minimum periods between UI claims), termination type at previous job, race, gender, weekly hours of work, years of schooling, industry, and federal state (27); all these interacted with year dummies. Notice that the dataset allows me to recall relevant workers' previous job characteristics, which are likely to be very informative on their current labor market outcomes. Figure 9 shows how this best linear prediction of job duration evolves around the kink. The first important thing to notice is that these predicted values seem to display a positive kink around the threshold. However, it is also worth noticing that this variable displays incredibly less variation for the same range of the running variable with respect to actual job duration $([36.4,36.8]$ vs. $[34,37]){ }^{8}$ This suggests that even if it were the case that pre-determined covariates are driving part of the results on job duration, the bias is likely to be very small. In any case, it may lead one to be suspicious that non-observables could be driving this effect. I address this reasonable concern by analyzing how these predicted values evolve on a year to year basis. ${ }^{9}$ I find that this apparent kink is driven by the years of 2005 and 2006. Therefore, to avoid concerns that results are driven by unbalances in covariates around the kink, I drop these years from the sample and run the regression analysis on a restricted sample containing data from 2007 to 2012.

Figure 11 shows how predicted job duration behaves in this restricted sample. The range of this outcome is still incredibly small $([37.6,38])$ and there seems to be no evidence of the presence of any slope change around the threshold. On the other hand, actual employment duration displays exactly the same pattern as in the full sample, as shown by figure 10. This indicates that the kinked pattern of job duration around kink 1 cannot be explained by unbalances in the rich set of observable covariates. To gain further insight on this issue, it is also useful to observe how these pre-determined covariates themselves evolve around the threshold, which is shown by figure 12. As for the predicted job duration, these variables seem to display no slope change around the kink point. Strikingly different is the pattern on job quitting rates displayed by figure 13. It shows that the probability of quitting starts to decrease

\footnotetext{
${ }^{8}$ Indeed, if these two graphs are set with the same scale, it is not to possible to observe any slope change in the predicted job duration.

${ }^{9}$ These graphs are displayed in the appendix by figures A5-A12
} 
sharply right after the kink point, suggesting that benefit level is affecting job duration through quits.

Overall, I interpret these results as evidence that UI causes job duration to increase around the first kink and that unbalances in predetermined covariates are not driving this effect. As regards the channel of this effect, it seems to be through a decrease in the probability of job quits. These impressions based on the graphical analysis are formally tested in the regression analysis.

\subsection{Bandwidths Choice}

A key issue in the RKD is the choice of the bandwidth and polynomial order, which essentially trades off bias and precision. The only bandwidth selector explicitly designed for the RKD is proposed by Calonico et al. (2014) - CCT from now on, where they develop a selector based on optimal mean square error. As in Card \& al (2015) - CLPW from now on, I consider this selector with and without its regularization term. ${ }^{10}$ Furthermore, I follow again CLPW and implement the FG bandwidth selector which is based on Fan and Gijbels (1996). To implement the two CCT bandwidths, I use the CLPW adaptation of the software developed by Calonico et al. (2014) which optimizes computational time in large samples. As regards polynomial order, I use a linear and quadratic specifications for each bandwidth selector. Therefore, I first consider six specifications to start the analysis: FG, CCT and CCT without the regularization term, each of these combined with a linear and quadratic local polynomial.

A pattern which emerges from these regressions is that results do not cover across specifications. I argue that none of these selectors perform satisfactorily on my data as they yield estimates which are too noisy. I provide two pieces of evidence which support this claim. The first is based on a Monte Carlo simulation exercise, as suggested by CLPW, in order to assess the performance of each specification considering two main criteria: the root mean-squared error (RMSE) and coverage rates. Similarly to CLPW, I set the data generation process (DGP) using an approximation of the data on job duration around the kink with a fifth order polynomial on each side of the threshold. The linear coefficient on the linear term to the right of the kink is held equal to zero for this approximation. Then I set the DGP to equal the coefficients of this regression and impose a value on the linear term after the kink point in order to set the actual slope change. The DGP for the error term is based on the empirical distribution of the residuals in this regression. For each simulation, I set the slope change in order have an elasticity of 0.5. I generate 300 samples of the same size as the actual data by sampling the running variables and errors with replacement.

The results from these simulations are shown in table 2. It is remarkable that coverage rates are well below the nominal rate $(95 \%)$ and that RMSE with respect to the true kink value is never lower than

\footnotetext{
${ }^{10}$ The original selector contains a regularization term to avoid bandwidths which are "too large", as noted in Calonico et al. (2014)
} 
0.70. Another pattern arising from this Monte Carlo study is that all the specifications seem to suffer from a strong negative bias ranging from 0.22 to 1.28 times the actual kink size set for the simulations. Overall, these simulations suggest that these specifications perform poorly in estimating slope changes on employment duration. Indeed, as shown by the appendix table 7, regression results based on these specifications vary to a great extent and do not allow for any conclusive assessment on the actual slope change. Around kink 1, three specifications point for a statistically significant negative slope change, two for a statistically significant positive slope change, and one is not significantly different from zero. I argue that the instability of these results is driven by the extremely small bandwidths chosen by these selectors. In the first kink, except for the FG quadratic specification, all selectors pick bandwidths ranging from $\mathrm{R} \$ 4(\approx \$ 2)$ to $\mathrm{R} \$ 12(\approx \$ 6)$ in terms of monthly earnings, which is clearly an extremely narrow range. Such small choices are possibly caused by the small global range of the available data around this kink, which is basically restricted by the distances to the minimum wage and the second kink in each year.

Therefore, I present a second piece of evidence suggesting that such small bandwidths indeed pick up too much noise. I implement the permutation test proposed by Ganong and Jäger (2014) for a range of small bandwidths. The idea of the test is, for a given bandwidth, to estimate the slope change around as many placebo points as possible, where there is no actual policy kink. This procedure is useful to assess the performance of the local linear estimator for each bandwidth since one expects to find no slope change around these placebo points. Of course the assumption for this procedure to make sense is that such points are reasonable counterfactuals of the actual kink point. Therefore, I use the distribution of these placebo estimates to construct critical values required for one to reject the null hypothesis of no slope change. Results are displayed in figure 14. The blue line reports the elasticities based on the estimated slope change at the kink with the nominal $95 \%$ confidence interval in red, based on the local linear regression. The gray lines display the critical values at the $90 \%$ and $95 \%$ confidence level based on the distribution of placebo estimates at which one would expect zero slope change. The critical values based on t-statistics at the right panel clearly suggest that such small bandwidths often lead to statistically significant results around the placebo points, where one should expect just the opposite.

I interpret these two results from above as strong evidence that such small bandwidth choices have unsatisfactory performance with this data: they do not provide much information neither on the existence of a kinked relationship between job duration and earnings nor on the size of the kink. In order to assess whether larger bandwidths yield better performance, I conduct again an identical Monte Carlo study to the one described above, but now using fix bandwidth choices. I consider the widest possible range of symmetric bandwidths around kink 1 with intervals of $\mathrm{R} \$ 5$. Results are displayed in table 3 . The first thing to notice is that they again provide compelling evidence that the range of small bandwidths picked by the selectors performs poorly. Local linear estimates based bandwidths smaller than $\mathrm{R} \$ 50$ always yield RMSEs which are larger than the actual slope change in the DGP. Moreover, in most cases 
estimates have a wrong sign while the null hypothesis is rejected. On the other hand, larger bandwidths provide much lower RMSE. Thus, I base the main regression analysis on bandwidths around $\mathrm{R} \$ 75$ as RMSE seems to minimized around this value. Coverage rates are poor for any range of bandwidths and seem to be driven by a overall strong negative bias, which is smaller but still substantial for larger bandwidths. In the next subsection, I show that results for larger bandwidths support the graphical intuition and point for a positive elasticity between employment duration and benefit level. It means the negative bias indicated by the monte carlo study should not be a reason of much concern. If anything, the positive elasticities reported in the next subsection constitute a lower bound of the actual effect.

\subsection{Estimation Results}

Figure 15 presents regression results for varying bandwidths, but now using larger ones. For bandwidths larger than $\mathrm{R} \$ 60(\approx \$ 30)$, estimates are statistically significant and positive, just in line with the graphical analysis. More importantly, they display some stability which suggests for the absence of bias within this range (Ruppert, 1997). A similar pattern is found on the t-statistics. Even though, the number of placebo points for the permutation tests becomes smaller, it is important to notice that the estimated slope chance is higher than any of those found on the placebo tests. Notice that when there are less than enough placebo estimates to draw the $90 \%$ and $95 \%$ critical value, gray lines display the largest and smallest placebo estimate results. On the other hand, the same results on predicted job duration in figure 15 point for very small and often statistically insignificant estimates. More importantly, except for one specific bandwidth, these estimates are always within the critical values based on permutation tests. I interpret this as strong evidence of the presence of an actual and statistically significant slope change in employment duration around the first kink caused by benefit level. Elasticities estimates around the preferred bandwidth of $\mathrm{R} \$ 75$ are shown in table 4 and point for a positive elasticity of around 0.3.

As regards the channel driving such effect, figure 17 displays the same estimates on quitting probability. Results clearly point for a strong and statistically significant negative effect which also displays stability for bandwidths larger than $\mathrm{R} \$ 55(\approx \$ 27.5)$. Moreover, slope estimates and t-statistics are well outside the range found in the placebo tests. The same estimates for lay-off and MER probabilities are displayed in appendix figures A13-A14 and indicate small and statistically insignificant results for these variables.

Despite all this evidence, there could still be a concern that these results are capturing a simple pre-determined kinked or quadratic relationship between job duration and the average earnings around the kink point. To address this issue and test for the robustness of the estimates presented above, I apply a RKD in double differences (Landais, 2014) which explores the fact that each kink point changes every year in real terms. The idea is to compare the estimated slope change on the actual policy kink to the slope change estimate at the same point in previous years, when no actual policy kink was in place. Therefore, if the results from above are simply picking up a quadratic relationship between job 
duration and earnings around the kink the points, the diff-in-diff RKD estimates should point toward a null result. To implement this procedure I need a minimum interval of time between the treatment and placebo year in order to ensure that there is enough distance between the policy kink in the treatment year and the policy kink in the placebo year. Otherwise bandwidths around the kink point used in the DD-RKD (from the treatment year) will be constrained by the kink point in the placebo year. This would lead for regression bandwidths which are too small and results will likely pick noise. Therefore, I use a three years lag to implement this procedure, and have also to drop the years of 2005 and 2011 because there is too little variation between kink points for 2008-2005 and 2011-2008. Therefore, the final sample contains the years of 2009, 2010 and 2012 as treatment years; and 2006, 2007, and 2009 as control years (there was no actual policy kink at these points in these years). Figure 18 shows how employment duration evolves around the years in which there was an actual policy kink (top panel), compared to the "control" years (bottom panel). This graphical evidence suggests that while there seems to be a kink on the top panel, job duration seems to evolve smoothly around the placebo points on the bottom panel. Such impression is confirmed by the regression results displayed in table 5. Estimates on employment duration and quitting probabilities yield very similar results to the standard RKD analysis, which are robust and relatively stable across bandwidths. No robust indication of slope change caused by UI benefit level is found on lay-off and MER probabilities. The same thing happens for the predicted job duration variable, indicating once again that the estimates on job duration and job quits are not driven by imbalances on pre-determined covariates.

Finally, I propose a further test to assess whether the differences in slopes on job duration detected in the DD-RKD is indeed caused by the UI benefit schedule. I repeat the same procedure from above but now adding a placebo kink point to the analysis. This point is not an actual policy kink neither in the "treatment" nor in the "control" year. Thus, I perform a RKD in triple differences: it assesses the differences in slope changes between "treatment" and "control" year at an actual kink point, vis-a-vis, the differences in slope changes between "treatment" and "control" year at a fake kink point, in which no policy kink was ever in place. The idea is to control for the fact that the overall curvature of the relationship between job duration and earnings may be changing over the years. In other words, it aims to control for the possibility that the differences in slope changes with a three years distance in time are spurious. I set this fake point as close as possible to the actual kink point but considering the constrain that some minimal bandwidth is required to run these regressions. Table 6 presents these DDD-RKD results. Even though the range of possible bandwidths is smaller, these results point to a similar pattern as the one found in the previous analysis.

Overall, I find the results around the first kink fairly robust. They indicate that an $1 \%$ increase in benefit level causes employment duration to increase by $0.3 \%$. This evidence is also robust for a substantial and negative effect of UI benefit level on quitting probabilities, which decreases by around $1.25 \%$ in response to a $1 \%$ increase in UI benefits. 


\section{Implications for Welfare}

Now I present a simple welfare calibration using the results from the previous section. The goal is to provide a sense of to what extent the estimated elasticity of job duration may matter for the optimal UI benefit level. To perform this simple exercise, I need to recall few other terms of the formula from the existing literature. Estimates on the elasticity of the covered unemployment duration to benefit level $\left(\epsilon_{D_{B}, b}\right)$ are not available for Brazilian data. I then assume this to equal 1 which is an upper bound on the empirical literature based on developed countries. As regards the liquidity to moral hazard $\operatorname{ratio}(\rho)$, I recover the value of 0.98 from Britto (2015), based on the same dataset.

The welfare formula as shown in (10) implies that there are still gains from increasing benefit level if:

$$
\frac{d W}{d b}>0 \Longleftrightarrow \frac{1}{1-s_{0}}(\rho+1)-\left(1+\epsilon_{f^{U I}, b}+\epsilon_{D_{B}, b}-\epsilon_{D_{E}, b}\right)>0
$$

From estimates around kink 1 , consider $\epsilon_{D_{E}, b}=0.3$ and $\epsilon_{f^{U I}, b}$ to equal zero. Also, I estimate $\frac{1}{1-s_{0}}=$ 1.04, where $s_{0}$ is the fraction of workers finding a new job within one week of unemployment. It implies that the welfare effect of raising UI benefits on welfare by $\$ 1$ is positive if:

$$
\frac{d W}{d b}>0 \Longleftrightarrow(0.98+1)-(1+0+1-0.3)=0.28>0
$$

If the elasticity of unemployment duration to benefit level is indeed approximately equal to 1 , the welfare formula suggests that there would still be gains from raising benefit level. If one instead neglects UI effects on the duration of employment, the result would point otherwise:

$$
\frac{d W}{d b}>0 \Longleftrightarrow(0.98+1)-(1+0+1-(\varnothing .3))^{0}=-0.02<0
$$

In any case, the main message from this simple exercise is that the effect found on the duration of employment is economically significant and clearly relevant for welfare. It lies within the same range of the literature estimates on the elasticity of unemployment duration to benefit level $(0.3$ vs. [0.1,0.9]) and impacts welfare just with the same weight. It strongly suggests that policy makers should be aware of such effect and take it into account in order to optimally set the level of unemployment benefits.

\section{Conclusion}

The main conclusion from this essay is that UI can affect the duration of employment spells in an economically meaningful way. Perhaps surprisingly, this effect is positive and driven by a negative strong 
effect on quitting rates. Such finding is of direct interest for policy makers when evaluating the social costs and benefits of UI provision. This work provides a welfare formula which incorporates this effect and delivers a clear message on how it affects the optimal level of unemployment benefits. Of course, these empirical findings are based in a developing country. Whether this is also the case for developed countries is left as a open question. Nevertheless, it is worth noting that the empirical strategy proposed in this paper could be applied elsewhere, since many UI systems follow a similar schedule type for benefit level. This could be an interesting direction for future research. 


\section{References}

Baker, M. and S. A. Rea Jr (1998). Employment spells and unemployment insurance eligibility requirements. Review of Economics and Statistics 80(1), 80-94.

Britto, D. (2015). The liquidity gains from unemployment insurance in markets with high informality: Evidence from brazil. mimeo.

Calonico, S., M. D. Cattaneo, and R. Titiunik (2014). Robust nonparametric confidence intervals for regression-discontinuity designs. Econometrica 82(6), 2295-2326.

Calonico, S., M. D. Cattaneo, R. Titiunik, et al. (2014). Robust data-driven inference in the regressiondiscontinuity design. Stata Journal 14(4), 909-946.

Card, D., Z. Pei, D. Lee, and A. Weber (2015). Inference on causal effects in a generalized regression kink design. Available at SSRN 2553874.

Chetty, R. (2008). Moral hazard versus liquidity and optimal unemployment insurance. Journal of Political Economy 116(2), 173-234.

Christofides, L. N. and C. J. McKenna (1995). Unemployment insurance and moral hazard in employment. Economics Letters 49(2), 205-210.

Christofides, L. N. and C. J. McKenna (1996). Unemployment insurance and job duration in canada. Journal of Labor Economics, 286-312.

Fan, J. and I. Gijbels (1996). Local polynomial modelling and its applications: monographs on statistics and applied probability 66, Volume 66. CRC Press.

Feldstein, M. (1976). Temporary layoffs in the theory of unemployment. The Journal of Political Economy, 937-957.

Feldstein, M. (1978). The effect of unemployment insurance on temporary layoff unemployment. The American Economic Review, 834-846.

Ganong, P. and S. Jäger (2014). A permutation test and estimation alternatives for the regression kink design.

Green, D. A. and T. C. Sargent (1998). Unemployment insurance and job durations: seasonal and non-seasonal jobs. Canadian Journal of Economics, 247-278.

Lalive, R., J. C. van Ours, and J. Zweimüller (2011). Equilibrium unemployment and the duration of unemployment benefits. Journal of Population Economics 24 (4), 1385-1409. 
Landais, C. (2014). Assessing the welfare effects of unemployment benefits using the regression kink design. American Economic Journal: Economic Policy, forthcoming.

Light, A. and Y. Omori (2004). Unemployment insurance and job quits. Journal of Labor Economics 22(1), 159-188.

McCrary, J. (2008). Manipulation of the running variable in the regression discontinuity design: A density test. Journal of Econometrics 142(2), 698-714.

Rebollo-Sanz, Y. (2012). Unemployment insurance and job turnover in spain. Labour Economics 19(3), $403-426$.

Ruppert, D. (1997). Empirical-bias bandwidths for local polynomial nonparametric regression and density estimation. Journal of the American Statistical Association 92(439), 1049-1062.

Solon, G. (1984). The effects of unemployment insurance eligibility rules on job quitting behavior. Journal of Human Resources, 118-126.

Topel, R. H. (1983). On layoffs and unemployment insurance. The American Economic Review, 541-559.

Topel, R. H. (1984). Experience rating of unemployment insurance and the incidence of unemployment. Journal of Law and Economics, 61-90.

Winter-Ebmer, R. (2003). Benefit duration and unemployment entry: A quasi-experiment in austria. European Economic Review 47(2), 259-273. 
Figure 3: Density of Earnings around Kink 1

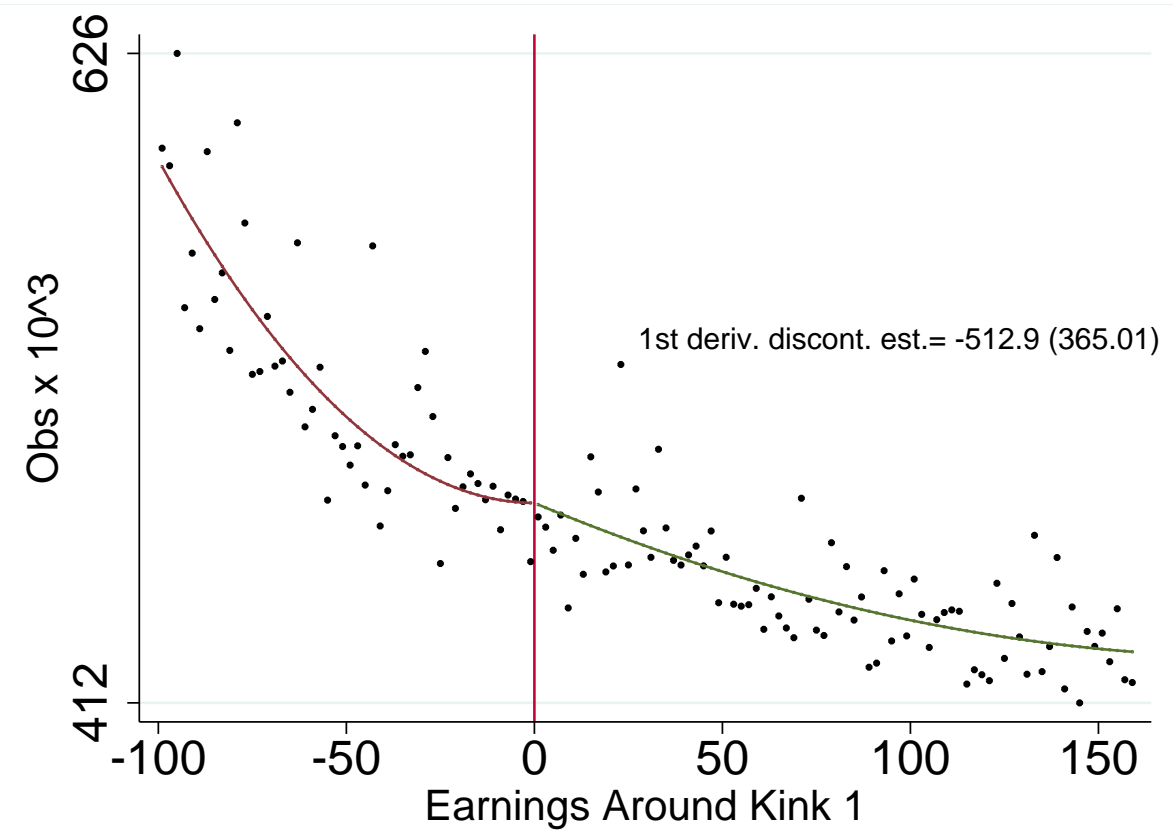

The graph displays how the density of earnings evolve around the kink. At each side of the kink, the density is approximated by the polynomial which minimizes the Akaike Criterion. The graph also displays the test statistics for the slope change of these polynomials at the kink. See the text for details. 
Figure 4: Employment Duration

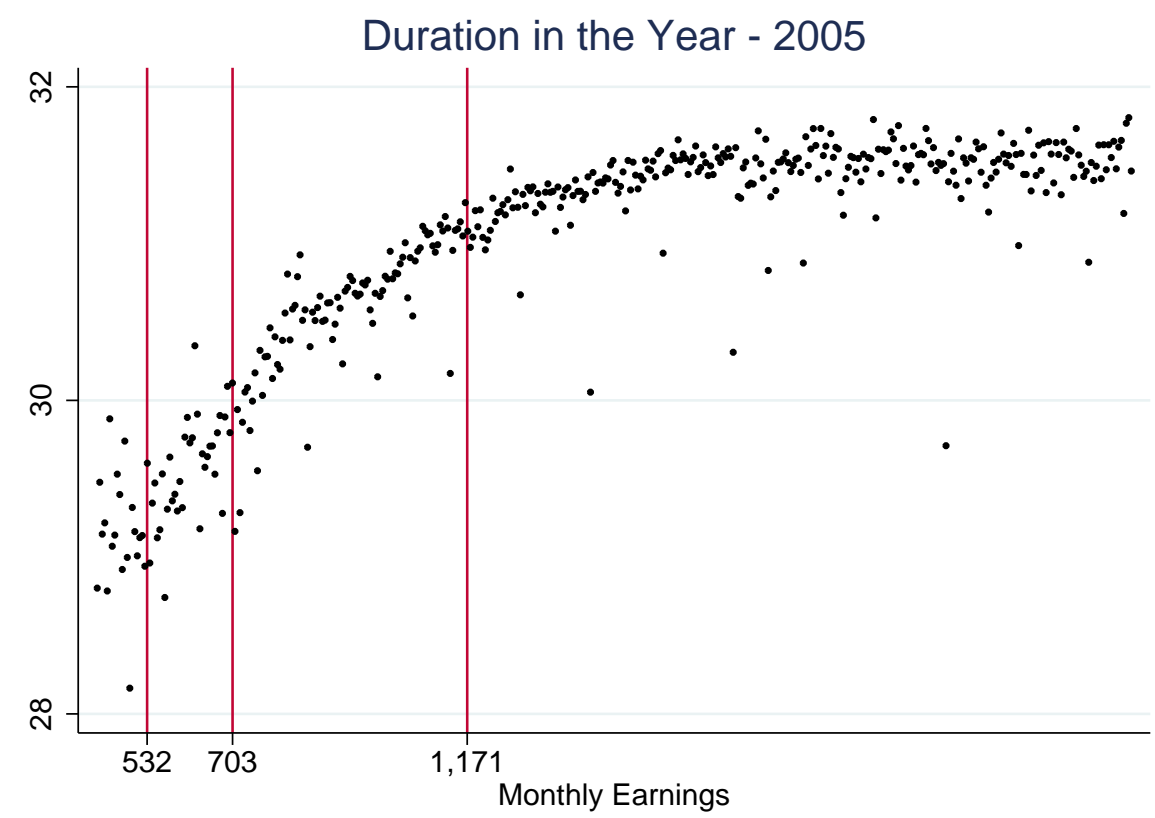

The graph displays how employment duration in the year evolves according to monthly average earnings, in 2012 prices. Duration is expressed in weeks.

Figure 5: Employment Duration

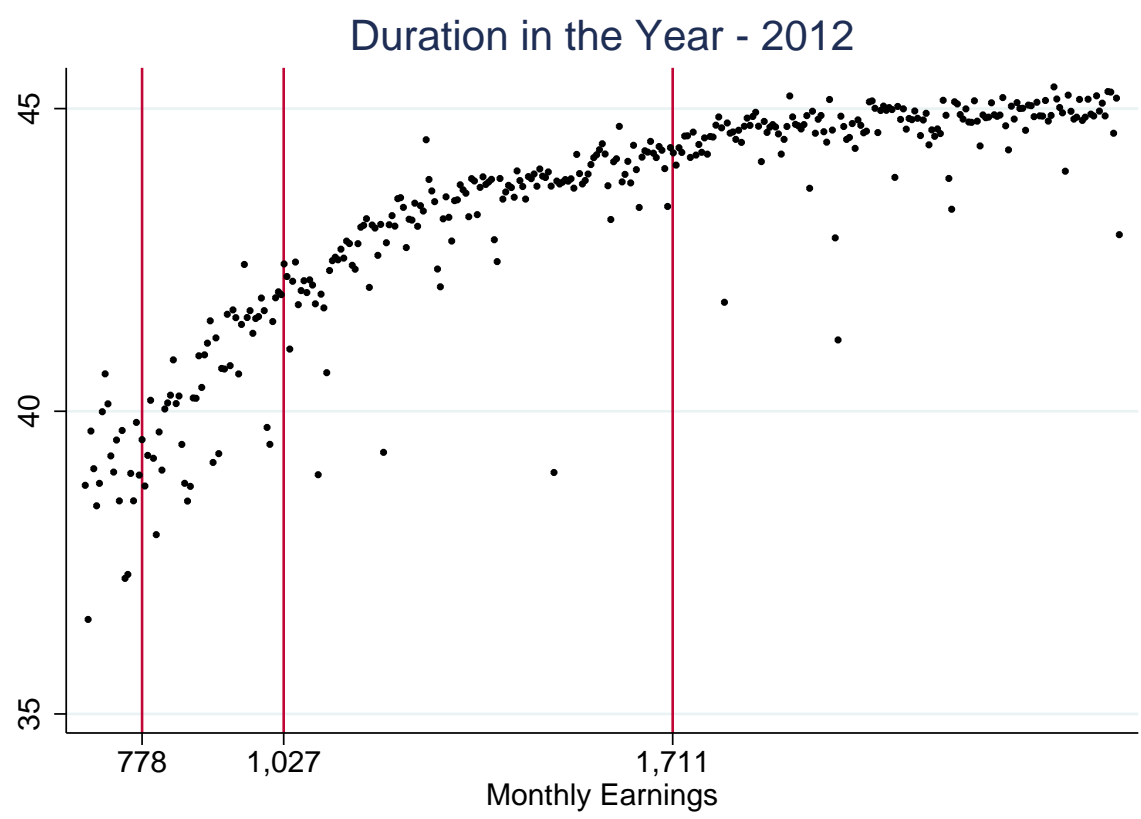

The graph displays how employment duration in the year evolves according to monthly average earnings, in 2012 prices. Duration is expressed in weeks. 
Figure 6: Job Quits

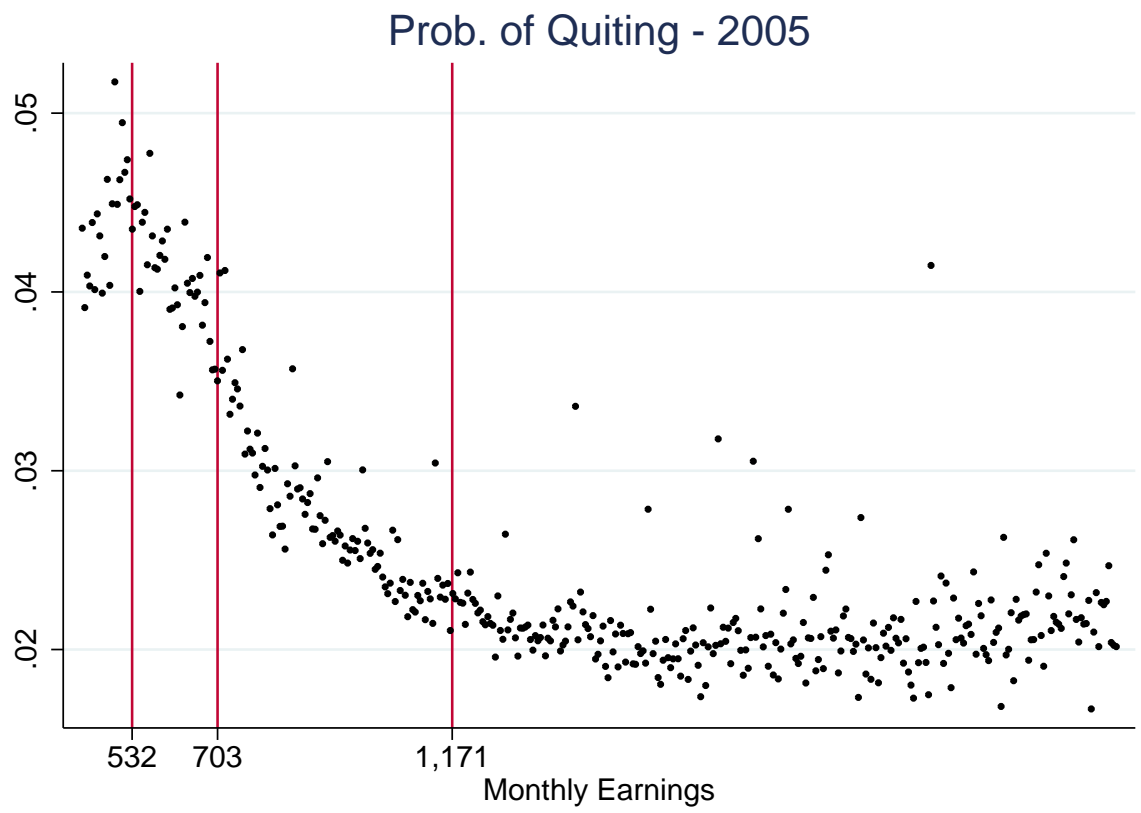

The graph displays how the prob. of quitting in the year evolves according to monthly average earnings, in 2012 prices. Duration is expressed in weeks.

Figure 7: Job Quits

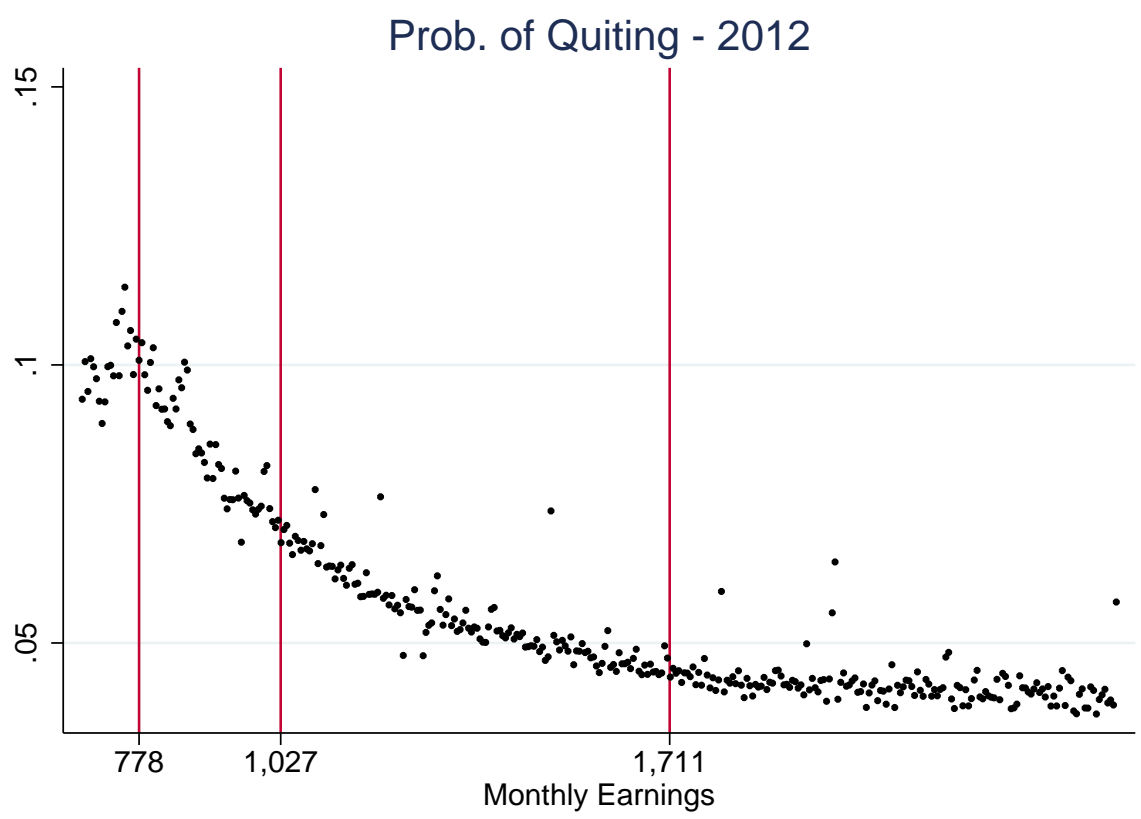

The graph displays how the prob. of quitting in the year evolves according to monthly average earnings, in 2012 prices. Duration is expressed in weeks. 
Figure 8: Employment Duration Around Kink 1 - All Years

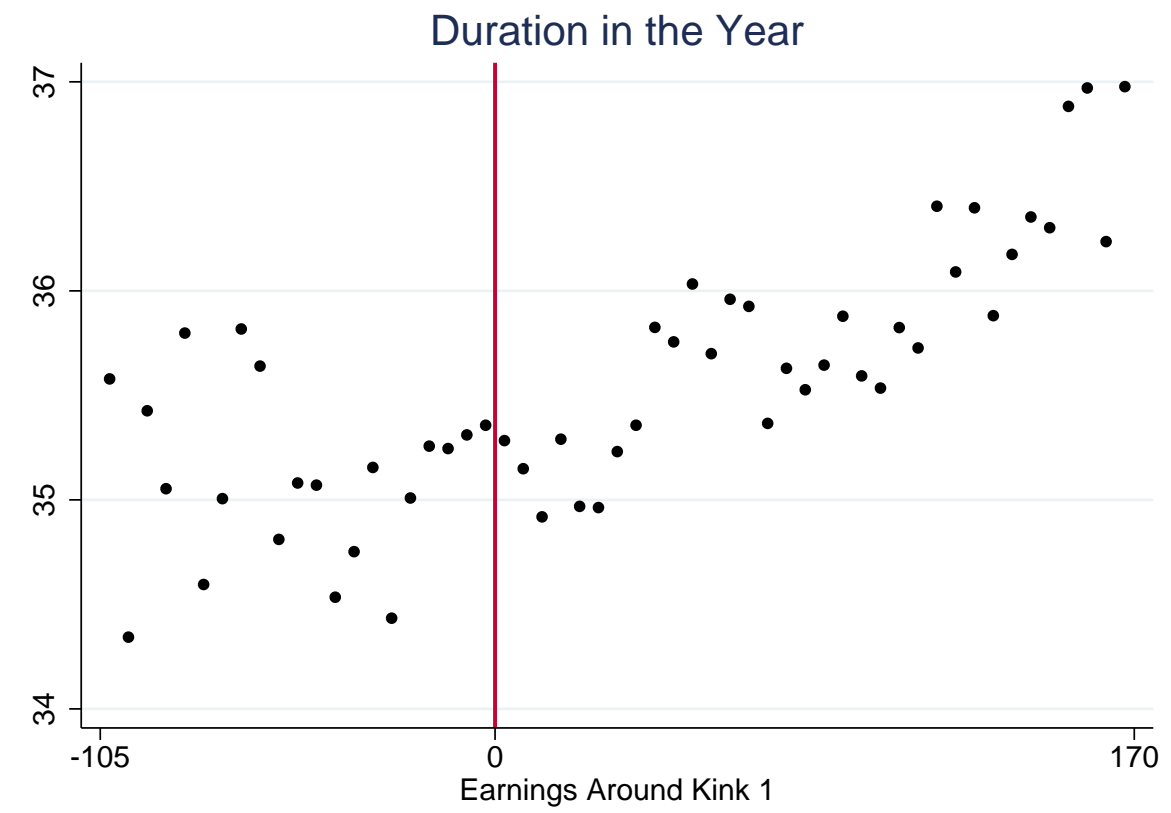

The graph displays how employment duration in the year evolves around the kink. Duration is expressed in weeks.

Figure 9: Predicted Employment Duration Around Kink 1 - All Years

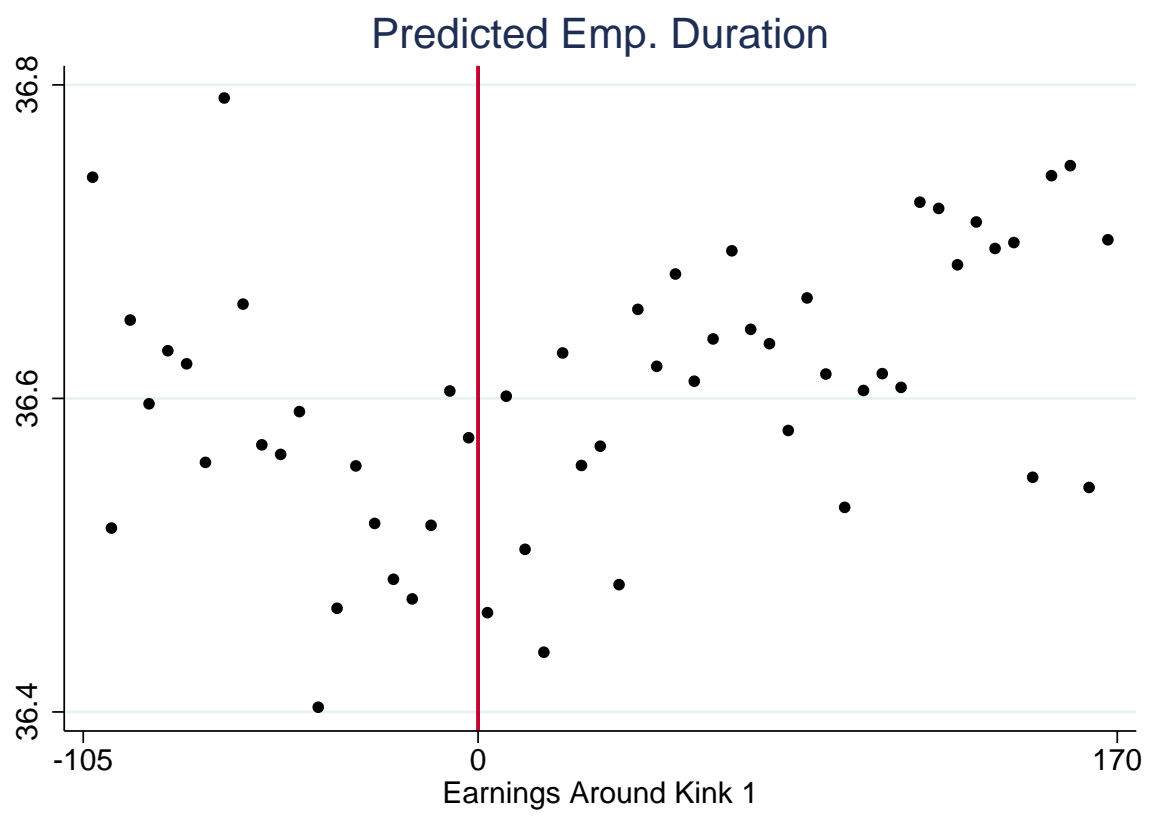

The graph displays how predicted employment duration in the year, based on a extremely rich set of covariates, evolves around the kink. Duration is expressed in weeks. See text for details on the construction of this predicted variabel. 
Figure 10: Employment Duration Around Kink 1 - Restricted Sample

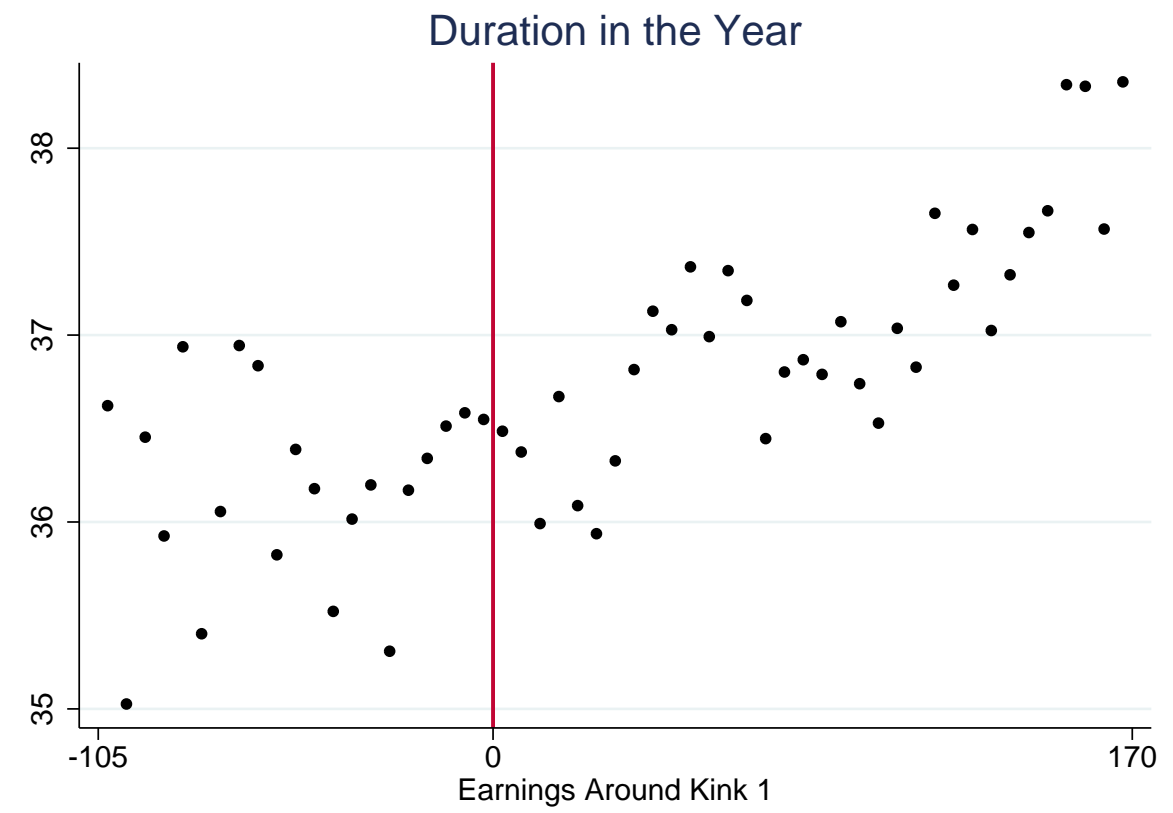

The graph displays how employment duration in the year evolves around the kink. This sample is restricted to the years from 2007 to 2012. Duration is expressed in weeks.

Figure 11: Predicted Employment Duration Around Kink 1 - Restricted Sample

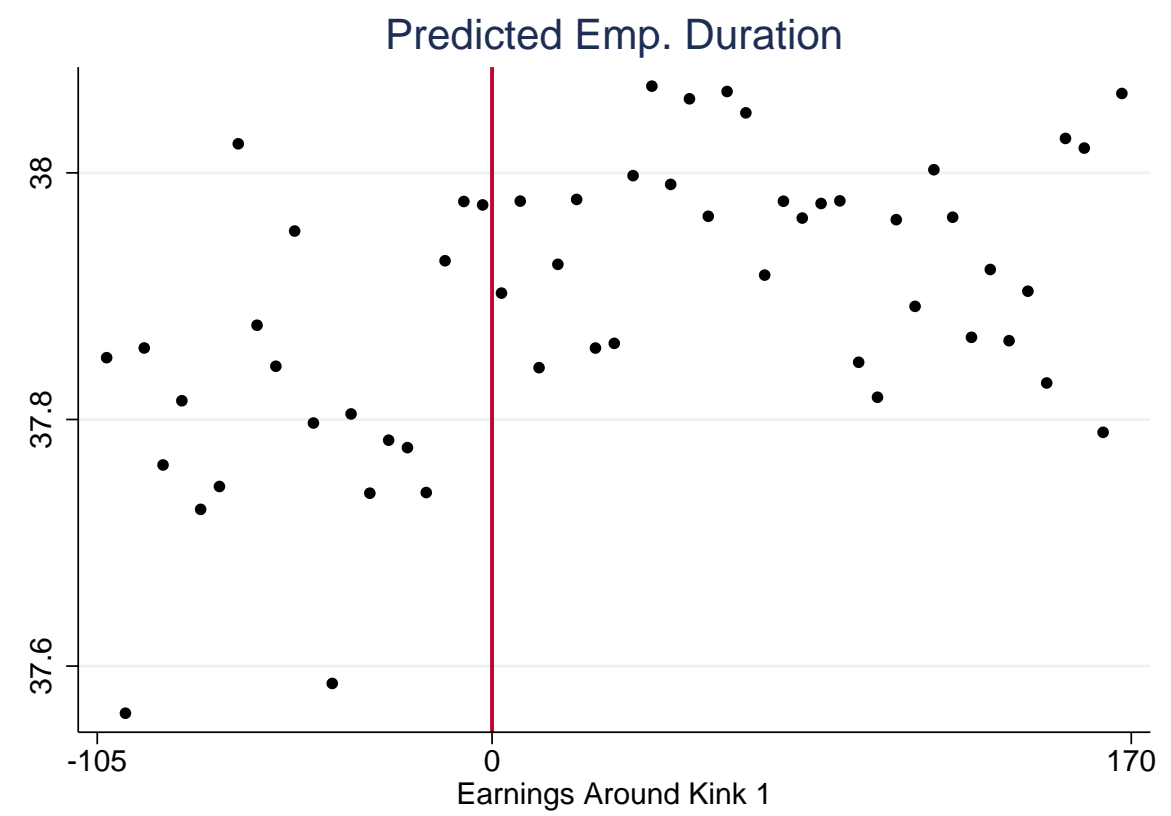

The graph displays how predicted employment duration in the year evolves around the kink. This sample is restricted to the years from 2007 to 2012 . Duration is expressed in weeks. See text for details on the construction of this predicted variabel. 
Figure 12: Covariates Around Kink 1 - Restricted Sample

\section{Smoothness of Covariates - Kink 1}
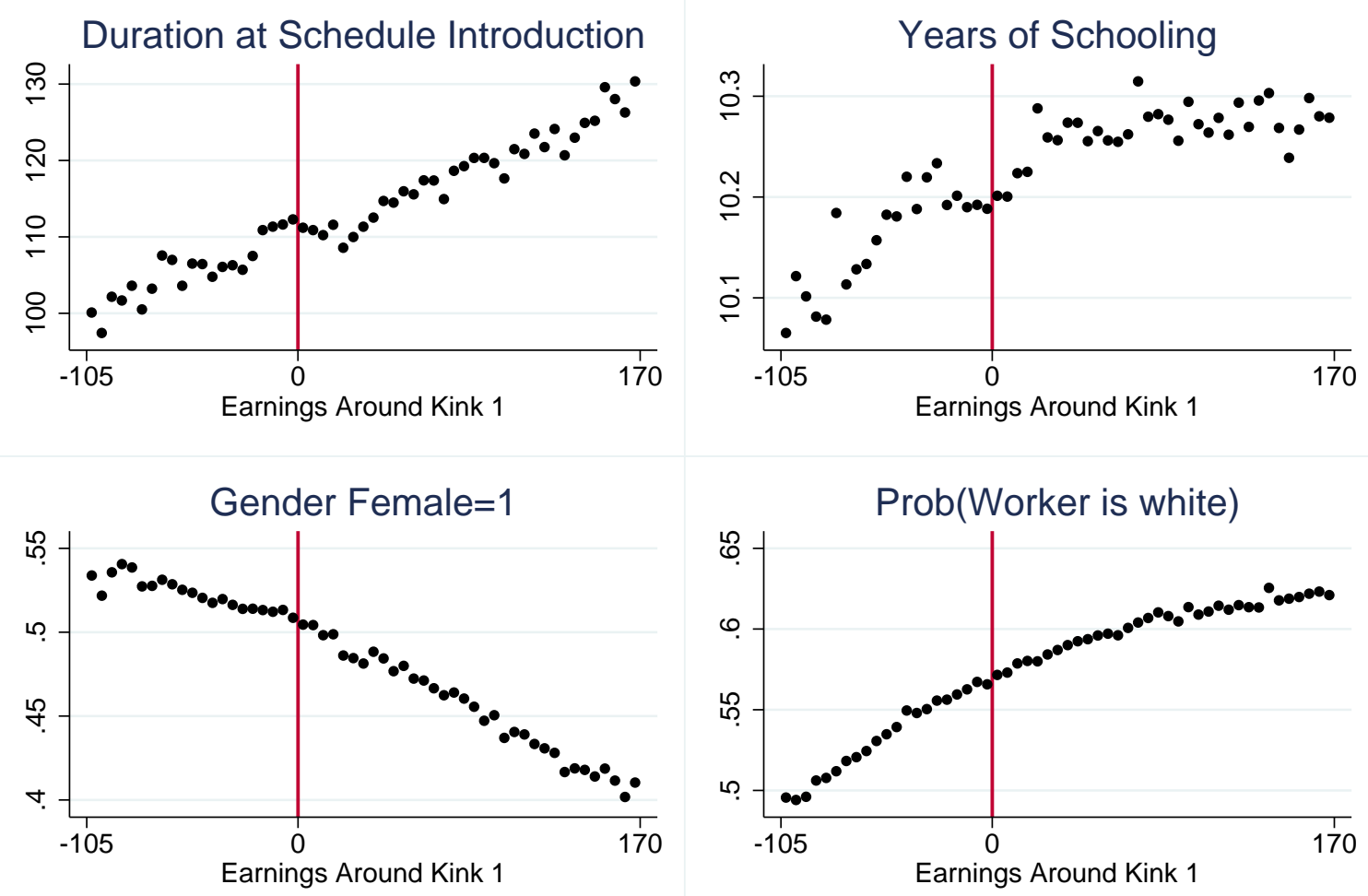

The graph displays how pre-determined covariates evolves around the kink. This sample is restricted to the years from 2007 to 2012. Duration is expressed in weeks. 
Figure 13: Job Quits Around Kink 1 - Restricted Sample

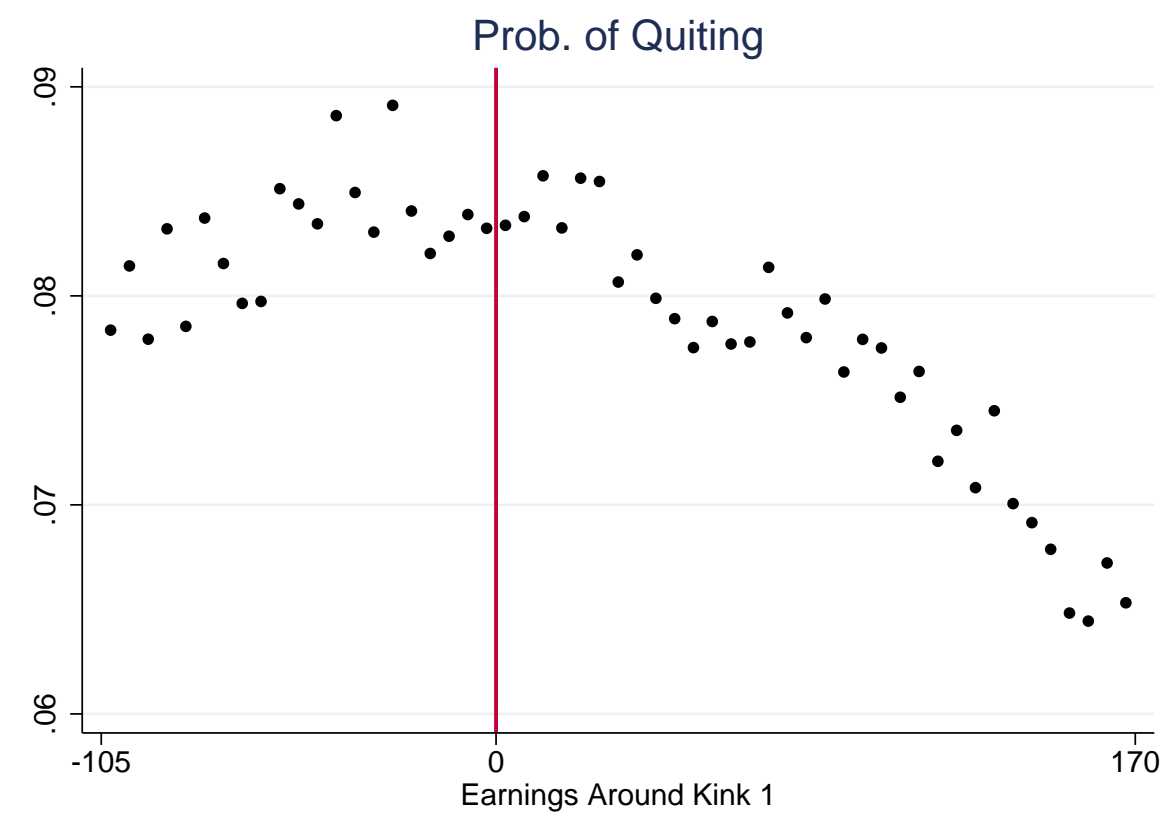

The graph displays how the prob. of quitting in the year evolves around the kink. This sample is restricted to the years from 2007 to 2012. Duration is expressed in weeks. 
Figure 14: RKD estimates with varying bandwidths and Permutation Test Critical Values - Kink 1 Small Bandwidths - Restricted Sample

\section{Duration in the Year - Kink 1}

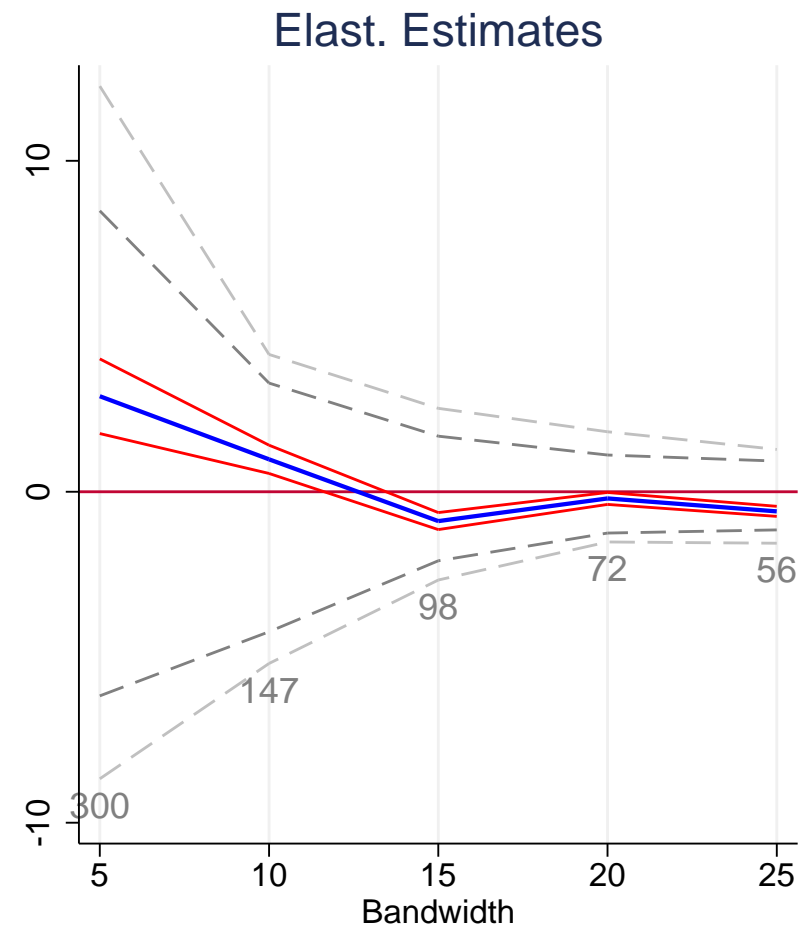

Crit. Value $95 \%---$ C.V. $90 \%$ $95 \%$ Nom. Cl

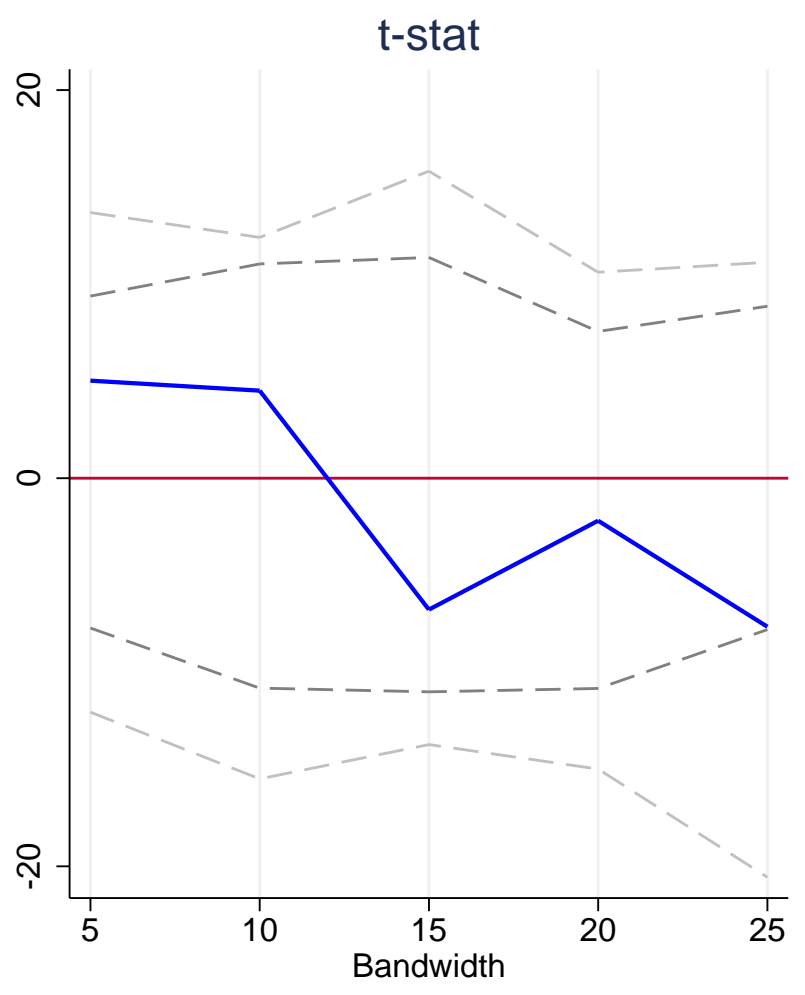

- - Crit. Value $95 \%---$ C.V. $90 \%$

The graph displays elasticities estimates and t-statistics based on a local linear regressions around kink 1 for varying bandwidths (blue line). The gray lines display the critical value in a two-sided test for rejecting the null hypothesis of zero effect, based on permutation tests along as many as possible placebo points located between the minimum wage and $\mathrm{R} \$ 4000$ (2012 prices). The gray number displays the number of placebo points for this test, according to the LLR bandwidth. This sample is restricted to the years from 2007 to 2012. Duration is expressed in weeks. Standard errors are clustered at the firm level. 
Figure 15: RKD estimates with varying bandwidths and Permutation Test Critical Values - Kink 1 Restricted Sample

\section{Duration in the Year - Kink 1}
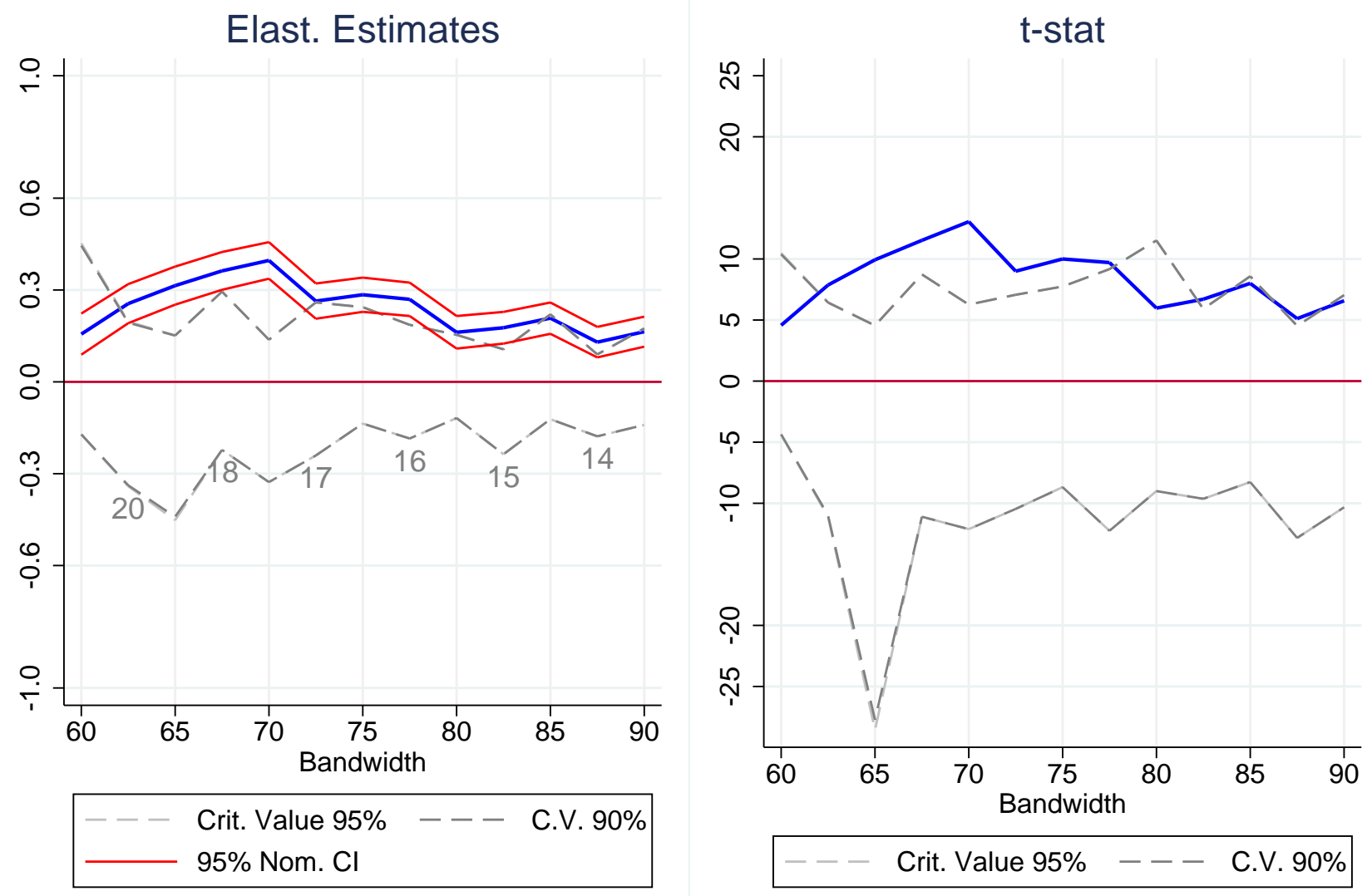

Crit. Value $95 \%---$ C.V. $90 \%$

The graph displays elasticities estimates and t-statistics based on a local linear regressions around kink 1 for varying bandwidths (blue line). The gray lines display the critical value in a two-sided test for rejecting the null hypothesis of zero effect, based on permutation tests along as many as possible placebo points located between the minimum wage and $\mathrm{R} \$ 4000$ (2012 prices). The gray number displays the number of placebo points for this test, according to the LLR bandwidth. This sample is restricted to the years from 2007 to 2012. Duration is expressed in weeks. Standard errors are clustered at the firm level. 
Figure 16: RKD estimates with varying bandwidths and Permutation Test Critical Values - Kink 1 Restricted Sample

\section{Predicted Emp. Duration - Kink 1}
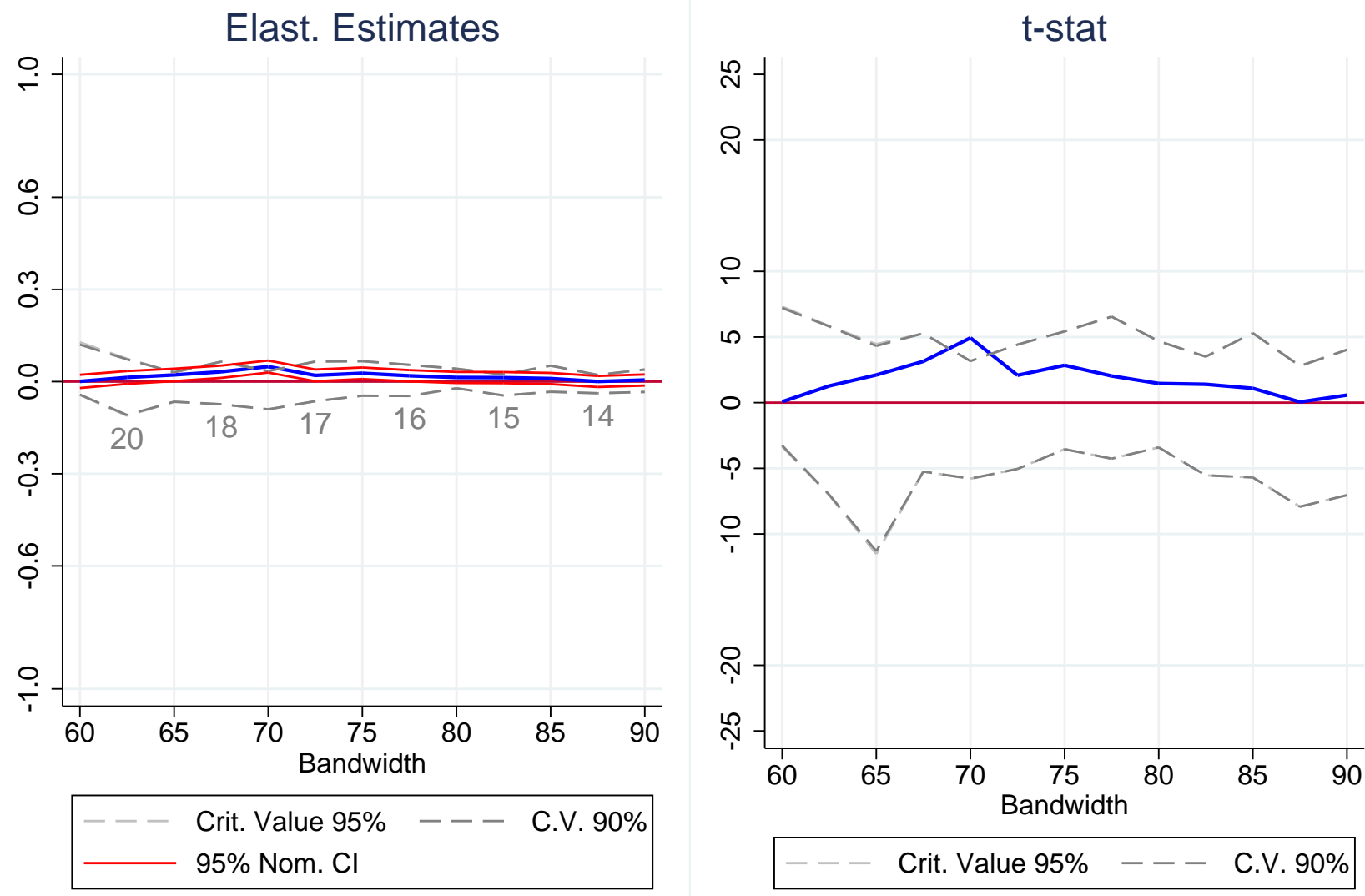

$95 \%$ Nom. Cl

Crit. Value $95 \%---$

C.V. $90 \%$

The graph displays elasticities estimates and t-statistics based on a local linear regressions around kink 1 for varying bandwidths (blue line). The gray lines display the critical value in a two-sided test for rejecting the null hypothesis of zero effect, based on permutation tests along as many as possible placebo points located between the minimum wage and $\mathrm{R} \$ 4000$ (2012 prices). The gray number displays the number of placebo points for this test, according to the LLR bandwidth. This sample is restricted to the years from 2007 to 2012. Duration is expressed in weeks. Standard errors are clustered at the firm level. 
Figure 17: RKD estimates with varying bandwidths and Permutation Test Critical Values - Kink 1 Restricted Sample

\section{Prob. of Quitting - Kink 1}
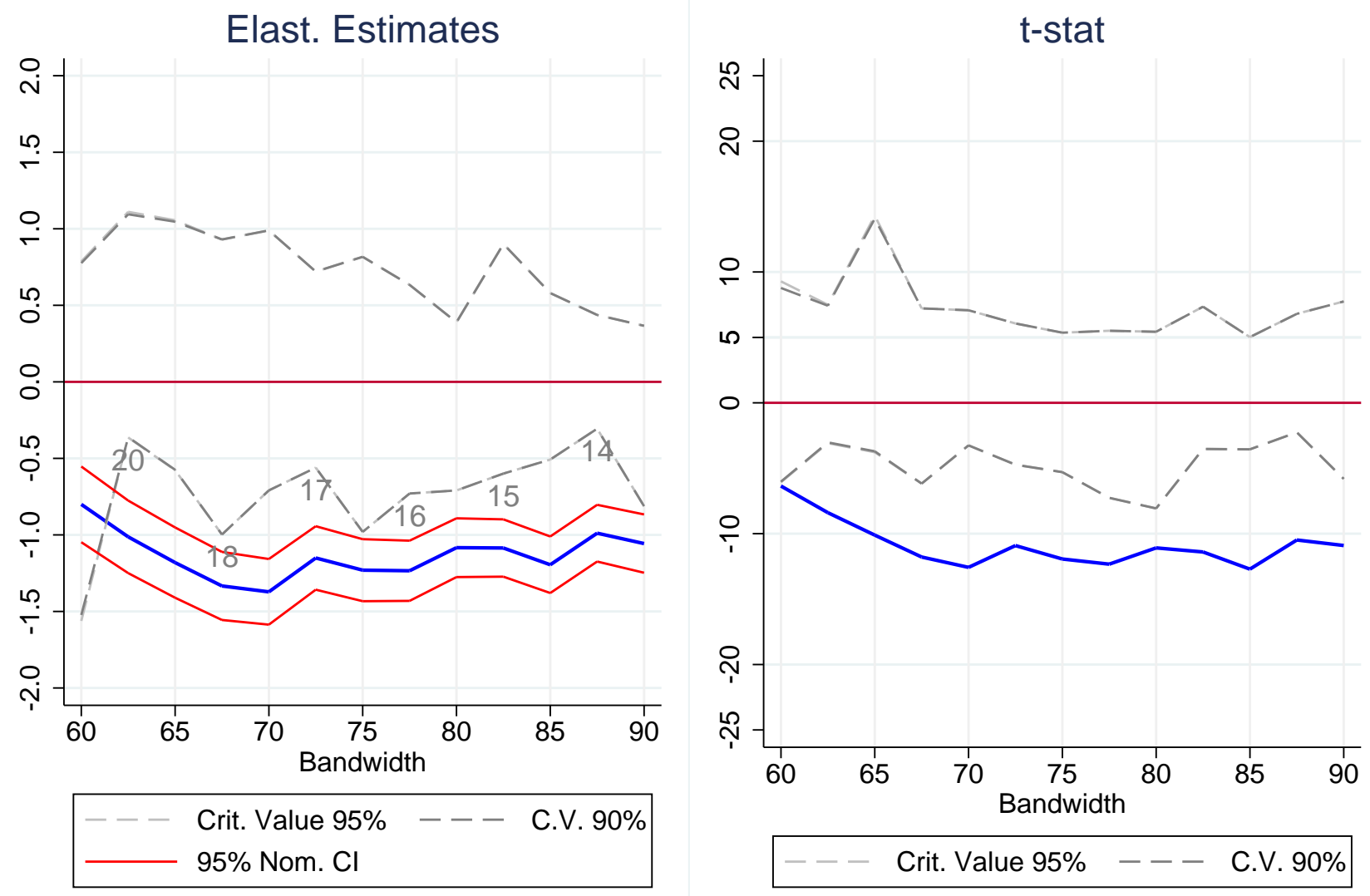

-- Crit. Value $95 \%---$ C.V. $90 \%$

The graph displays elasticities estimates and t-statistics based on a local linear regressions around kink 1 for varying bandwidths (blue line). The gray lines display the critical value in a two-sided test for rejecting the null hypothesis of zero effect, based on permutation tests along as many as possible placebo points located between the minimum wage and $\mathrm{R} \$ 4000$ (2012 prices). The gray number displays the number of placebo points for this test, according to the LLR bandwidth. This sample is restricted to the years from 2007 to 2012. Duration is expressed in weeks. Standard errors are clustered at the firm level. 
Figure 18: Diff. in Diff. RKD - Actual Policy Kink vs. Previous Years Placebo - Kink 1

\section{Diff-in-Diff RKD - Kink 1}
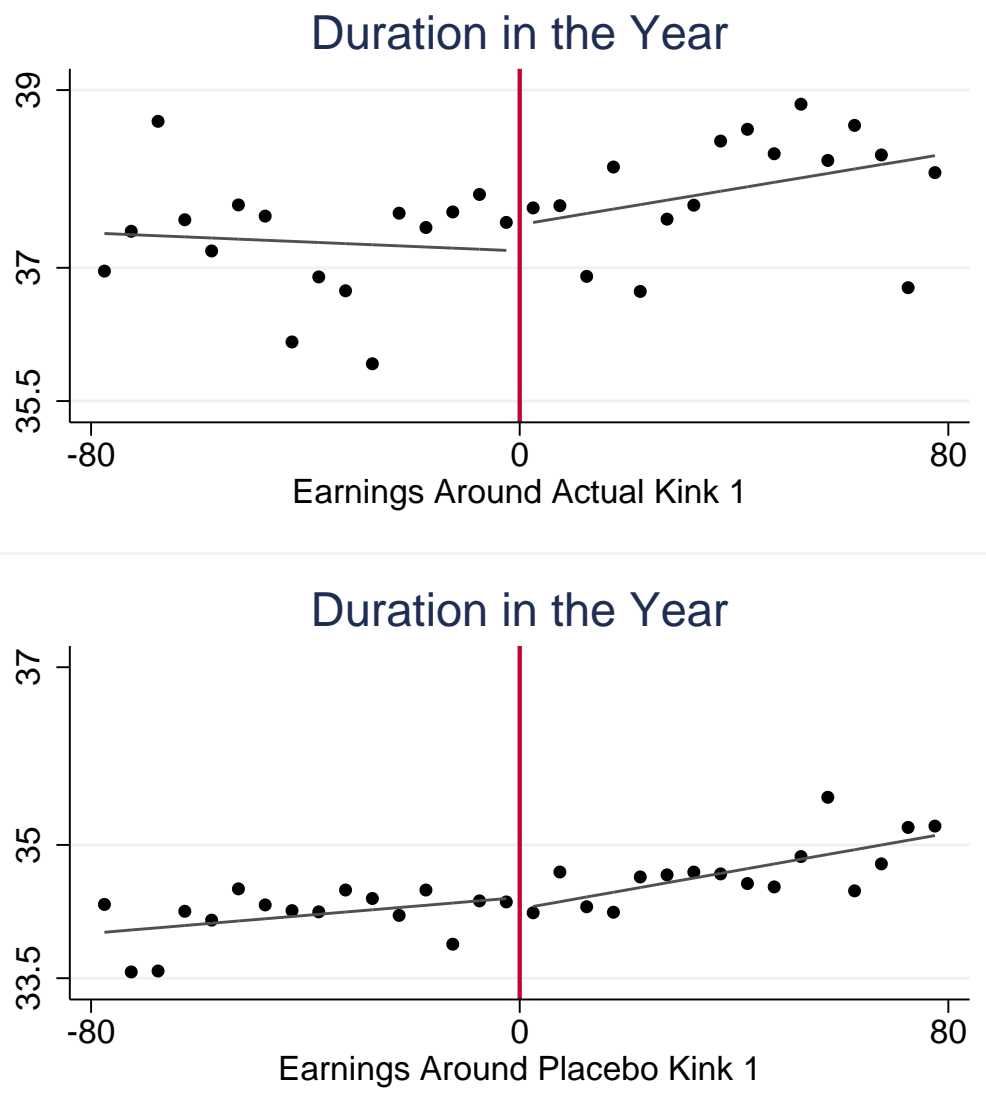

Note: The table shows how employment duration evolves around actual policy kinks (top pane) compared to how the same outcome evolves three years before around the same points, when no actual policy kink was in place (bottom panel). These results consider the policy kink of the years 2009, 2010 and 2012, and use as placebo kinks the same points on data in years 2006, 2007, and 2009. It is necessary to use a three years and drop some years in order to have a minimum bandwidth range around the kink points. 
Table 2: Monte Carlo Simulations - Bandwidth Selectors Performance - Kink 1

First Kink

Bandwidth Selector Mean RMSE over Coverage Bias over Rejects null Rejects null

b.w. True Value Rate True Value correct sign wrong sign

standard

FG linear

9.3

1.08

0.30

$-0.81$

0.09

0.05

CCT linear, no regul.

18.5

1.10

0.05

$-1.06$

0.08

0.35

CCT linear

11.3

1.03

0.09

$-0.98$

0.05

0.08

FG quadratic

20.2

1.15

0.55

$-0.64$

0.17

0.08

CCT quadratic, no regul.

0.85

0.56

$-0.63$

0.15

0.03

CCT quadratic

16.7

0.80

0.70

$-0.51$

0.13

0.01

bias correction

CCT linear, no regul.

26.3

1.01

0.23

$-0.93$

0.08

0.11

CCT linear

24.9

0.92

0.29

$-0.83$

0.09

0.02

CCT quadratic, no regul.

0.70

0.81

$-0.28$

0.20

0.01

CCT quadratic

28.5

0.74

0.91

$-0.22$

0.20

0.00

Note: Results are based on 300 simulations. DGP is based on $5^{\text {th }}$ degree polynomial approximation of the actual data around this kink. The sample size for each simulation equals the actual sample size. The true elasticity is 0.5.Standard errors are clustered at the firm level. 
Table 3: Monte Carlo Simulations - Linear Fix Bandwidths Performance - Kink 1

\begin{tabular}{|c|c|c|c|c|c|}
\hline First Kink & & & & & \\
\hline & & Coverage & & & \\
\hline Bandwidth & True Value & Rate & True Value & correct sign & wrong sign \\
\hline 5 & 1.289 & 0.70 & -1.07 & 0.02 & 0.02 \\
\hline 10 & 1.785 & 0.00 & -1.77 & 0.00 & 0.83 \\
\hline 15 & 2.166 & 0.00 & -2.16 & 0.00 & 1.00 \\
\hline 20 & 2.344 & 0.00 & -2.34 & 0.00 & 1.00 \\
\hline 25 & 2.329 & 0.00 & -2.33 & 0.00 & 1.00 \\
\hline 30 & 2.203 & 0.00 & -2.20 & 0.00 & 1.00 \\
\hline 35 & 1.980 & 0.00 & -1.98 & 0.00 & 1.00 \\
\hline 40 & 1.706 & 0.00 & -1.71 & 0.00 & 1.00 \\
\hline 45 & 1.406 & 0.00 & -1.41 & 0.00 & 1.00 \\
\hline 50 & 1.121 & 0.00 & -1.12 & 0.00 & 1.00 \\
\hline 55 & 0.863 & 0.00 & -0.86 & 1.00 & 0.00 \\
\hline 60 & 0.641 & 0.00 & -0.64 & 1.00 & 0.00 \\
\hline 65 & 0.470 & 0.00 & -0.47 & 1.00 & 0.00 \\
\hline 70 & 0.363 & 0.00 & -0.36 & 1.00 & 0.00 \\
\hline 75 & 0.316 & 0.00 & -0.32 & 1.00 & 0.00 \\
\hline 80 & 0.320 & 0.00 & -0.32 & 1.00 & 0.00 \\
\hline 85 & 0.367 & 0.00 & -0.37 & 1.00 & 0.00 \\
\hline 90 & 0.437 & 0.00 & -0.44 & 1.00 & 0.00 \\
\hline 95 & 0.510 & 0.00 & -0.51 & 1.00 & 0.00 \\
\hline 100 & 0.558 & 0.00 & -0.56 & 1.00 & 0.00 \\
\hline 105 & 0.546 & 0.00 & -0.55 & 1.00 & 0.00 \\
\hline
\end{tabular}

Note: Results are based on 300 simulations. DGP is based on $5^{\text {th }}$ degree polynomial approximation of the actual data around this kink. The sample size for each simulation equals the actual sample size. The true elasticity is 0.5.Standard errors are clustered at the firm level. 
Table 4: RKD Estimates - First Kink - Restricted Sample

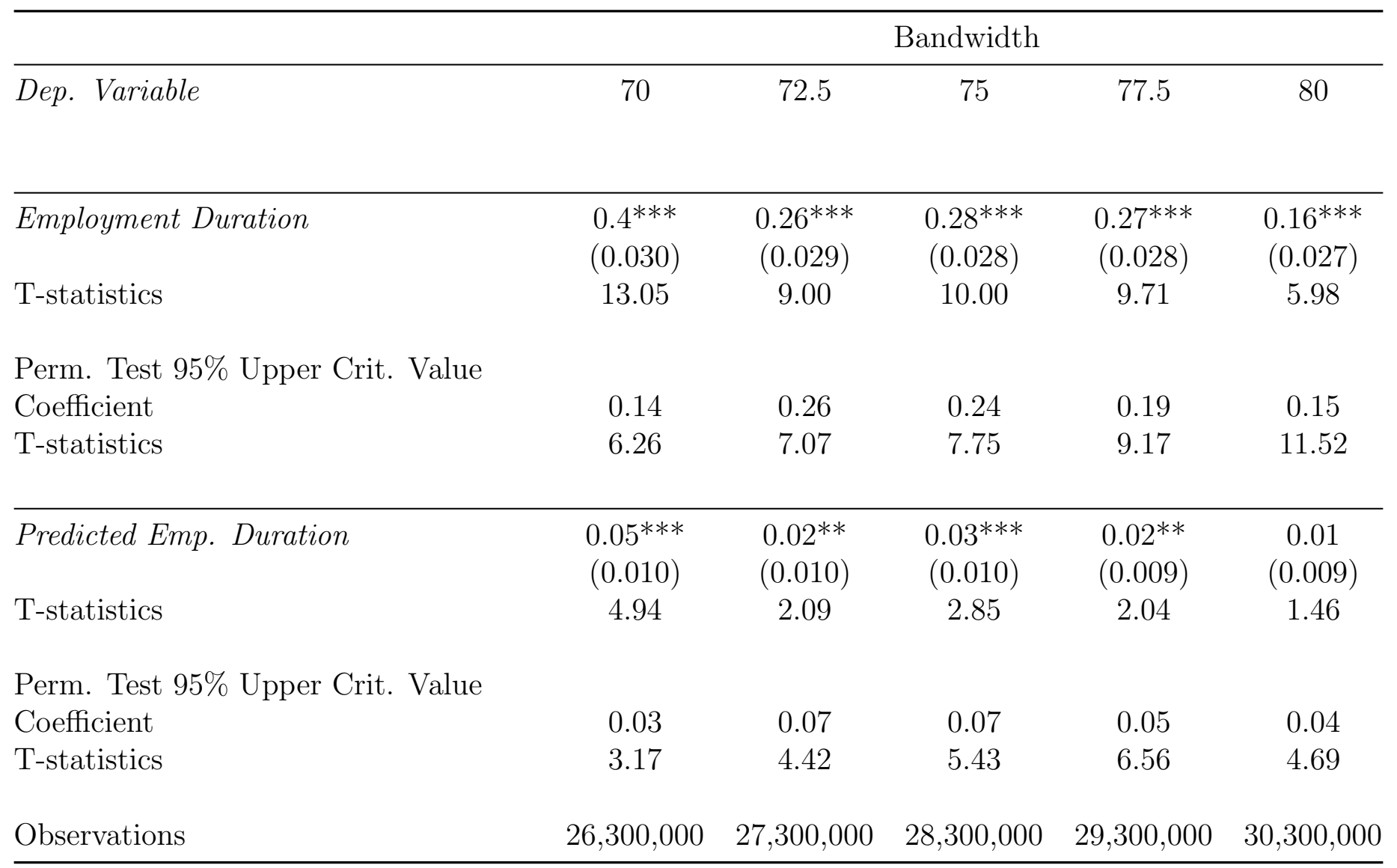

Note: The table displays RKD elasticities estimates based on local linear regressions as in equation 11. The sample is restricted for the years from 2007 to 2012, as discussed in the text. For a given bandwidth, permutation test $95 \%$ critical values are derived from a number of RKD estimates on placebo points where no policy kink is in placed. Standard errors are clustered at the firm level. 


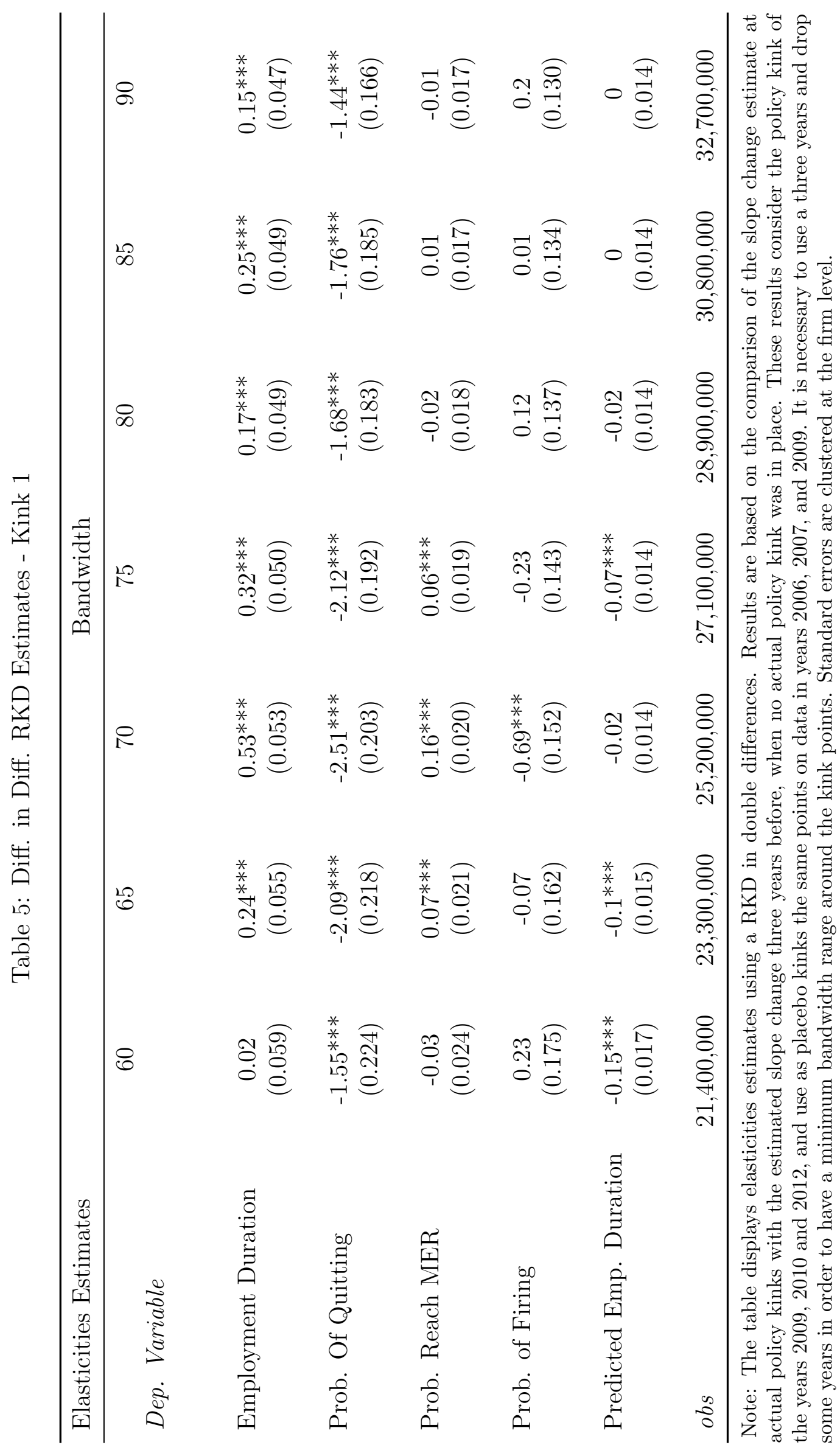


Table 6: Diff. in Diff. in Diff. RKD Estimates - Kink 1

\begin{tabular}{lccc}
\hline Elasticities Estimates & & Bandwidth & 65 \\
\hline Dep. Variable & 55 & 60 & \\
& & & \\
Employment Duration & $0.54^{* * *}$ & $0.44^{* * *}$ & $(0.072)$ \\
& $(0.081)$ & $(0.076)$ & $-4.23^{* * *}$ \\
Prob. Of Quitting & $-3.92^{* * *}$ & $-3.56^{* * *}$ & $(0.386473)$ \\
& $(0.416587)$ & $(0.380598)$ & $0.19^{* * *}$ \\
Prob. Reach MER & $0.13^{* * *}$ & & $(0.039456)$ \\
& $(0.033888)$ & $(0.041618)$ & $-1.99^{* * *}$ \\
Prob. of Firing & $-1.47^{* * *}$ & $-0.99^{* * *}$ & $(0.24443)$ \\
& $(0.27688)$ & $(0.25716)$ & $-0.33^{* * *}$ \\
Predicted Emp. Duration & $-0.22^{* * *}$ & $-0.19^{* * *}$ & $(0.02189)$ \\
& $(0.02475)$ & $(0.02237)$ & $41,400,000$ \\
\hline obs & $35,300,000$ & $38,500,000$ & \\
\hline
\end{tabular}

Note: The table displays elasticities estimates using a RKD in triple differences. These results are the difference between the DD-RKD from table (5) and the estimates from implementing the same DD-RKD in a point which had no actual policy kink in any year. These results consider the policy kink of the years 2009, 2010 and 2012, and use as placebo kinks the same points on data in years 2006, 2007, and 2009. It is necessary to use a three years and drop some years in order to have a minimum bandwidth range around the kink points. Standard errors are clustered at the firm level. 


\section{A Appendix}

\section{A.1 Figures}

\section{A.1.1 Supplementary Results - Kink 1}

Figure A1

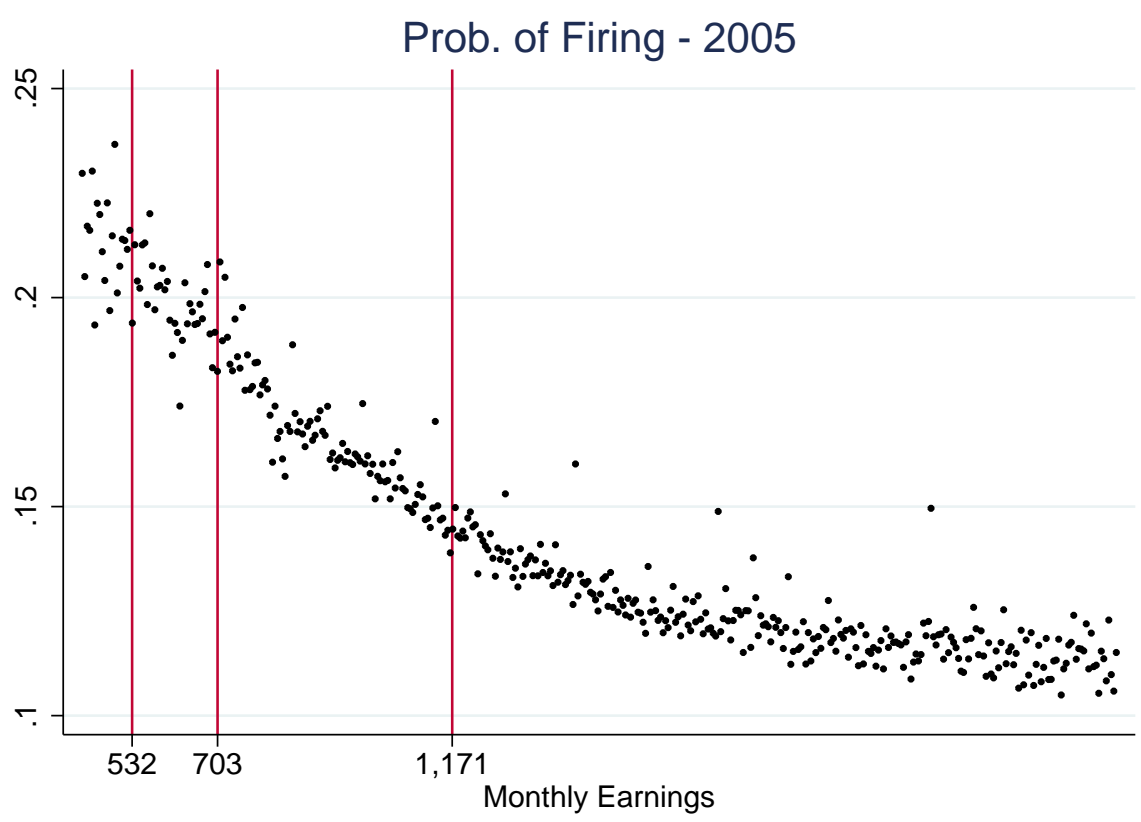

The graph displays how the prob. of lay-off in the year evolves according to monthly average earnings, in 2012 prices. Duration is expressed in weeks 


\section{Figure A2}

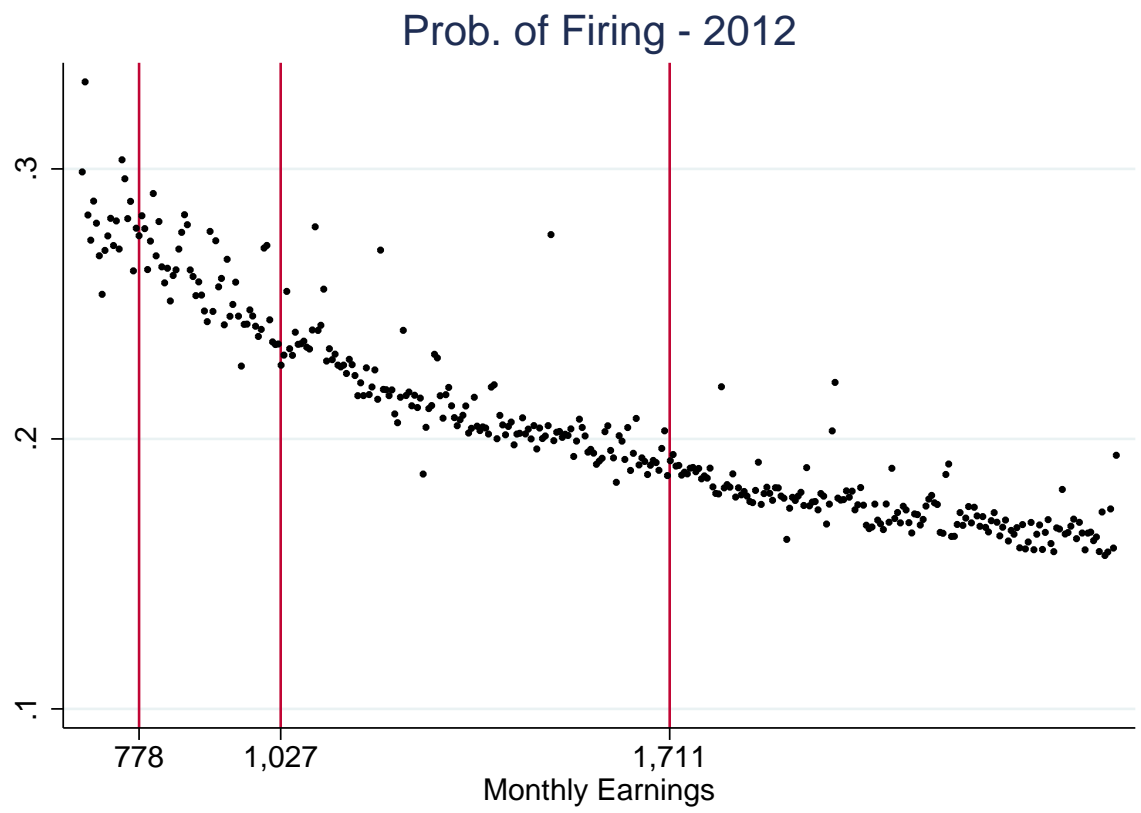

The graph displays how the prob. of lay-off in the year evolves according to monthly average earnings, in 2012 prices. Duration is expressed in weeks 
Figure A3

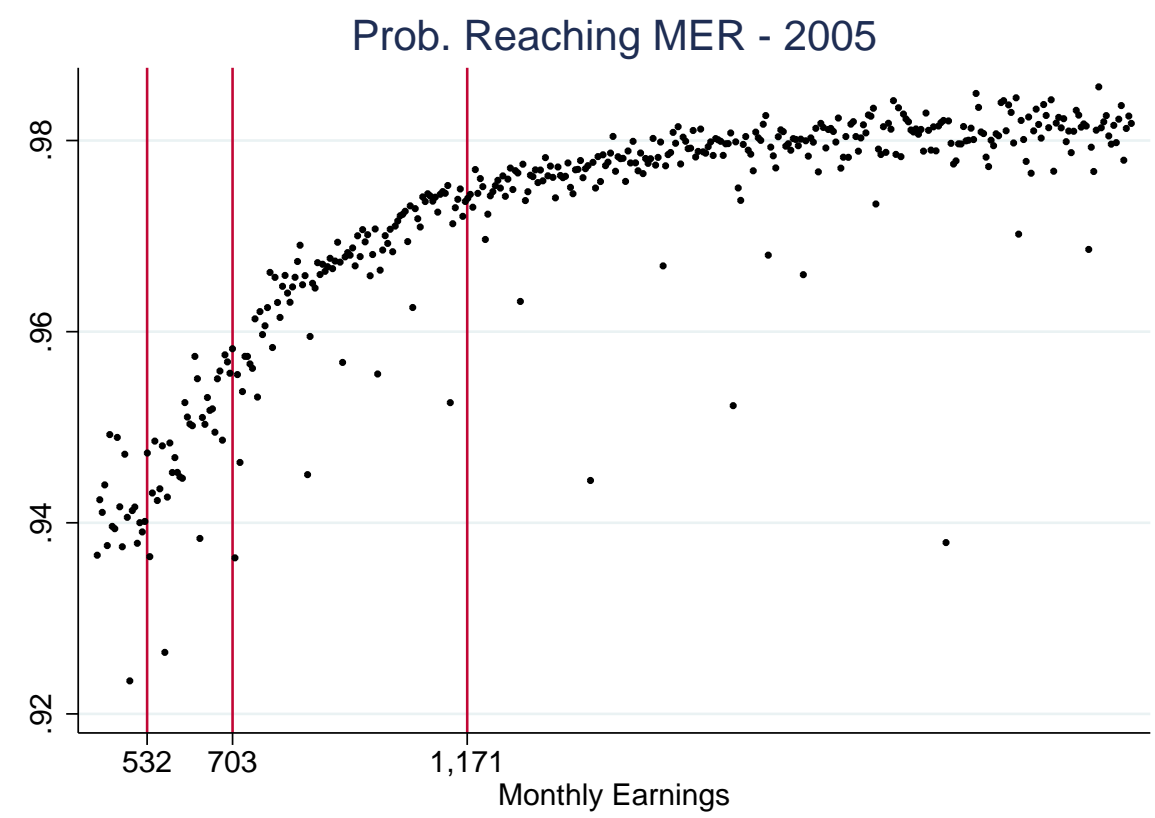

The graph displays how the prob. of reaching MER in the year evolves according to monthly average earnings, in 2012 prices. Duration is expressed in weeks

Figure A4

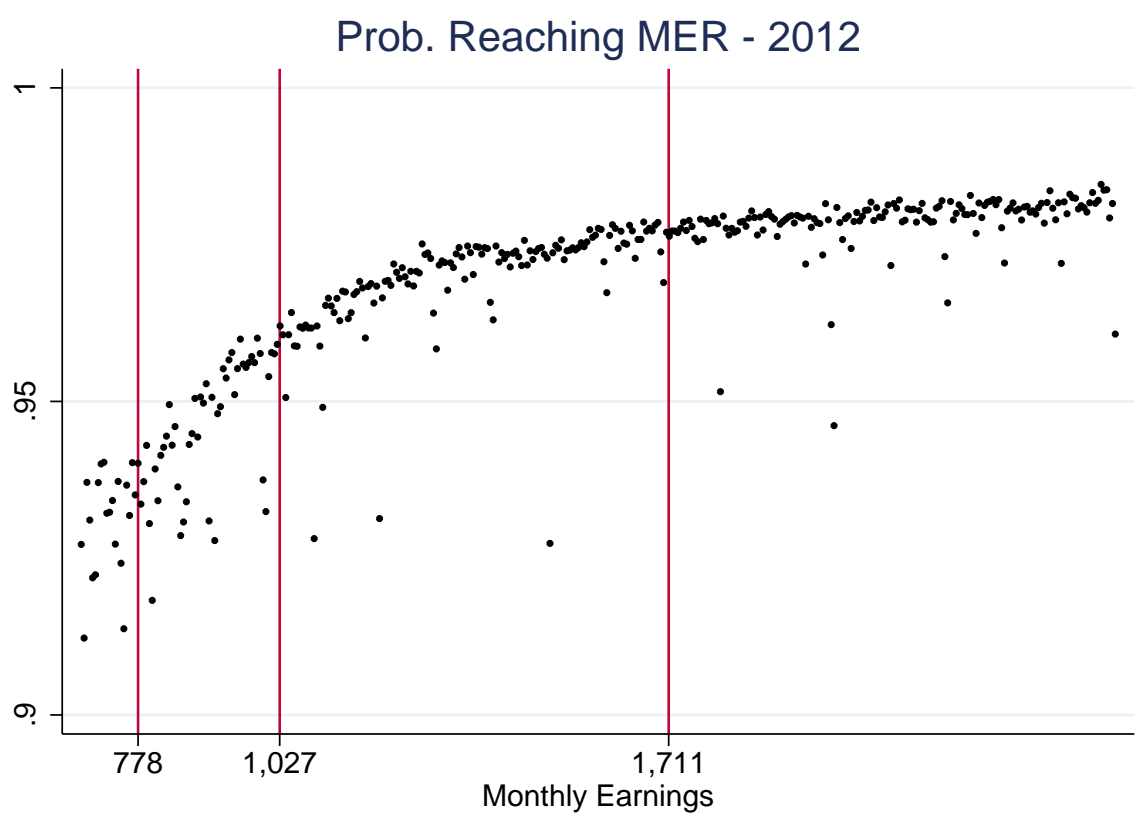

The graph displays how the prob. of reaching MER in the year evolves according to monthly average earnings, in 2012 prices. Duration is expressed in weeks 
Figure A5

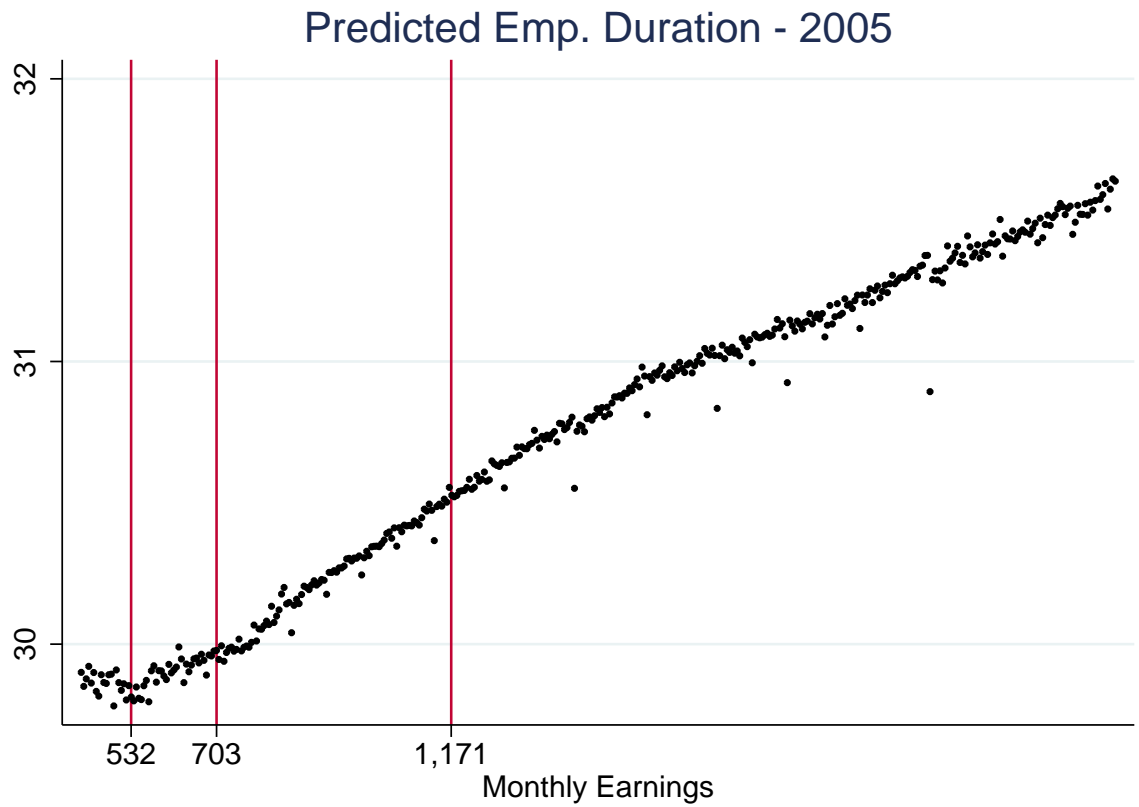

The graph displays how the predicted duration of employment in the year evolves according to monthly average earnings, in 2012 prices. Duration is expressed in weeks

Figure A6

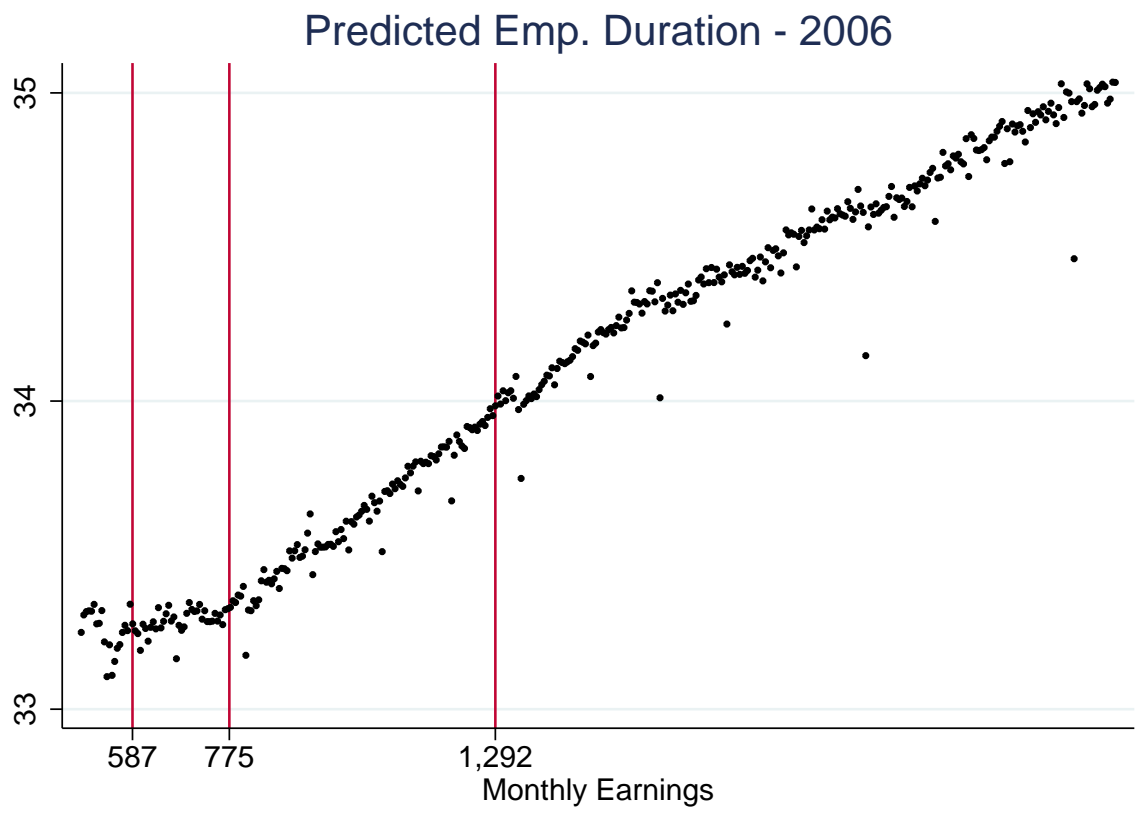

The graph displays how the predicted duration of employment in the year evolves according to monthly average earnings, in 2012 prices. Duration is expressed in weeks 
Figure A7

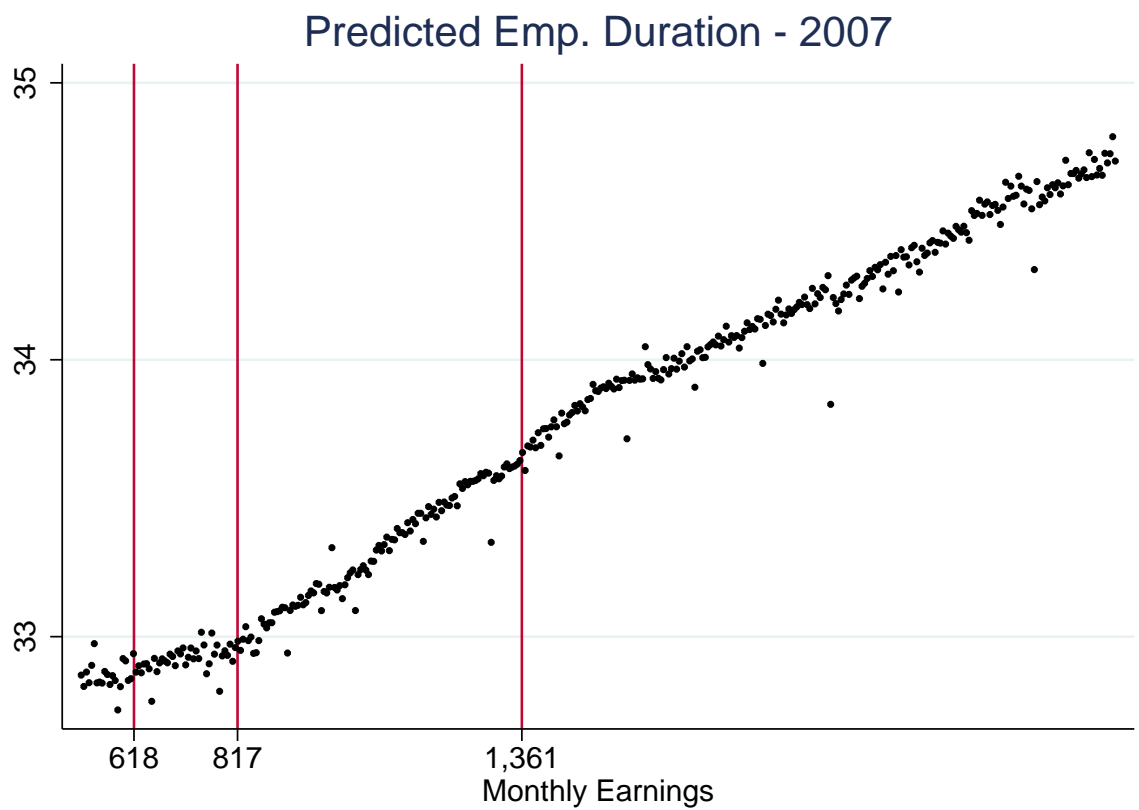

The graph displays how the predicted duration of employment in the year evolves according to monthly average earnings, in 2012 prices. Duration is expressed in weeks

Figure A8

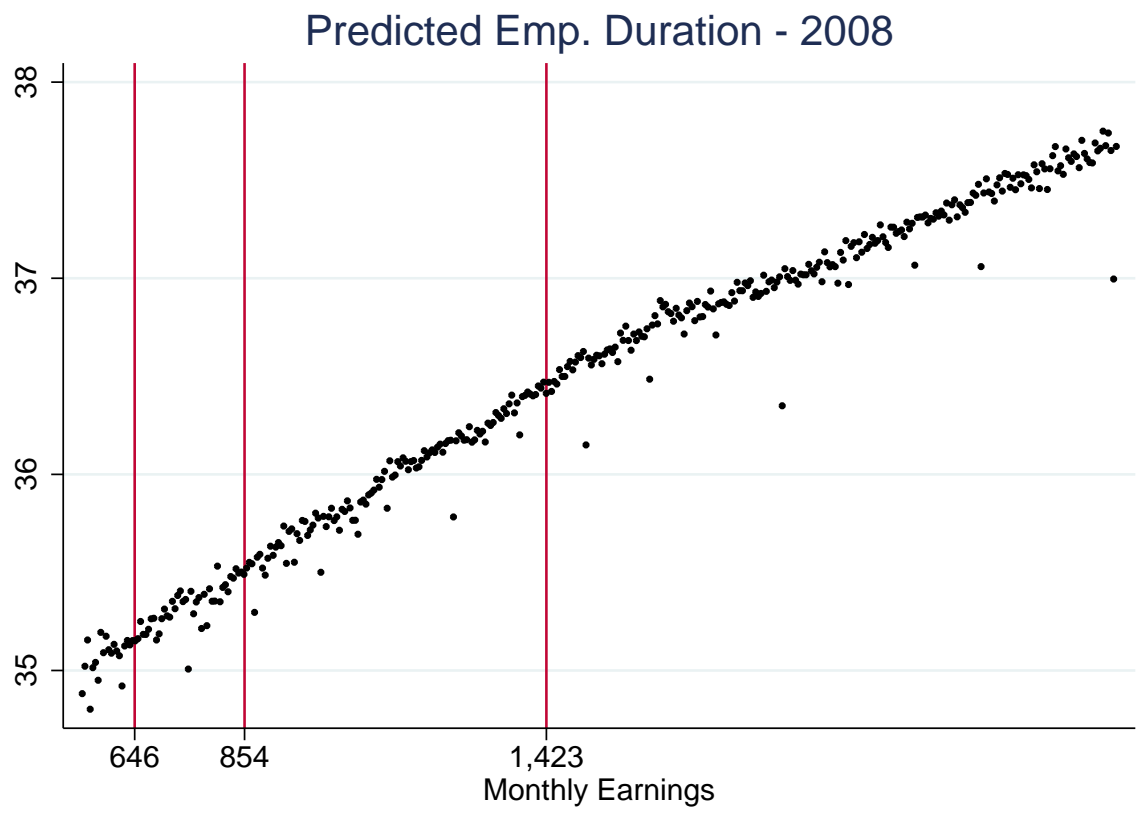

The graph displays how the predicted duration of employment in the year evolves according to monthly average earnings, in 2012 prices. Duration is expressed in weeks 


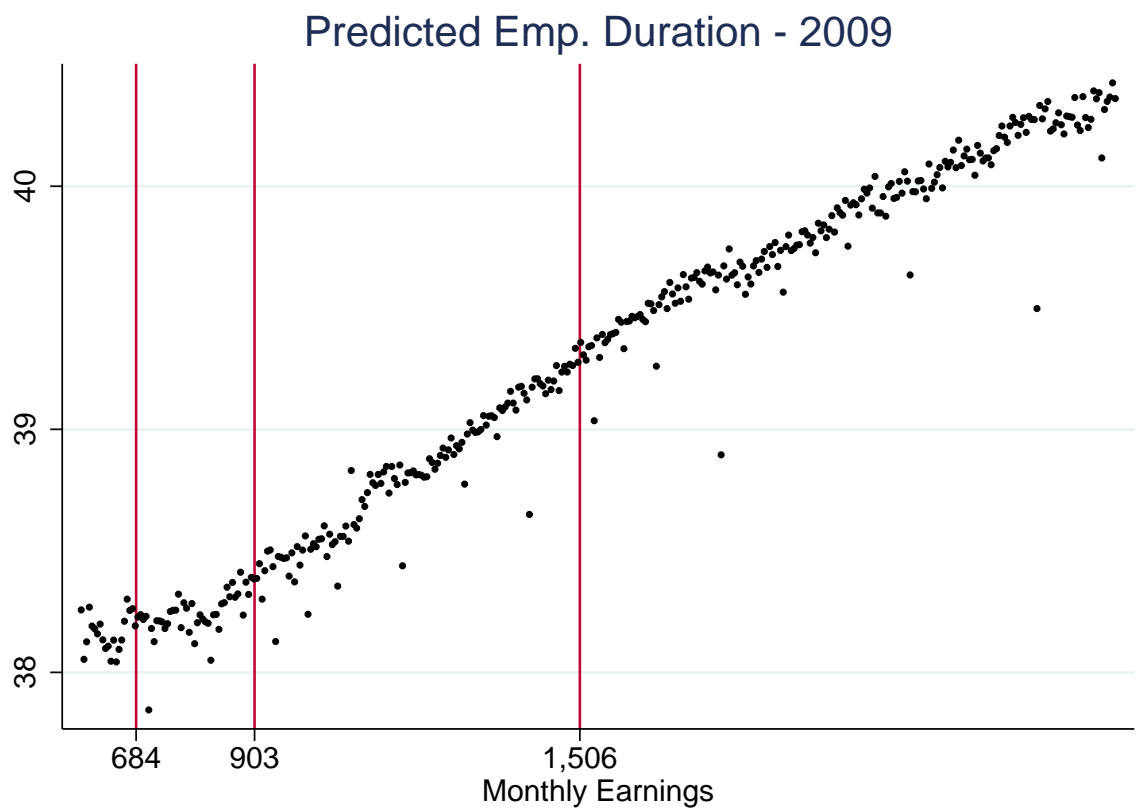

The graph displays how the predicted duration of employment in the year evolves according to monthly average earnings, in 2012 prices. Duration is expressed in weeks

Figure A10

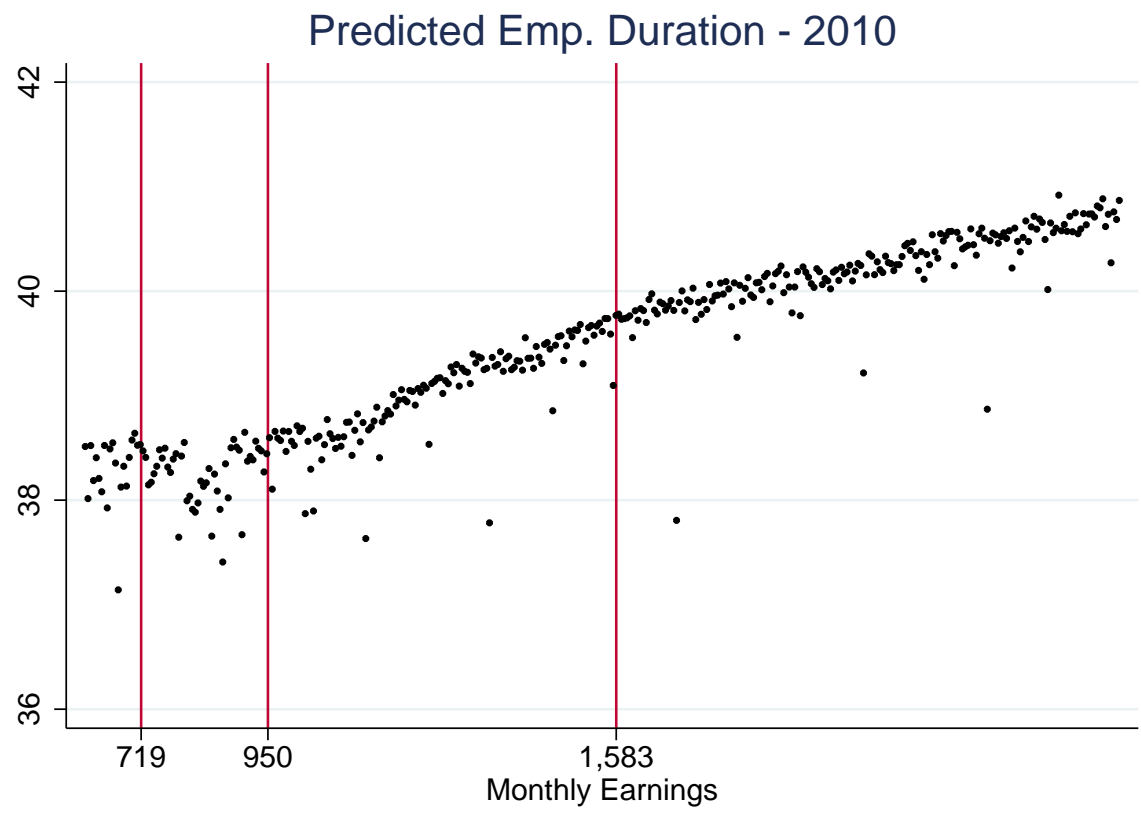

The graph displays how the predicted duration of employment in the year evolves according to monthly average earnings, in 2012 prices. Duration is expressed in weeks 


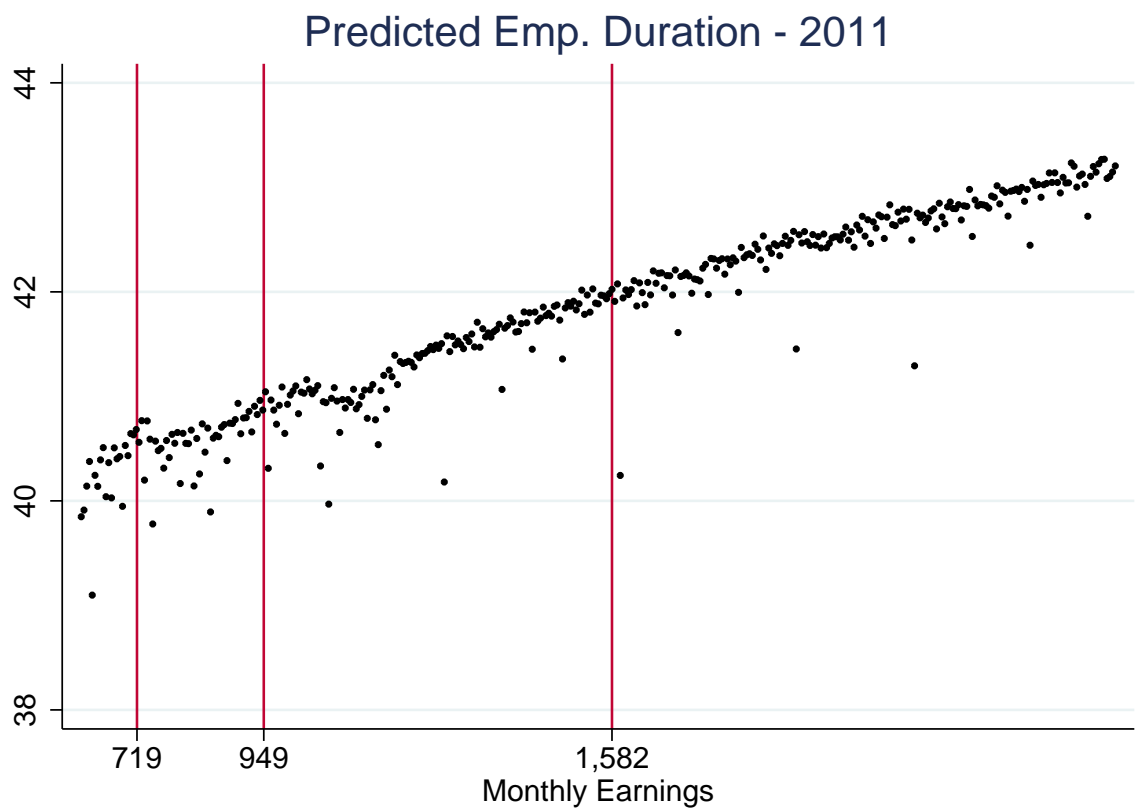

The graph displays how the predicted duration of employment in the year evolves according to monthly average earnings, in 2012 prices. Duration is expressed in weeks

Figure A12

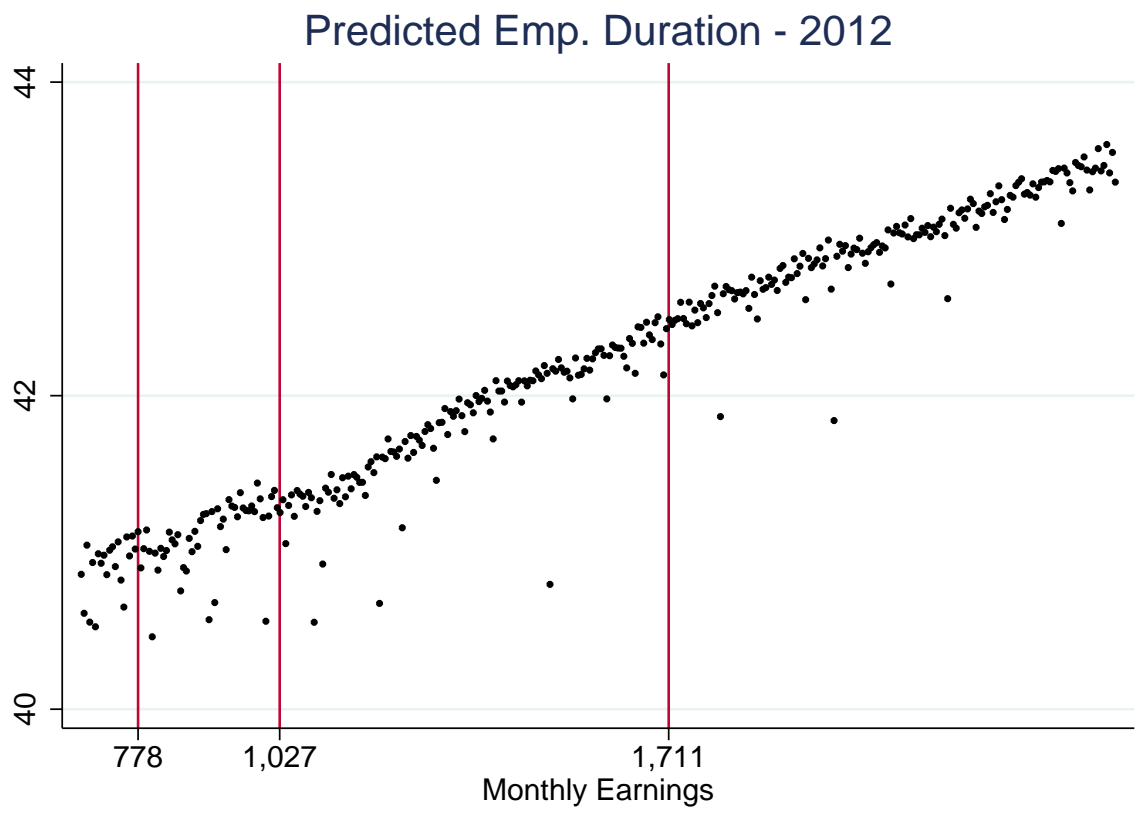

The graph displays how the predicted duration of employment in the year evolves according to monthly average earnings, in 2012 prices. Duration is expressed in weeks 
Figure A13: RKD estimates with varying bandwidths and Permutation Test Critical Values - Kink 1 Restricted Sample

\section{Prob. Reaching MER - Kink 1}
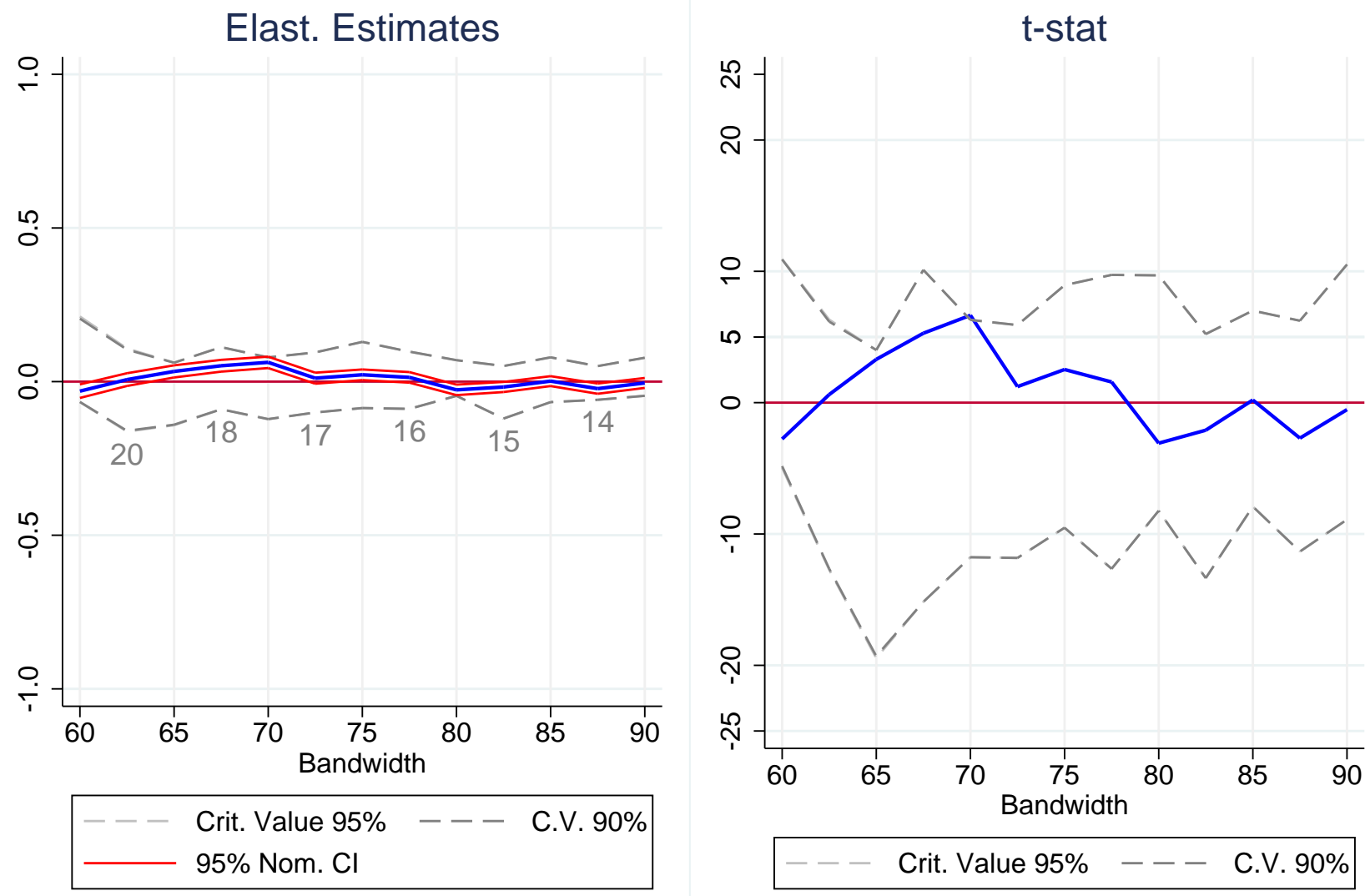

-- Crit. Value $95 \%---$ C.V. $90 \%$

The graph displays elasticities estimates and t-statistics based on a local linear regressions around kink 1 for varying bandwidths (blue line). The gray lines display the critical value in a two-sided test for rejecting the null hypothesis of zero effect, based on permutation tests along as many as possible placebo points located between the minimum wage and $\mathrm{R} \$ 4000$ (2012 prices). The gray number displays the number of placebo points for this test, according to the LLR bandwidth. This sample is restricted to the years from 2007 to 2012. Duration is expressed in weeks. Standard errors are clustered at the firm level. 
Figure A14: RKD estimates with varying bandwidths and Permutation Test Critical Values - Kink 1 Restricted Sample

\section{Prob. of Firing - Kink 1}

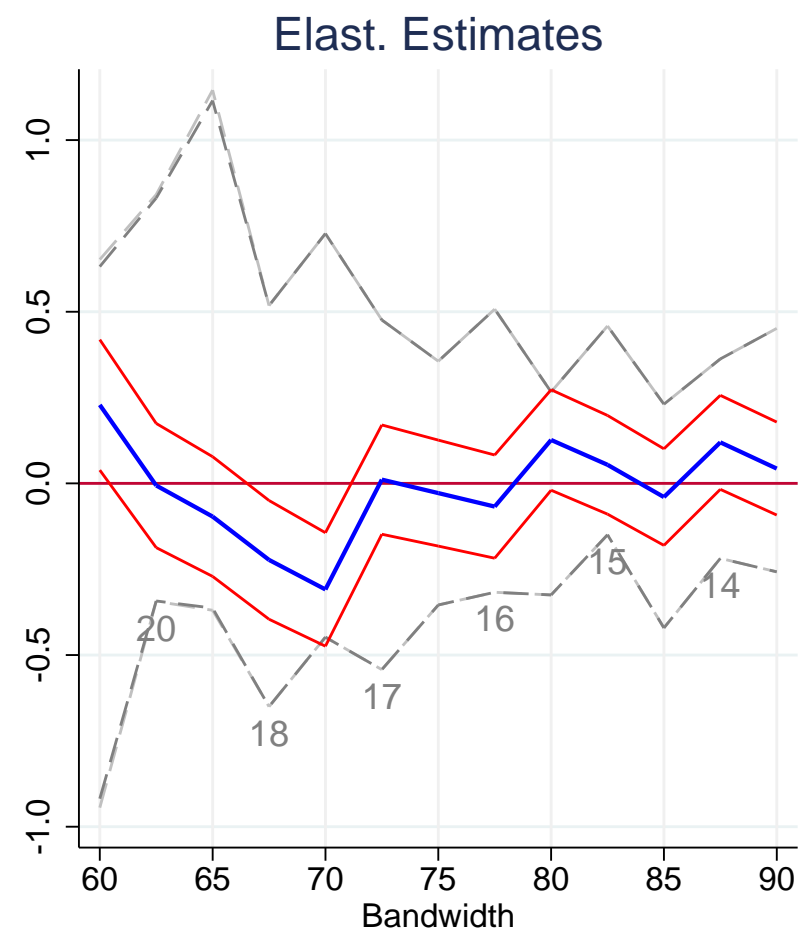

Crit. Value $95 \%---$ C.V. $90 \%$ $95 \%$ Nom. Cl

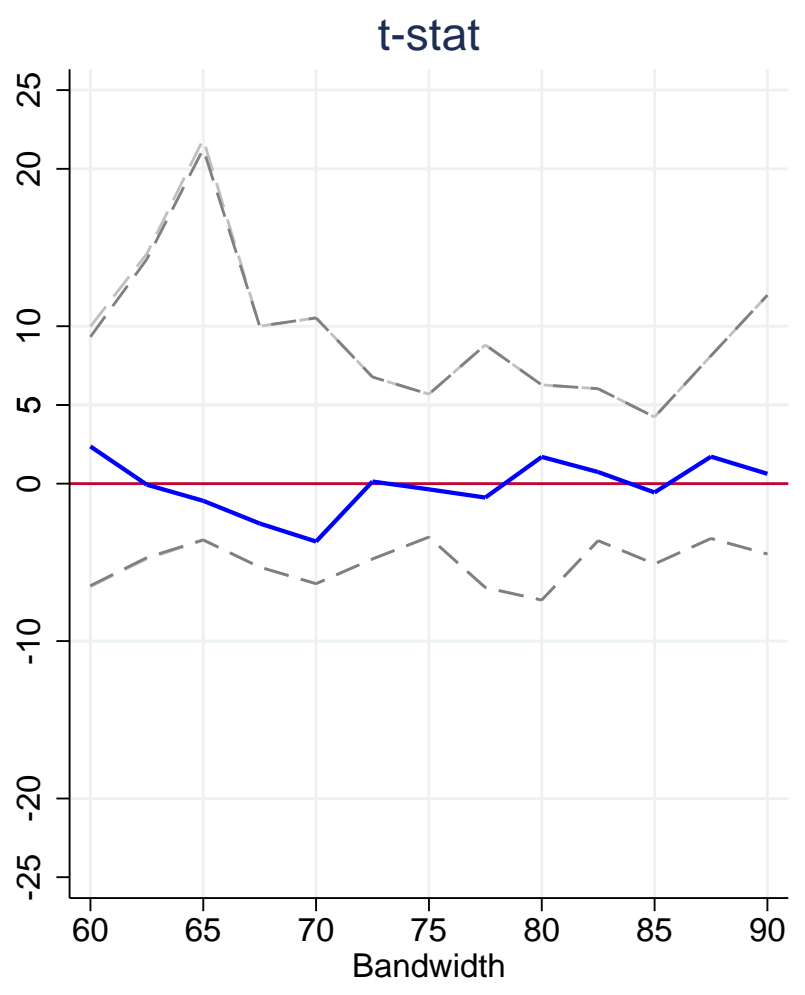

Crit. Value $95 \%---$ C.V. $90 \%$

The graph displays elasticities estimates and t-statistics based on a local linear regressions around kink 1 for varying bandwidths (blue line). The gray lines display the critical value in a two-sided test for rejecting the null hypothesis of zero effect, based on permutation tests along as many as possible placebo points located between the minimum wage and $\mathrm{R} \$ 4000$ (2012 prices). The gray number displays the number of placebo points for this test, according to the LLR bandwidth. This sample is restricted to the years from 2007 to 2012. Duration is expressed in weeks. Standard errors are clustered at the firm level. 


\section{A.2 Supplementary Results - Kink 2 and 3}

Figure B1: Density of Wages the Around Kink 2

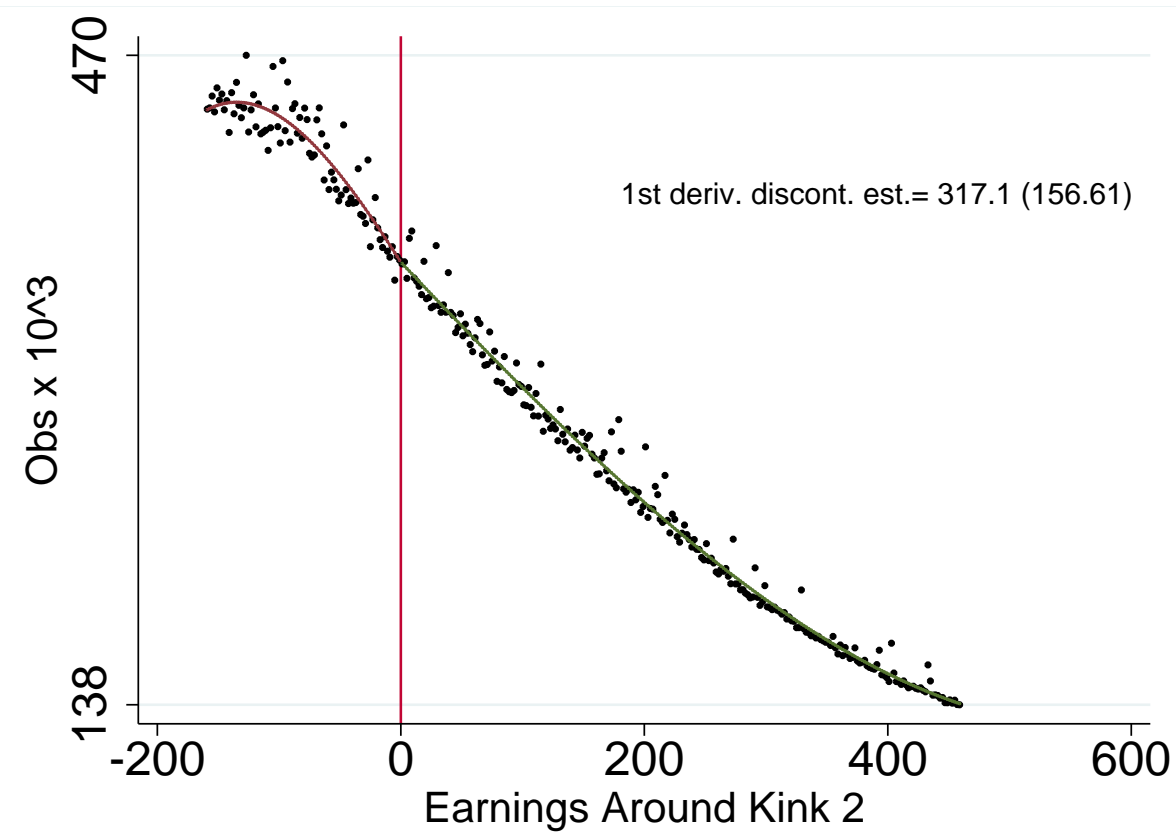

The graph displays how the density of earnings evolve around the kink. At each side of the kink, the density is approximated by the polynomial which minimizes the Akaike Criterion. The graph also displays the test statistics for the slope change of these polynomials at the kink. See the text for details. 
Figure B2: Density of Wages the Around Kink 3

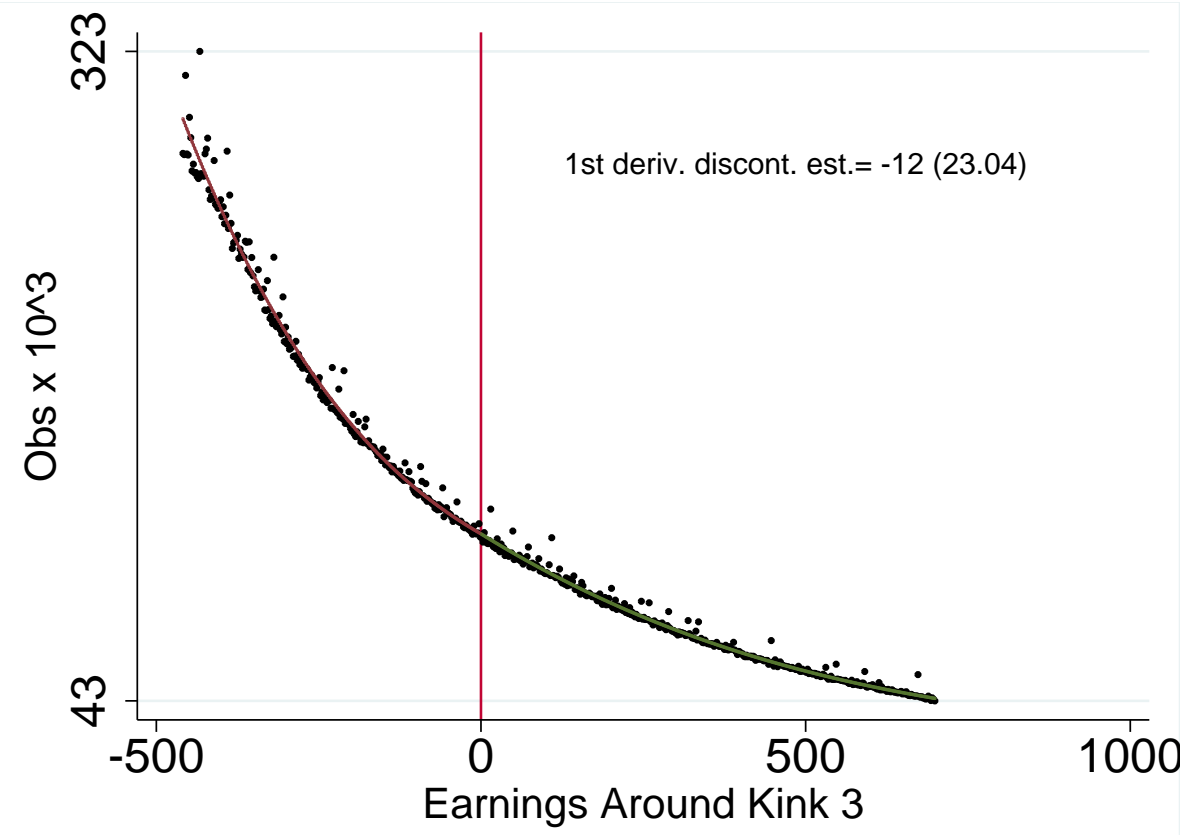

The graph displays how the density of earnings evolve around the kink. At each side of the kink, the density is approximated by the polynomial which minimizes the Akaike Criterion. The graph also displays the test statistics for the slope change of these polynomials at the kink. See the text for details. 
Figure B3: Employment Duration Around Kink 2

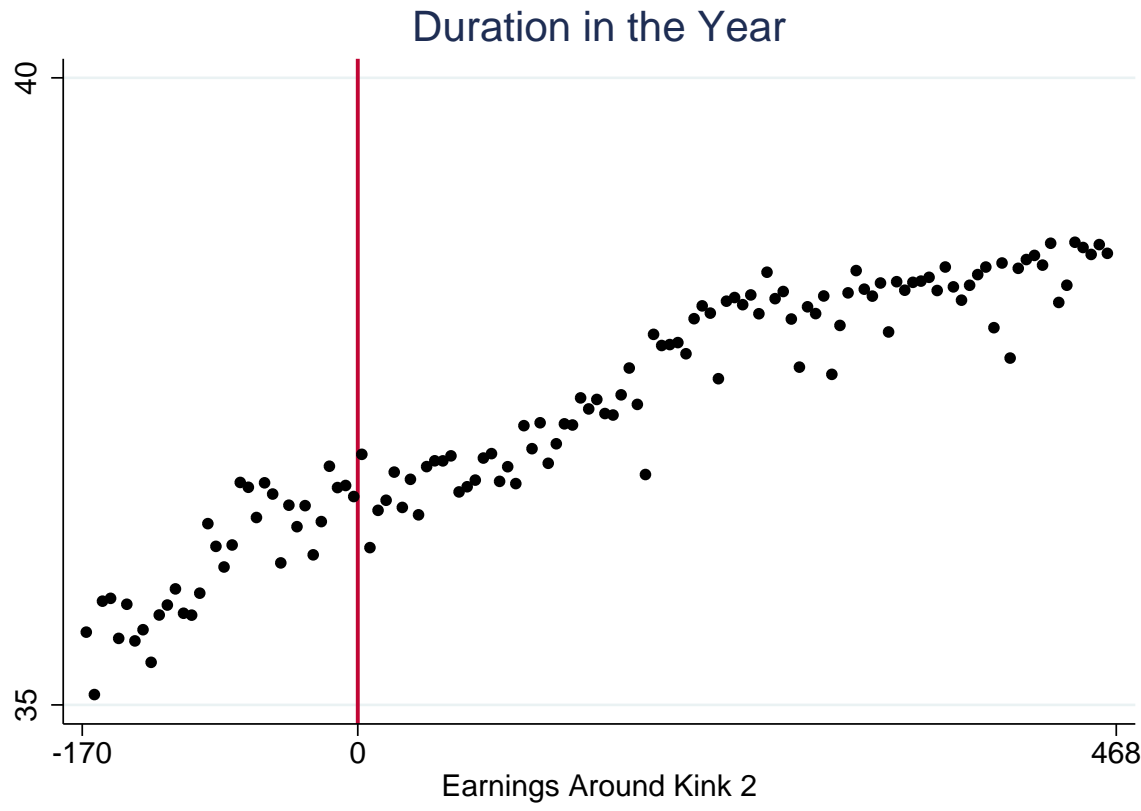

The graph displays how employment duration in the year evolve around the kink. Duration is expressed in weeks

Figure B4: Employment Duration Around Kink 3

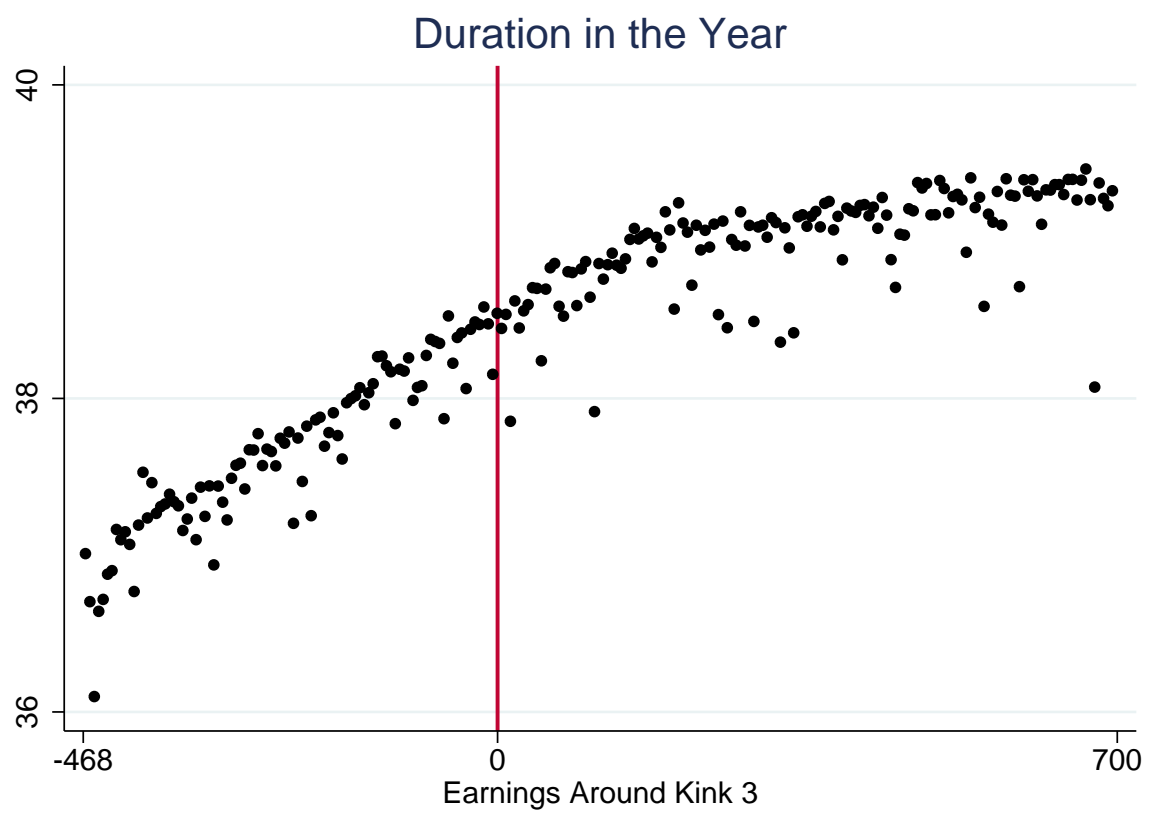

The graph displays how employment duration in the year evolve around the kink. Duration is expressed in weeks

\section{A.3 Tables}


Table 7: RKD Estimates based on standard Bandwidth Selectors

Elasticity of Employment Duration with Respect to Benefit Level

\begin{tabular}{llll}
\hline Bandwidth Selectors & b.w. & Estimated Elasticity std. Error p-robust
\end{tabular}

\section{First Kink}

FG linear

CCT linear, no regularization

$11.6 \quad 0.31^{* * *}$

$\begin{array}{lll}5.0 & -0.23 & (0.367)\end{array}$

CCT linear

4.6

FG quadratic

207.7

CCT quadratic, no regularization

8.4

9.1

$-1.35^{* * *}$

$0.86 * * *$

$(0.404)$

(0.008)

$(0.659)$

$-2.33^{* * *}$

(0.590)

CCT quadratic

\section{Second Kink}

FG linear

CCT linear, no regularization

CCT linear

FG quadratic

CCT quadratic, no regularization

CCT quadratic
(0.000)

$\begin{array}{lccc}33.9 & 0.75^{* * *} & (0.072) & \\ 20.1 & 0.84^{* * *} & (0.157) & (0.000) \\ 19.6 & 1 * * * & (0.163) & (0.000) \\ 72.3 & 1.33^{* * *} & (0.092) & \\ 43.6 & 2.28^{* * *} & (0.197) & (0.000) \\ 29.1 & -0.48^{*} & (0.361) & (0.067)\end{array}$

33.9

20.1

19.6

43.6

$-3.05^{* * *}$

(0.067)

\section{Third Kink}

FG linear

CCT linear, no regularization

CCT linear

FG quadratic

CCT quadratic, no regularization

CCT quadratic

$\begin{array}{ccc}104.7 & -0.04^{* *} & (0.017) \\ 63.5 & 0.1^{* * *} & (0.037) \\ 66.3 & 0.04 & (0.035) \\ 189.0 & -0.12^{* * *} & (0.029) \\ 59.8 & -0.13 & (0.162) \\ 53.8 & -0.05 & (0.190)\end{array}$

$(0.162)$

Note: The table displays estimates for the elasticity based on the estimated slope change for each variable at each of the three kinks using equation (11). P-robust displays p-values based on CCT robust confidence intervals. 


\section{B Appendix}

\section{B.1 Benefit Level and the Choice of Search Effort by the Unemployed}

I first characterize the agent's optimal choice of search effort and then analyze how this choice reacts to variations in the level of unemployment benefits. The analysis regards the case of unemployed workers who have to choose a level of search intensity for a given level of benefits as stated in equation (4). First-order conditions are given by: ${ }^{11}$

$$
\psi^{\prime}\left(s_{t}\right)=E_{t}\left(A_{t}\right)-U_{t}\left(A_{t}\right)
$$

The optimal level of search intensity is simply the one where the marginal cost of search (left-handside of the equation) equals the net gain from finding a new job (right-hand-side of the equation). Such gains are given by the difference between the value of a new job $E_{t}\left(A_{t}\right)$ and the value of unemployment $U_{t}\left(A_{t}\right)$. The larger the value of finding a new job vis-a-vis the value of remaining unemployed, the greater the incentive to search.

At this point, it is possible to approach the question of how a small change in the level of benefits affects the incentives to search. From the previous first-order condition and by applying the envelope theorem we have: 12

$$
\frac{\partial s_{t}}{\partial b_{t}}=\frac{-u^{\prime}\left(c_{t}^{u}\right)}{\psi^{\prime \prime}\left(s_{t}\right)}<0
$$

It shows that an $\$ 1$ increase in UI benefits decreases search intensity by an amount which depends on the marginal utility of consumption of the unemployed worker adjusted by how the marginal cost of search is increasing at a given point. For instance, it means that if an unemployed worker is already enjoying a high level of consumption, his marginal utility of consumption is low and, thus, a small increase in benefits will not affect by much his level of search intensity.

As in Chetty (2008), it is possible to show that an increase in the level of benefits affects search through two distinct channels: a liquidity and a moral hazard effect. With this purpose, we notice that:

\footnotetext{
${ }^{11}$ Here we adopt the so-called "first-order approach" and assume $U_{t}\left(A_{t}\right)$ to be concave as in Chetty (2008), which shows that for plausible parameters non-concavity never arises.

${ }^{12}$ The envelope theorem states that for small changes of parameter values in an optimization problem, the relevant effects on the function of interest are the direct effects. It means that indirect effects should be ignored. In our case, $b_{t}$ is the changing parameters of the optimization problem. The envelope condition allows us to ignore the effects of $b_{t}$ on both $E_{t}\left(A_{t}\right)$ and $U_{t}\left(A_{t}\right)$. In other words, $\frac{\partial E_{t}\left(A_{t}\right)}{\partial b_{t}}=0$ and $\frac{\partial U_{t}\left(A_{t}\right)}{\partial b_{t}}=0$.
} 


$$
\begin{array}{r}
\frac{\partial s_{t}}{\partial A_{t}}=\frac{v^{\prime}\left(c_{t}^{e}\right)-u^{\prime}\left(c_{t}^{u}\right)}{\psi^{\prime \prime}\left(s_{t}\right)} \leq 0 \\
\frac{\partial s_{t}}{\partial w_{t}}=\frac{v^{\prime}\left(c_{t}^{e}\right)}{\psi^{\prime \prime}\left(s_{t}\right)} \geq 0
\end{array}
$$

Equation (7) shows that the larger the gap between the marginal utilities of consumption when employed $\left(v^{\prime}\left(c_{t}^{e}\right)\right)$ and unemployed $\left(u^{\prime}\left(c_{t}^{u}\right)\right)$, the larger the effect of an increase in the agent's asset level on search intensity. This means that when unemployed workers are significantly liquidity constrained, and so the gap in consumption between unemployment and employment is sizable, providing an extra small amount of liquidity to this agent will lower his search intensity significantly. Equation (8), instead, shows that an increase in the pay-off of finding a new job (higher $w_{t}$ ) positively affects search intensity. The magnitude of this effect depends on the marginal utility of consumption when employed adjusted by the slope of the marginal cost of search at a given point. The intuition is that if consumption when employed is already large, so marginal utility is low, an small increase of $w_{t}$ does not change substantially the reward of finding a job and, thus, the change in search intensity is small.

By combining the results of (7) and (8) with (6), we can decompose the marginal distortion of unemployment benefits on search in two distinct elements: liquidity and moral hazard effect:

$$
\frac{\partial s_{t}}{\partial b_{t}}=\frac{\partial s_{t}}{\partial A_{t}}-\frac{\partial s_{t}}{\partial w_{t}}<0
$$

This is the core result provided by Chetty (2008). It highlights that the effect of UI benefits on search intensity is a mix between a moral hazard component $\left(\frac{\partial s_{t}}{\partial w_{t}}\right)$ and a liquidity effect $\left(\frac{\partial s_{t}}{\partial A_{t}}\right)$. The moral hazard regards the that fact unemployment benefits distort the pay-off from leaving unemployment because as soon as the worker finds a new job, his benefits are ceased. Therefore, it directly decreases the net benefits of search which are given by $\left(w_{t}-b_{t}\right)$ and characterizes a substitution effect. ${ }^{13}$ The liquidity effect, on the other hand, has to do with the ability the agent has to smooth consumption across states. It means that when workers are liquidity constrained, they search more intensely than they would if credit markets were complete. Once you provide these workers with UI benefits, they decrease their search intensity because now they are less liquidity constrained and thus can better smooth consumption across states.

For example, suppose an unemployed worker has zero liquid assets, no access to credit markets and is not entitled to UI benefits in this model. This worker searches very intensely for a new job because he

\footnotetext{
${ }^{13}$ Technically, it also embodies a wealth effect as a variation in the net value of finding a job also affects life time wealth. However, in the context of unemployment benefits such effect is arguably very low since the total amount of benefits are only a very small fraction of lifetime earnings.
} 
cannot borrow against the future and, thus, he experiences a very low (zero) level of consumption while unemployed. If he is granted with a lump sum cash grant, he will decrease search effort not because the net benefit of finding a job changes (as is the case for UI benefits), but simply because he is less liquidity constrained and can now better smooth consumption across states. Therefore, a hypothetical cash grant unveils the liquidity effects on search. Such effect is embodied in the total distortion caused by UI benefits because it also provides more liquidity to workers.

The other part of the distortion relates to the fact that when such a worker is granted with UI, the net benefit of finding a new job decreases. This happens because, differently from the cash grant, benefits cease as soon as he comes back to employment, representing a decrease in the reward of finding a new job.

Equation (19), however, shows how the effect of an one period increase in UI benefits on search can be decomposed into a liquidity and a moral hazard effect. The expression bellow shows how the decomposition applies for a B-periods increase in the level of UI benefits, as shown in Appendix B.3:

$$
\frac{\partial s_{t}}{\partial b}=\left.\frac{\partial s_{t}}{\partial a}\right|_{B}-\left.\frac{\partial s_{t}}{\partial w}\right|_{B}
$$

where $\frac{\partial s_{t}}{\partial b}$ denotes the effect on search at the initial period when the level of UI benefits increase for all

the B periods. $\frac{\partial s_{t}}{\partial a} \mid B=\sum_{i=t}^{t+B-1} \frac{\partial s_{t}}{\partial a_{i}}$ and $\frac{\partial s_{t}}{\partial w} \mid B=\sum_{i=t}^{t+B-1} \frac{\partial s_{t}}{\partial w_{i}}$ describe, respectively, the liquidity and moral hazard effect on search in the first $B$ periods of unemployment.

\section{B.2 Benefit Level and the Choice of Work Effort by the Employed}

Here I approach the problem of how variations in benefit levels affect the the choice of effort by the employed. This analysis is analytically symmetric to the one found in the previous subsection. Equation (2) states the problem faced by the employed worker. First, the worker decides whether or not quit his job. He quits whenever the value of the quitting state happens to be higher than the value of remain employed, given an optimal effort level. Thus:

$$
\begin{aligned}
& x_{t}=1 \Longleftrightarrow Q_{t}>e_{t}^{*} V_{t}\left(A_{t}\right)+\left(1-e_{t}^{*}\right) U_{t} \\
& x_{t}=0 \Longleftrightarrow Q_{t} \leq e_{t}^{*} V_{t}\left(A_{t}\right)+\left(1-e_{t}^{*}\right) U_{t}
\end{aligned}
$$

In turn, the optimal effort level is characterized by the following first-order condition: ${ }^{14}$

\footnotetext{
${ }^{14}$ As for the problem of the unemployed worker, I take the "first-order" approach and assume $V_{t}\left(A_{t}\right)$ to be concave.
} 


$$
c^{\prime}\left(e_{t}\right)=V_{t}\left(A_{t}\right)-U_{t}\left(A_{t}\right)
$$

It shows that employed workers decide their level of effort by adjusting the marginal cost of effort to keep his job (left-hand-side of the equation) to the net gain of keeping their jobs, which is given by the difference between the value of employment and unemployment.

From the first-order condition above, it is possible to assess how work effort reacts to a small variation in the level of benefits:

$$
\frac{\partial e_{t}}{\partial b_{t}}=\frac{-u^{\prime}\left(c_{t}^{u}\right)}{c^{\prime \prime}\left(e_{t}\right)}<0
$$

If the agent's level of consumption when unemployed is expected to be low, so that marginal utility is high, the distortion caused by a small variation in potential benefits will be large. Analogously to the case analyzed in the previous subsection, it is possible to decompose this distortion into a liquidity and a moral hazard problem. The derivatives below show how the level of work effort reacts to a small change in asset levels and wages, respectively:

$$
\begin{aligned}
\frac{\partial e_{t}}{\partial A_{t}}=\frac{v^{\prime}\left(c_{t}^{v}\right)-u^{\prime}\left(c_{t}^{u}\right)}{c^{\prime \prime}\left(e_{t}\right)} & \leq 0 \\
\frac{\partial e_{t}}{\partial w_{t}}=\frac{v^{\prime}\left(c_{t}^{v}\right)}{c^{\prime \prime}\left(e_{t}\right)} & \geq 0
\end{aligned}
$$

By combining equation (12) and (13) with (11), we can decompose the effect of UI benefits on work effort as:

$$
\frac{\partial e_{t}}{\partial b_{t}}=\frac{\partial e_{t}}{\partial A_{t}}-\frac{\partial e_{t}}{\partial w_{t}}<0
$$

Similarly to the case of the unemployed, this equation shows that effects of benefits on work effort depends on two distinct factors: a liquidity $\left(\frac{\partial e_{t}}{\partial A_{t}}\right)$ and a moral hazard $\left(\frac{\partial e_{t}}{\partial w_{t}}\right)$ component. The moral hazard effect concerns the fact that UI benefits imply a decrease of the net loss caused by a lay-off. In other words, unemployment is less unattractive relatively to being employed. The liquidity effect, however, has to do with the fact that UI raises asset level and may help the worker to smooth consumption between employment and unemployment. 
Once again, the decomposition above applies for a one period increase in benefit level. Below is the decomposition for a $\mathrm{B}$ periods increase in the level of benefits:

$$
\left.\frac{\partial e_{t}}{\partial b}\right|_{B}=\left.\frac{\partial e_{t}}{\partial a}\right|_{B}-\left.\frac{\partial e_{t}}{\partial w}\right|_{B}
$$

where $\frac{\partial e_{t}}{\partial a} \mid B=\sum_{i=t}^{t+B-1} \frac{\partial e_{t}}{\partial a_{i}}$ and $\frac{\partial e_{t}}{\partial w} \mid B=\sum_{i=t}^{t+B-1} \frac{\partial e_{t}}{\partial w_{i}}$.

\section{B.3 Liquidity and Moral Hazard in the T Periods Model}

Let $x \in\{a, b, w\}, s \in\{0,1, \ldots, T-1\}$ and $\frac{\partial s_{0}}{\partial x} \mid s=\sum_{t=0}^{T-1} \frac{\partial s_{0}}{\partial x_{t}}$.

Exploiting the FOCs with envelope conditions, we have:

$$
\frac{\partial s_{0}}{\partial x} \mid s=\frac{1}{\psi^{\prime \prime}\left(s_{0}\right)}\left\{\frac{\partial E_{0}}{\partial x}\left|s-\frac{\partial U_{0}}{\partial x}\right| s\right\}
$$

Notice that:

$$
\begin{aligned}
& \left.\frac{\partial E_{0}}{\partial a}\right|_{B}=\left.\frac{\partial E_{0}}{\partial w}\right|_{B} \\
& \left.\frac{\partial U_{0}}{\partial a}\right|_{B}=\left.\frac{\partial U_{0}}{\partial w}\right|_{B}+\left.\frac{\partial U_{0}}{\partial b}\right|_{B}
\end{aligned}
$$

Combining these conditions, it follows that:

$$
\left.\frac{\partial s_{0}}{\partial b}\right|_{B}=\left.\frac{\partial s_{0}}{\partial a}\right|_{B}-\left.\frac{\partial s_{0}}{\partial w}\right|_{B}
$$

\section{B.4 The Welfare Formula in the T Periods Model}

$$
\begin{aligned}
\max _{b, \tau} J_{0}^{V}(b, \tau) & =\left(1-x_{0}\right)\left[\left(1-e_{0}\right) U_{0}(b, \tau)+e_{0} V_{0}(b, \tau)\right]-c\left(e_{0}\right)+x_{0} Q_{0} \\
\text { s.t.f } f^{U I} D_{B} b & =D_{E} \tau
\end{aligned}
$$

Deriving with respect to the level of benefits: 


$$
\frac{d J_{0}}{d b}=\left(1-x_{0}\right) e_{0} \frac{\partial V_{0}}{\partial b}-\frac{d \tau}{d b}\left[\left(1-x_{0}\right) e_{0} \frac{\partial V_{0}}{\partial w}\right]
$$

Notice that $\frac{\partial U_{0}}{\partial b}=0$ because workers laid-off in the first period are not eligible for UI and $\frac{\partial U_{0}}{\partial \tau}=0$ because workers no longer collect UI taxes upon reemployment. Let $E_{0, T-1} v^{\prime}\left(c_{t}^{V}\right)$ denote the unconditional average marginal utility while in the initial employed stage and $D_{E}$ the respective expected duration of this spell. Then:

$$
E_{0, T-1} v^{\prime}\left(c_{t}^{V}\right)=\frac{1}{D_{E}}\left[\left(1-x_{0}\right) e_{0} \frac{\partial V_{0}}{\partial w}\right]
$$

Also:

$$
\left(1-x_{0}\right) e_{0} \frac{\partial V_{0}}{\partial b}=\sum_{i=k}^{T-1}\left[\Pi_{j=0}^{i-1}\left(1-x_{j}\right) e_{j}\right]\left(1-x_{i}\right)\left(1-e_{i}\right) \frac{\partial U_{i}}{\partial B_{i}}
$$

Where $\frac{\partial U_{i}}{\partial B_{i}}$ is the effect of raising UI benefit level for workers entering unemployment at period $i$. Then, it implies:

$$
\frac{d J_{0}}{d b}=\sum_{i=k}^{T-1}\left\{\left[\Pi_{j=0}^{i-1}\left(1-x_{j}\right) e_{j}\right]\left(1-x_{i}\right)\left(1-e_{i}\right) \frac{\partial U_{i}}{\partial B_{i}}\right\}-\frac{d \tau}{d b}\left(D_{E}\right) E_{0, T-1} v^{\prime}\left(c_{t}^{V}\right)
$$

Higher benefit level increase the value of employment at $t=0$ by raising the value of subsequent unemployment after minimum eligibility requirement, at period $k$.

Normalize welfare by the gain from raising wages by $\$ 1$ :

$$
\frac{d J_{0}}{d w}=\left(1-x_{0}\right) e_{0} \frac{\partial V_{0}}{\partial w}=\left(D_{E}\right) E_{0, T-1} v^{\prime}\left(c_{t}^{V}\right)
$$

Therefore:

$$
\frac{d W}{d b}=\frac{\frac{d J_{0}}{d b}}{\frac{d J_{0}}{d w}}=\frac{\sum_{i=k}^{T-1}\left\{\left[\Pi_{j=0}^{i-1}\left(1-x_{j}\right) e_{j}\right]\left(1-x_{i}\right)\left(1-e_{i}\right) \frac{\partial U_{i}}{\partial B_{i}}\right\}}{\left(D_{E}\right) E_{0, T-1} v^{\prime}\left(c_{t}^{V}\right)}-\frac{d \tau}{d b}
$$

For workers becoming unemployed at period $i$, it is true that: 


$$
\begin{aligned}
\frac{\partial s_{i}}{\partial B_{i}} & =\frac{1}{\psi^{\prime \prime}\left(s_{i}\right)}\left\{\frac{\partial E_{i}^{\prime}}{\partial B_{i}}-\frac{\partial U_{i}}{\partial B_{i}}\right\} \\
& \Longrightarrow \frac{\partial U_{i}}{\partial B_{i}}=-\psi^{\prime \prime}\left(s_{i}\right) \frac{\partial s_{i}}{\partial B_{i}}
\end{aligned}
$$

Then, it follows that:

$$
\frac{d W}{d b}=\frac{\sum_{i=k}^{T-1}\left\{\left[\Pi_{j=0}^{i-1}\left(1-x_{j}\right) e_{j}\right]\left(1-x_{i}\right)\left(1-e_{i}\right)\left(-\psi^{\prime \prime}\left(s_{i}\right) \frac{\partial s_{i}}{\partial B_{i}}\right)\right\}}{\left(D_{E}\right) E_{0, T-1} v^{\prime}\left(c_{t}^{V}\right)}-\frac{d \tau}{d b}
$$

Now since:

$$
\frac{\partial s_{i}}{\partial B_{i}}=\frac{\partial s_{i}}{\partial A_{i}}\left|B-\frac{\partial s_{i}}{\partial W_{i}}\right| B
$$

We have:

$$
\frac{d W}{d b}=\frac{\sum_{i=k}^{T-1}\left\{\left[\prod_{j=0}^{i-1}\left(1-x_{j}\right) e_{j}\right]\left(1-x_{i}\right)\left(1-e_{i}\right)\left[-\psi^{\prime \prime}\left(s_{i}\right) \frac{\partial s_{i}}{\partial W_{i}} \mid B\left(\frac{\frac{\partial s_{i}}{\partial A_{i}} \mid B}{\frac{\partial s_{i}}{\partial W_{i}} \mid B}-1\right)\right]\right\}}{\left(D_{E}\right) E_{0, T-1} v^{\prime}\left(c_{t}^{V}\right)}-\frac{d \tau}{d b}
$$

Let $E_{i, i+B-1} v^{\prime}\left(c_{t}^{E}\right)$ be the average marginal utility upon reemployment over the first $B$ periods after becoming unemployed at $t=i$, and notice that:

$$
E_{i, i+B-1} v^{\prime}\left(c_{t}^{E}\right)=\frac{1}{B-D_{B}}\left(\left.s_{i} \frac{\partial E_{i}}{\partial W_{i}}\right|_{B}+\left.\left(1-s_{i}\right) \frac{\partial U_{i}}{\partial W_{i}}\right|_{B}\right)
$$

From (??) and (29), after some manipulation, it follows that:

$$
\begin{aligned}
\frac{\partial s_{i}}{\partial W_{i}} \mid B & =\frac{1}{\psi^{\prime \prime}\left(s_{i}\right)} \frac{1}{1-s_{i}}\left\{\left.\frac{\partial E_{i}}{\partial W_{i}}\right|_{B}-\left(\left.s_{i} \frac{\partial E_{i}}{\partial W_{i}}\right|_{B}+\left.\left(1-s_{i}\right) \frac{\partial U_{i}}{\partial W_{i}}\right|_{B}\right)\right\} \\
& =\frac{1}{\psi^{\prime \prime}\left(s_{i}\right)} \frac{1}{1-s_{i}}\left\{B v^{\prime}\left(c_{i}^{E}\right)-\left(B-D_{B}\right) E_{i, i+B-1} v^{\prime}\left(c_{t}^{E}\right)\right\}
\end{aligned}
$$

These results in $\frac{d W}{d b}$ imply: 
$\frac{d W}{d b}=\frac{\sum_{i=k}^{T-1}\left\{\left[\Pi_{j=0}^{i-1}\left(1-x_{j}\right) e_{j}\right]\left(1-x_{i}\right)\left(1-e_{i}\right)\left[\frac{1}{1-s_{i}}\left\{B v^{\prime}\left(c_{i}^{E}\right)-\left(B-D_{B}\right) E_{i, i+B-1} v^{\prime}\left(c_{t}^{E}\right)\right\}\left(-\rho_{i}-1\right)\right]\right\}}{\left(D_{E}\right) E_{0, T-1} v^{\prime}\left(c_{t}^{V}\right)}-\frac{d \tau}{d b}$

where $\rho_{i}=-\frac{\frac{\partial s_{i}}{\partial i_{i}} \mid B}{\frac{\partial s_{i}}{\partial w_{i}} \mid B}$ is the liquidity to moral hazard ratio at period $i$.

Notice that from the government budget constraint:

$$
\frac{d \tau}{d b}=f^{U I} \frac{D_{B}}{D_{E}}\left\{1+\epsilon_{f U I, b}+\epsilon_{D_{B}, b}-\epsilon_{D_{E}, b}\right\}
$$

As in Chetty (2008), assume that the consumption path during employment is constant since unemployment is unlikely to cause large losses on life cycle earnings. This means that $E_{i, i+B-1} v^{\prime}\left(c_{t}^{E}\right)=$ $E_{0, T-1} v^{\prime}\left(c_{t}^{V}\right)=v^{\prime}\left(c_{i}^{E}\right), \forall i$. Using this assumption and the budget constrain, it implies that:

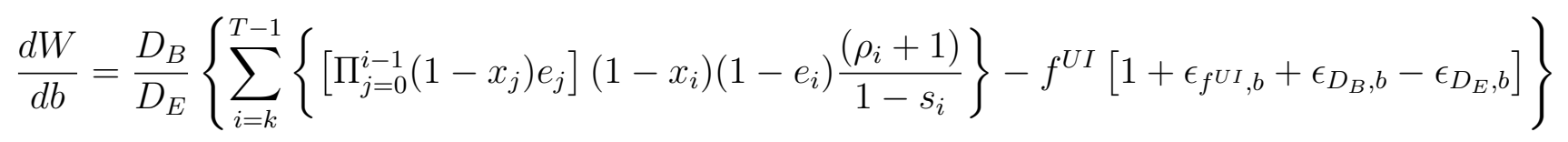

The term $\sum_{i=k}^{T-1}\left[\Pi_{j=0}^{i-1}\left(1-x_{j}\right) e_{j}\right]\left(1-x_{i}\right)\left(1-e_{i}\right) \frac{\left(\rho_{i}+1\right)}{1-s_{i}}$ is the weighted average of the liquidity-to-moral hazard ratio of a worker becoming unemployed at period $i>k$, divided by the probability that he does not find a job at the first period of the spell. If we assume that both the liquidity-to-moral ratio and $s_{i}$ at the first period of the spell do not vary with respect to the period in which workers become unemployed, as is implicity in Chetty (2008), it is true that $\rho_{i}=\rho$ and $s_{i}=s_{0}$. Then it follows our final welfare formula:

$$
\frac{d W}{d b}=f^{U I} \frac{D_{B}}{D_{E}}\left\{\frac{1}{1-s_{0}}(\rho+1)-\left(1+\epsilon_{f}^{U I}, b+\epsilon_{D_{B}, b}-\epsilon_{D_{E}, b}\right)\right\}
$$

where $f^{U I}=\sum_{i=k}^{T-1}\left[\Pi_{j=0}^{i-1}\left(1-x_{j}\right) e_{j}\right]\left(1-x_{i}\right)\left(1-e_{i}\right)$ is the share of laid-off workers eligible for UI due to MER. 


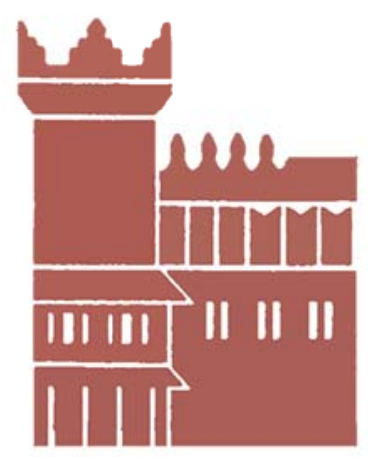

Alma Mater Studiorum - Università di Bologna DEPARTMENT OF ECONOMICS

Strada Maggiore 45

40125 Bologna - Italy

Tel. +39051 2092604

Fax +390512092664

http://www.dse.unibo.it 